$$
\text { Pontifícia } U_{\text {Niversidade }} C_{\text {datólica }}
$$

Ângelo Antônio Caldeira Canavitsas

\title{
Predição de Intervalos Espectrais para Uso de Rádios Cognitivos: Metodologia, Algoritmos, Simulação e \\ Desempenho
}

\section{Tese de Doutorado}

Tese apresentada ao programa de Pós-Graduação em Engenharia Elétrica do Departamento de Engenharia Elétrica da PUC-Rio como parte dos requisitos parciais para obtenção do título de Doutor em Engenharia Elétrica.

Orientador: Prof. Luiz Alencar Reis da Silva Mello Co-orientador: Prof. Marco Antonio Grivet Mattoso Maia

Rio de Janeiro 


\section{Pontifícia Universidade Católica $_{\text {a }}$ DO RIO DE JANEIRO

Ângelo Antônio Caldeira Canavitsas

\section{Predição de Intervalos Espectrais para Uso de Rádios Cognitivos: Metodologia, Algoritmos, Simulação e Desempenho}

Tese apresentada como requisito parcial para obtenção do grau de Doutor pelo Programa de Pós-Graduação em Engenharia Elétrica do Departamento de Engenharia Elétrica do Centro Técnico Científico da PUC-Rio. Aprovada pela Comissão Examinadora abaixo assinada.

Prof. Luiz Alencar Reis da Silva Mello Centro de Estudos em Telecomunicações / PUC-Rio

Prof. Dr. Marco Antonio Grivet Mattoso Maia Centro de Estudos em Telecomunicações / PUC-Rio

Prof. Gláucio Lima Siqueira Centro de Estudos em Telecomunicações /PUC-Rio

Prof. Raimundo Sampaio Neto Centro de Estudos em Telecomunicações /PUC-Rio

Profa. Leni Joaquim de Matos UFF

Prof. Ernesto Leite Pinto IME

Prof. Rodolfo Saboia Lima de Souza Inmetro

Prof. José Eugênio Leal Coordenador Setorial do Centro Técnico Científico - PUC-Rio

Rio de Janeiro, 26 de setembro de 2014. 
Todos os direitos reservados. É proibida a reprodução total ou parcial do trabalho sem autorização da universidade, do autor e do orientador.

\section{Ângelo Antônio Caldeira Canavitsas}

Graduou-se em Engenharia Elétrica - Modalidade Eletrônica em 1986, concluiu o curso de pós-graduação em Análise de Sistemas em 1988, em dezembro de 2000, recebeu o título de Mestre em Ciências de Engenharia Elétrica pelo Instituto Militar de Engenharia (Rio de Janeiro - RJ) na Área de Eletromagnetismo Aplicado e, em dezembro de 2001concluiu o Master Business Administration em Gerência de Telecomunicações na Fundação Getúlio Vargas. Suas áreas de interesse são propagação ionosférica e troposférica, gerência do espectro de radiofrequências, regulamentação em telecomunicações e sistemas de rádios cognitivos.

Ficha Catalográfica

Canavitsas, Ângelo Antônio Caldeira

Predição de intervalos espectrais para uso de rádios cognitivos: metodologia, algoritmos, simulação e desempenho / Ângelo Antônio Caldeira Canavitsas; orientador: Luiz Alencar Reis da Silva Mello ; co-orinetador: Marco Antonio Grivet Mattoso Maia. - 2014.

105 f. ; $30 \mathrm{~cm}$

Tese (doutorado) - Pontifícia Universidade Católica do Rio de Janeiro, Departamento de Engenharia Elétrica, 2014.

Inclui bibliografia

1. Engenharia elétrica - Teses. 2. Eficiência de uso do espectro. 3. Rádios cognitivos. 4. Predição de espaços espectrais. I. Mello, Luiz Alencar Reis da Silva. II. Maia, Marco Antonio Grivet Mattoso. III. Pontifícia Universidade Católica do Rio de Janeiro. Departamento de Engenharia Elétrica. IV. Título. 


\section{Agradecimentos}

A Deus pela oportunidade recebida e pela saúde que me permitiu desenvolver este estudo.

Ao meu orientador, Professor Luiz Alencar Reis da Silva Mello, pela amizade, acolhimento, paciência, dedicação e sabedoria na condução deste trabalho.

Ao meu co-orientador, Professor Marco Antônio Grivet Mattoso Maia, pela amizade, companheirismo, direcionamento do estudo e entusiasmo no nosso convívio na universidade.

À Professora Leni Joaquim de Matos, pelo seu carinho e motivação, estando sempre à disposição para colaborar com imenso conhecimento na área de telecomunicações.

Ao Professor Gláucio Siqueira, pelo exemplo de ser um verdadeiro Mestre, motivador e entusiasta no estudo das ciências.

À Professora Marlene Sabino Pontes, pela amizade, oportunidades e desafios oferecidos durante o desenvolvimento dos trabalhos.

Ao Gerente Geral de Telecomunicações da PETROBRAS, Firmiano Ramos Perlingeiro, pela confiança depositada e fomento ao desenvolvimento deste estudo.

Ao Gerente Setorial da área de Regulamentação da PETROBRAS, Raymundo Isaac Chapermann, pela amizade e compreensão da importância do trabalho desenvolvido para a empresa.

Ao Consultor Sênior, Marcos Albagli, pela amizade e motivação e oportunidades oferecidas que contribuíram em muito para a concretização deste trabalho.

Ao Consultor, Marco Antonio Alves da Silva, pela grande amizade ao longo de tanto tempo, ajuda em todos os momentos, confiança incondicional e sua competência profissional. 
Ao meu Mestre Mauro Assis, pela amizade de inestimável valor, tantas jornadas e convívio no meio acadêmico, pelo qual desenvolvemos inúmeros trabalhos científicos.

Ao amigo Firmo Menezes do Couto Filho, uma das minhas referências profissionais, pela confiança, apoio total e motivação para desenvolver os meus estudos de doutorado.

Ao professor Raimundo Sampaio Neto pelas significativas contribuições oferecidas para aprimoramento deste estudo.

Ao Professor Ernesto Leite Pinto pela criteriosa revisão deste trabalho e sugestões que, certamente o refinaram.

Ao Professor Emanoel Paiva Oliveira Costa pelo inestimável apoio fornecido nas medições realizadas na Pontifícia Universidade Católica.

A minha filha Érica de Paula Canavitsas, e ao meu filho Pedro Henrique Canavitsas, pelo grande amor, motivação e compreensão, especialmente, nos momentos de ausência, devidos aos meus estudos. 


\section{Resumo}

Canavitsas, Ângelo Antônio Caldeira; Mello, Luiz Alencar Reis da Silva (Orientador); Maia, Marco Antonio Grivet Mattoso (Co-orientador). Predição de Intervalos Espectrais para Uso de Rádios Cognitivos: Metodologia, Algoritmos, Simulação e Desempenho. Rio de Janeiro, 2014. 105p. Tese de Doutorado. Departamento de Engenharia Elétrica, Pontifícia Universidade Católica do Rio de Janeiro.

A tecnologia de rádio cognitivo está em pleno desenvolvimento na academia e indústria, sendo apresentada como uma solução para o reduzir o congestionamento do espectro radioelétrico. Dessa forma, diversos estudos têm sido desenvolvidos para obter novas técnicas de compartilhamento do espectro entre usuários ditos primários e secundários. Estas técnicas devem ser robustas o suficiente para minimizar as colisões de ocupação do espectro entre os usuários supracitados, quando o acesso dinâmico ao espectro for aplicado. O presenteestudo investigou as soluções de ocupação compartilhada do espectro, em especial nos paraserviços de voz na faixa de $450 \mathrm{MHz}$. A modelagem de ocupação dos canais, a partir de medidas de transmissões reais, permitiu o desenvolvimento de algoritmo robusto que realiza a predição de espaços espectrais (white spaces) dentro de canais destinados a usuários primários. Esse método proposto define, estatisticamente, uma janela de intervalos de tempo futuros que pode ser utilizada por usuários secundários, por apresentar maior probabilidade de possuir espaços espectrais livres, minimizandoas possíveis colisões. O emprego do método proposto aumenta a vazão de informações de modo seguro e,com alto desempenho, otimizando,assim,a utilização do espectro radioelétrico.

\section{Palavras-chave}

Eficiência de uso do espectro; rádios cognitivos; predição de espaços espectrais. 


\section{Abstract}

Canavitsas, Ângelo Antônio Caldeira; Mello, Luiz Alencar Reis da Silva (Advisor); Maia, Marco Antonio Grivet Mattoso (Co-advisor). Prediction of White Spaces for Cognitive Radios: Methodology, Algorithms, Simulation and performance. Rio de Janeiro, 2014. 105p. PhD Thesis. Departamento de Engenharia Elétrica, Pontifícia Universidade Católica do Rio de Janeiro.

The cognitive radio technology is being developedin universities and industry as a solution to the radio spectrum scarcity. This technology willallow spectrum sharing between primary and secondary telecommunication users. The techniques employed must be robust enough to minimize spectrum occupancy collisions, when the dynamic spectrum access is applied. This study investigates the trends of spectrum usersoccupation, particularly in voice services in the 450 $\mathrm{MHz}$ frequency band.An users occupancy model was developed taking into accountmeasured data of real transmissions. It allowed the development of a robust algorithm that predicts spectral vacancy in channels allocated to primary users. The method selects, statistically, a group of future time intervalsthat can be used by secondary users, due to a higher probability of having a free spectral space. The use of this new technique minimizes possible collisions, increasing the flow of information in secure way and optimizing the radio spectrum use.

\section{Keywords}

Radio spectrum efficiency use; cognitive radio; white space prediction. 


\section{Sumário}

1 Introdução $\quad 15$

1.1 Descrição do Problema 16

$\begin{array}{lr}1.2 \text { Objetivos } & 17\end{array}$

1.3 Descrição do Cenário Atual 188

1.4 Visão da União Internacional de Telecomunicações 22

$\begin{array}{ll}1.5 \text { Organização do Trabalho } & 24\end{array}$

2 Tecnologia dos rádios cognitivos $\quad 26$

2.1 Conceito de cognição $\quad 26$

2.2 Ocupação oportunística do espectro $\quad 27$

$\begin{array}{ll}2.3 \text { Estrutura do Sistema Cognitivo } & 30\end{array}$

$\begin{array}{ll}\text { 2.3.1 Ambiente de operação } & 30\end{array}$

2.3.2 Sensoriamento do espectro 31

2.3.3 Módulo de decisão $\quad 31$

2.3.4 Caracterização do modelo de ocupação 32

2.3.5 Compartilhamento do espectro 32

2.3.6 Mobilidade no espectro 32

3 Detecção e medições 33

3.1 Sensoriamento do espectro 33

3.2 Métodos de detecção 33

3.2.1 Detecção de energia 34

3.2.2 Filtro casado 36

$\begin{array}{ll}3.2 .3 \text { Cicloestacionariedade } & 37\end{array}$

3.3 Medições 37

3.3.1 Resultados obtidos em Campinas - SP 37

4 Metodologia, Simulação e Desempenho 52

4.1 Metodologia $\quad 52$

4.1.1 Descrição do Problema

4.1.2 Modelagem estatística 53

4.1.3 Probabilidades de Permanência nos Estados em Regime Permanente 58

4.1.4 Cálculo da probabilidade de não ocupação da janela de predição pelo usuário primário $\quad 61$

4.1.5 Modelagem do Erro de Estimação de Estado 66

4.1.6 Dimensionamento da janela de predição para um caso específico 69

$\begin{array}{ll}4.2 \text { Predição de intervalos espectrais } & 74\end{array}$

$\begin{array}{ll}\text { 4.2.1 Estudos afins } & 75\end{array}$

$\begin{array}{ll}\text { 4.2.2 Esquema proposto para predição de uso do espectro } & 77\end{array}$

$\begin{array}{ll}\text { 4.2.3 Formulação do Problema } & 78\end{array}$

$\begin{array}{ll}\text { 4.2.4 Solução proposta } & 79\end{array}$

4.2.5 Experimentos $\quad 82$

4.2.6 Resultados obtidos e comparação com outros trabalhos 83 
5 Conclusões $\quad 91$

5.1 Comentários 92

5.2 Soluções apresentadas $\quad 92$

5.3 Futuros estudos 93

6 Referências bibliográficas $\quad 94$

$\begin{array}{llr}7 & \text { Anexos } & 99\end{array}$

$\begin{array}{ll}\text { Anexo } 1 \text { - Diagrama de Estados Completo } & 100\end{array}$

$\begin{array}{ll}\text { Anexo } 2 \text { - Estatísticas das Medições em Campo } & 101\end{array}$

$\begin{array}{ll}\text { Anexo } 3 \text { - Resultadfos das simulações } & 104\end{array}$ 


\section{Lista de Figuras}

Figura 2.1 - Percurso de pilotos de motocicleta 26

Figura 2.2 - Cognição \& exploração do espectro 28

Figura 2.3 - Esquemático básico de um sistema cognitivo 29

Figura 2.4 - Sistema cognitivo em desenvolvimento 30

Figura 3.1 - Detector de energia 35

Figura 3.2 - Localização das medições em Campinas - SP 38

Figura 3.3 - Antena J-Pole 39

Figura 3.4 - Níveis de ruído $452 \mathrm{MHz}$ - Topo do prédio e no nível da rua 39

Figura 3.5 - Gráfico de ocupação espectral em função de distintos limiares 40

Figura 3.6 - Ocupação do espectro em Campinas - SP -457,530 MHz 41

Figura 3.7 - Ocupação do espectro em Campinas - SP -463,550 MHz 41

Figura 3.8 - Critério para definição de ocupação do canal 42

Figura 3.9 - Gráfico de porcentagem de ocupação dos canais - Campinas 42

Figura 3.10 - Instantâneo do espectro de 450 a 470 MHz Campinas - SP 43

Figura 3.11 - Avaliação das conversas por meio de software de áudio 44

Figura 3.12 - Indicação dos parâmetros medidos 46

Figura 3.13 - Quantidade dos bursts de conversação (ordem de captação) 46

Figura 3.14 - Quantidade dos bursts de conversação em ordem crescente 46

Figura 3.15 - Distribuição da quantidade dos bursts de conversação 47

Figura 3.16 - TECs em sequência de medição 48

Figura 3.17 - TECs ordenados por valores crescentes 48

Figura 3.18 - Tempos dos BS(1) em ordem de captação 49

Figura 3.19 - Tempos dos BS(1) em ordem crescente, média e 90\% 49

Figura 3.20 - Tempos dos WS(1) em ordem de captação 50

Figura 3.21 - Tempos dos WS(1) em ordem crescente, média e 90\% 50

Figura 3.22 -Ciclos de conversação - TBC, BS(n) e WS(n) 51

Figura 4.1 - Janelas históricas e de predição 53

Figura 4.2 - Períodos de silêncio, ocupação e pausa 54

Figura 4.3 -Modelo Escondido de Markov 56

Figura 4.4 -Cadeia de Markov Ajustada 57 
Figura 4.5 - Erros associados aos estados $\quad 57$

Figura 4.6 - Observação sem estado de erro 66

Figura 4.7 - Observação com estado de erro 66

Figura 4.8 - Discriminante $\quad 68$

Figura 4.9 - Observaçãosem estado de erro 68

Figura 4.10 - Observação com estado de erro 69

Figura 4.11 - Parâmetros medidos $\quad 70$

Figura 4.12 - Probabilidade da ausência de colisões com $\mathrm{O}_{\mathrm{t}}=0 \quad 71$

Figura 4.13-Probabilidade da ausência de colisões comOt $=0$ - Detalhado 71

Figura 4.14 - Probabilidade da ausência de colisões com Ot = 1

Figura 4.15 - Probabilidade da ausência de colisões com Ot = 1 - Detalhado 72

Figura 4.16 - Ausência de colisões versus tamanho da janela $\mathrm{H}$

Figura 4.17 - Avaliação da janela histórica $\quad 78$

Figura 4.18 - Representação do algoritmo de estimação 81

Figura 4.19 - Resultados da simulação 83

Figura 4.20 - System Utility - Janelas: observação: 1000, predição: 600

Figura 4.21 - System Utility - Janelas: observação: 1000, predição: $700 \quad 86$

Figura 4.22 - System Utility - Janelas: observação: 1000, predição: $1000 \quad 86$

Figura 4.23 - Disturbance Ratio - Janelas: observação: 1000, predição: 60087

Figura 4.24 - Disturbance Ratio - Janelas:observação: 1000, predição: $700 \quad 87$

Figura 4.25 - Disturbance Ratio - Janelas: observação: 1000, predição: 100088

Figura 4.26 - System Utility - Janelas de predição de 1.000 até 3.000

Figura 4.27 - Disturbance Ratio - Janelas pred. de 1.000 até 3.000 - Erro 0\% 89

Figura 4.28 - System Utility - Janelas pred. de 1.000 até 3.000 - Erro 20\% 90

Figura 4.29 - Disturbance Ratio - Janelas pred. de 1.000 - 3.000 - Erro 20\% 90 


\section{Lista de Tabelas}

Tabela 1.1 - Alocação de frequências para usuários primários e secundários 20

Tabela 1.2 - Destinação de frequências e regulamentação 20

Tabela 3.1 - Segmentos do espectro investigados 40

Tabela 3.2 - Canais investigados separadamente 40

Tabela 3.3 - Parâmetros de caracterização das conversações 45

Tabela 3.4 - Caracterização das conversações 45

Tabela 3.5 - Tempos mínimo e máximo (ms) entre conversações 47 


\section{Lista de Siglas}

ANATEL - Agência Nacional de Telecomunicações

AWGN-Ruído Branco Gaussiano Aditivo

BS - Black space (espaço espectral ocupado)

CDMA - Code Division Multiple Access (Acesso Múltiplo por Divisão de Código)

CME - Cadeia de Markov Escondida

DR - Disturbance Ratio (degradação sofrida pelo usuário primário)

FFT - Transformada rápida de Forrier

FM - Modulação em Frequência

FTP - File Transfer Protocol (Protocolo de Transferência de Arquivos)

HMM - Cadeia de Markov Escondida

HTTP - Hypertext Transfer Protocol (Protocolo de Transferência de Hipertexto)

IID - Independentes e identicamente distribuídos

ISDB-T - Serviço Integrado de Transmissão Digital e Terrestre

MAC - Media Access Control

MIMO - Multiple-Input Multiple-Output

OFDM - Orthogonal frequency-division multiplexing

PHY - Camada física

QBC - Quantidade de bursts de conversação

RDS - Rádios definidos por software

RC - Rádio cognitivo

RR - Regulamento de Radiocomunicações

SLP - Serviço Limitado Privado

SU - System Utility (mostra o quanto o usuário secundário foi eficiente)

SRC - Sistema de rádio cognitivo

TEC - Tempo entre Conversações

UIT - União Internacional de Telecomunicações

UP - Usuário primário

US - Usuário secundário

v.a.r. - Variável aleatória real

VoIP - Voice over Internet Protocol

WRC - Conferência Mundial de Radiocomunicações

WS - White space(espaço espectral livre) 
Nós somos o que fazemos repetidamente, a excelência não é um feito, e sim, um hábito.

Aristóteles 


\section{Introdução}

O foco do trabalho é a implementação de técnicas de predição de intervalos espectrais livres, para aplicação de sistemas cognitivos. São apresentados a metodologia proposta, os algoritmos de predição desenvolvidos e resultados de simulações para previsão do desempenho obtido.

O espectro de radiofrequências é um recurso finito e público, que é concedido para exploração em caráter oneroso, para viabilizarserviços de telecomunicações que dependem da sua aplicação. Por se tratar de um recurso público, as definições para a exploração do espectro e a respectiva fiscalização do seu uso estão a cargo das administrações governamentais. Estes Órgãos Reguladores particionam o espectro em faixas com destinações específicas para a prestação de diversos tipos de serviços. No Brasil está incumbida desta atividade a Agência Nacional de Telecomunicações - ANATEL.

Tradicionalmente as empresas, em sua maioria privadas,interessadas em explorar serviços de telecomunicações, adquirem as porções necessárias do espectro por meio de licitações ou outra modalidade de compra e apropriam-se da referida banda de frequências para seu próprio uso. Essas empresas concessionárias que têm o direito de exploração de segmentos espectrais adquiridos e operados por estações licenciadas, são chamados de usuários primários (UP). Estes usuários têm prioridade no emprego das frequências e proteção contra interferências eletromagnéticas, provenientes dos demais usuários, chamados de secundários (US).

Os rádios cognitivos possuem a capacidade de utilizar as mesmas faixas de frequências dos usuários licenciados, em um compartilhamento no domínio do tempo, em momentos nos quais há vacância espectral.

Esta tese tem por objetivo apresentar novas técnicas de predição de espaços espectrais para uso de rádios cognitivos como usuários secundários, aumentando a eficiência de utilização das radiofrequências. O estudo foi desenvolvido tendo por base a observação, através de medições, do comportamento de usuários primários, em janelas de tempo preestabelecidas. A partir desta caracterização foi 
desenvolvido um algoritmo que, a partir de um instante de tempo, avalia a probabilidade de intervalos de tempo futuros apresentarem espaços espectrais livres e prediz a quantidade de intervalos que deve ser utilizada pelos usuários secundários.

\section{1}

\section{Descrição do Problema}

Com a evolução natural das tecnologias usadas nos equipamentos de telecomunicações e o crescimento da população, maiores demandas foram surgindo e o espectro foi ficando cada vez mais congestionado, com um aumento exponencial de usuários, mormente em grandes centros urbanos. A gestão exercida pelos Órgãos Reguladores na área de telecomunicações começou a se mostrar ineficaz, devido ao modo conservador pelo qual são manipuladas as permissões de acesso e exploração do espectro radioelétrico.

Esses fatores fomentaram várias pesquisas científicas sobre a quantificação da eficiência de uso do espectro e também de novas tecnologias que pudessem solucionar os impasses detectados, devido a falta de radiofrequências disponíveis. Esse esforço visa atender as referidas demandas reprimidas de serviços de telecomunicações, sejam eles para transmissão de voz, vídeo, ou dados.

Surgiu, então, a ideia de se utilizar rádios cognitivos - RC [1], cujo pioneiro no desenvolvimento desta tecnologia foi o Dr. Joseph Mitola, que apresentou este novo conceito pela primeira vez no Royal Institute of Technology em 1998 e, após isso, em seus estudos de doutorado, desenvolveu a base dos RC, sedimentando a tese de que as redes computacionais teriam inteligência suficiente para avaliar os recursos de rádio existentes em determinados ambientes para efetuarem suas comunicações sem fio, em função do contexto de uso.

Entende-se basicamente como rádio cognitivo, um dispositivo de telecomunicações, que presta um determinado serviço, capaz de avaliar o ambiente espectral no qual está instalado, registrar estas informações captadas e tomar decisões, individualmente ou baseadas em sistemas de cooperação, definindo quando e como ocupar o espectro e deixá-lo livre novamente. 
Estes dispositivos devem, ainda, ser capazes de aprender continuamente com as informações recebidas e utilizar estes "ensinamentos” para aprimorar a sua modalidade de ocupação do espectro. Algumas políticas de operação podem ser definidas, conforme o objetivo do rádio (tipo de serviço a ser executado) e as faixas de frequências a serem utilizadas.

Neste novo campo de aplicação dos rádios cognitivos, ainda há questões em aberto como as técnicas para monitoração do espectro radioelétrico objetivando a predição e utilização dinâmica de intervalos espectrais livres (do inglês, white spaces - WS), nos domínios do tempo e da frequência, de modo a otimizar o desempenho dos rádios cognitivos (RC).

Em um processo de comunicação, quando se utiliza transmissão por sistemas cognitivos, é importante não causar interferências nos usuários primários e, para tal, e é necessário compreender o modelo de ocupação utilizado, pela avaliação do histórico desses usuários. O acúmulo e estudo dos dados gerados no histórico de ocupação do RC, permitem projetar com maior precisão os espaços espectrais livres e, também, definir quando os espaços estarão ocupados, de modo que não seja efetuada transmissão, que provocaria colisão e degradação do serviço primário.

Assim, o tema da predição de intervalos espectrais livres é um desafio a ser vencido para viabilizar a operação segura dos sistemas cognitivos. O sensoriamento simples dos canais e a decisão de utilizá-los ou não, devido ao processamento e coordenação envolvidos, gera uma latência, que pode reduzir a taxa de transferência das informações desejadas.

A técnica de predição de intervalos espectrais por tornar a operação dos sistemas cognitivos mais robusta e eficiente, merece ser devidamente investigada, por essa razão é foco do presente estudo.

\section{2}

\section{Objetivos}

O trabalho parte do estudo do comportamento de ocupação do espectro por usuários primários, que permite entender as tendências de utilização futura e a ocorrência de vacâncias das radiofrequências no domínio do tempo. Essa técnica permite, ainda, avaliar estatisticamente as possibilidades de 
compartilhamento do espectro entre os usuários primários e os secundários (de modo oportunístico).Também são consideradas as possíveis colisões entre os usuários citados.

É desenvolvida uma metodologia para estimativa e predição do comportamento dos usuários primários, sugerindo a observação de "janelas" históricas, que permitam realizar uma avaliação do passado de ocupação do espectro de um usuário primário e, realizar uma predição dos espaços espectrais futuros que estarão vagos.

O objetivo final do algoritmo desenvolvido é prever quantos intervalos de tempo futuros podem ser utilizados, ou seja e definir o tamanho ideal da "janela" de predição para incrementar o desempenho dos rádios cognitivos.

O desempenho dos rádios cognitivos é medido estimado por meio de uma simulação, na qual é gerada a ocupação do espectro de um usuário primário,(baseada na estatística suportada por dados levantados em campo). De posse de um período de ocupação simulado, é inserido o usuário secundário (RC), dentro dos intervalos espectrais futuros, preditos como livres. Esta inserção é feita com base no algoritmo desenvolvido, que define a ocupação de "janelas" futuras. O resultado do desempenho do algoritmo é avaliado por meio da quantidade de colisões verificadas entre usuários primários e secundários e da vazão efetiva de dados nos aceites de intervalos espectrais livres.

\section{3}

\section{Descrição do Cenário Atual}

A literatura técnica, disponível, sobre a utilização do espectro e eficiência do seu uso apresenta alguns pontos convergentes como, por exemplo, a carência de faixas de frequências para a implantação de novos serviços de telecomunicações, fato gerador consequentemente de uma demanda reprimida em áreas com maior densidade populacional. Essa escassez é sempre associada ao modo ortodoxo, com o qual os Órgãos Reguladores realizam a gestão das faixas de frequências mais requisitadas.

Convém ressaltar que a forma de gerência gestão aplicada, embora seja conservadora, também é segura, garantindo que teórica e institucionalmente a 
utilização do espectro pelos usuários primários seja normalmente, imune a interferências. Os usuários primários são aqueles que adquirem oficialmente bandas do espectro, ficando legalmente protegidos contra interferências de outros usuários, em especial dos classificados como secundários.

Embora essa prática de gerência do espectro ainda seja largamente aplicada, ela começou a ser questionada devido ao aparecimento de novos pleitos, fomentados pelo crescimento da população e uma larga diversificação dos serviços de telecomunicações, que, agora, podem ser viabilizados com recentes tecnologias, que aperfeiçoam a utilização das radiofrequências, propondo um novo modelo de compartilhamento entre os diversos usuários.

Como exemplo, a Figura 1.1 mostra parte do Plano de Atribuição, Destinação e Distribuição de Faixas de Frequências no Brasil - Versão 2013 [10], gerado pela Agência Nacional de Telecomunicações - ANATEL, destacando a faixa de frequências de 300 até 806 MHz.

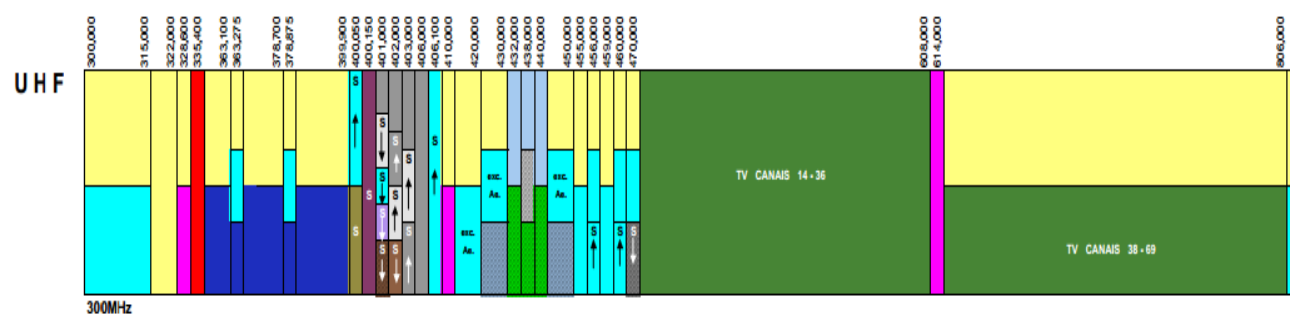

Figura 1.1 - Divisão da faixa de frequências de 300 a 806 MHz no Brasil.

Detalhando ainda mais a alocação das faixas do espectro radioelétrico, temos a tabela 1.1 que mostra a aplicação das frequências de 460 até $470 \mathrm{MHz}$. A primeira coluna mostra a destinação das frequências na Região 2, que é representada pelas Américas do Norte, Central e Sul e a segunda coluna indica como a faixa é aplicada no Brasil. Os serviços fixo e móvel são serviços primários (mostrados em letras maiúsculas) e o de Meteorologia por satélite é um serviço secundário (indicado em letras minúsculas). Esses serviços citados operam dentro da mesma faixa de espectro, porém, não necessariamente nas mesmas frequências. A tabela 1.2 mostra a destinação da faixa de frequências de 461 até $468 \mathrm{MHz}$, os serviços e a respectiva regulamentação publicada no Brasil. 
Tabela 1.1 - Alocação de frequências para usuários primários e secundários

\begin{tabular}{|l|l|}
\hline \multicolumn{1}{|c|}{ MHz } \\
\hline \multicolumn{1}{|c|}{ REGIÃO 2 } & \multicolumn{1}{c|}{ BRASIL } \\
\hline $\begin{array}{l}\text { 460-470 } \\
\text { FIXO } \\
\text { MÓVEL 5.286AA } \\
\text { Meteorologia por Satélite (espaço para Terra) }\end{array}$ & $\begin{array}{l}\text { 460-470 } \\
\text { FIXO } \\
\text { MóvEL } \\
\text { Meteorologia por Satélite (espaço para Tema) }\end{array}$ \\
\hline
\end{tabular}

Tabela 1.2 - Destinação de frequências e regulamentação.

\begin{tabular}{|c|c|c|}
\hline \multicolumn{3}{|c|}{ MHz } \\
\hline 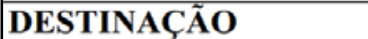 & DISTRIBUIÇÃO & REGULAMENTAÇ̃̃O \\
\hline $461-467$ & & \\
\hline $\begin{array}{l}\text { COMUNICAÇÃO MULTIMIDIA (SCM) } \\
\text { MÓVEL PESSOAL (SMP) } \\
\text { TELEFÔNICO FIXO COMUTADO (STFC) }\end{array}$ & & Resolução Anatel n 558/2010 (D.O.U. de 24.12.2010) \\
\hline & & Resoluçào Anatel n 506/2008 (D.O.U. de 7.07.2008) \\
\hline $\begin{array}{l}467-468 \\
\text { COMUNICACCÃO MULTIMIDIA (SCM) } \\
\text { MÓVFI PFSSOAI. (SMP) } \\
\text { TELEFÔNICO FIXO COMUTADO (STFC) }\end{array}$ & & Resolução Anatel n 558/2010 (D.O.U. de 24.12.2010) \\
\hline
\end{tabular}

Na realidade, em termos práticos, a alocação de blocos consideráveis do espectro a serviços primários (os detentores de licenças) que os subutilizam, está impedindo a exploração de novos serviços de telecomunicações. Conforme citado por George Thomas em [4], ainda há muito conservadorismo na forma utilização simultânea de faixas do espectro por usuários primários e secundários (sem licença ou sem proteção contra interferências).

A proposta, de exploração conjunta das radiofrequências por diferentes serviços, com acesso ao espectro por usuários secundários em períodos em que detectam ociosidade dos usuários primários, representa a essência do conceito de utilização dos rádios cognitivos.

Pelas razões descritas, foram iniciados estudos objetivando a utilização mais eficiente do espectro, sendo consideradas novas dimensões, além dos clássicos parâmetros tais como: domínio do tempo, faixas de frequências, separações geográficas, fronteiras municipais, interestaduais e internacionais. As novas dimensões e características técnicas e operacionais, que começaram a ser consideradas são: o tempo de ocupação do espectro em cada canal, níveis de ruído aceitáveis de interferência, tecnologia e tipos de serviços.

Neste contexto, as técnicas de detecção e predição de espaços espectrais assumem fundamental importância e, estão associadas às maiores capacidades computacionais dos novos dispositivos, que terão de realizar um sensoriamento 
do ambiente no qual estão imersos e alocar, dinamicamente, os canais a serem utilizados, abandonando em definitivo as alocações estáticas de frequências.

No estudo da literatura técnica sobre rádios cognitivos, quando abordado o aspecto de ocupação do espectro, há uma unanimidade nas citações, quanto à baixa utilização do espectro, como disposto, por exemplo, em [5 - 6]. Em muitas abordagens, destacam-se casos extremos com uso inferior a 20\%. Embora esta seja uma constatação experimental, algum cuidado deve ser tomado ao afirmar, de modo generalizado, que o espectro é utilizado com baixa eficiência em toda a sua gama de frequências e nas dimensões temporais e geográficas.

Há nítidas variações no modo de ocupação das frequências ao longo do tempo nos grandes centros, pois existe maior densidade de usuários operando nos horários comerciais e forte decaimento durante a noite e madrugada.

Em áreas suburbanas e rurais observa-se uma baixa ocupação de frequências, o que favorece o uso oportunista do espectro. Assim, a detecção de white spaces (WS) é uma tarefa de menor ou maior complexidade, dependendo do cenário e horários considerados.

A academia e indústria se mobilizam para buscar soluções inovadoras focadas no aumento da eficiência de uso do espectro, por meio da utilização de rádios cognitivos, desenvolvendo diversos algoritmos de detecção do espectro, técnicas de predição de WS e protótipos de rádios inteligentes, denominados rádios definidos por software, os RDS.

Os RDS são a base dos rádios cognitivos (RC), pois os dispositivos terão que se reconfigurar conforme a necessidade, trocando as frequências de operação e/ou as modulações empregadas, em função do nível de interferência detectado.

Os rádios cognitivos devem, além isso, aprender com o ambiente no qual estão inseridos e utilizar este conhecimento para definição do método de acesso ao espectro, visando aumentar o desempenho dos sistemas e evitar interferências indesejáveis nos rádios dos usuários primários.

As implementaçõescom aplicações comerciais não devem tardar.Entretanto, enfrentam grandes desafios regulatórios pois há a necessidade de desenvolvimento de novos conceitos sobre níveis de interferência aceitáveis para os usuários ditos primários. Além disso, devem ser geradas novas regras de compartilhamento do espectro, o que representa uma grande quebra de paradigmas clássicos, já consagrados no mercado de telecomunicações. 
Atualmente, embora já existam no mundo iniciativas para viabilizar a aplicação futura dos rádios cognitivos, no âmbito nacional há uma carência de nova regulamentação mais flexível, que permita o compartilhamento do espectro, em especial nas faixas com menor eficiência de utilização. Neste panorama, o conservadorismo é uma grande barreira, pois a normatização existente defende e protege fortemente usuários primários licenciados junto aos Órgãos Reguladores.

Um relevante tema que preocupa os reguladores governamentais é a possível perda de controle de utilização das radiofrequências, pois o sensoriamento automático a ser realizado pelos novos dispositivos encontrará espaços espectrais vagos e os transformará em canais ativos de forma dinâmica.

Desta forma, as possíveis interferências geradas não poderão ser resolvidas pela forma convencional como hoje são solucionadas, com a identificação da fonte de emanação com posição fixa e geração de sinal de modo estático, o que facilita a ação das equipes de fiscalização do espectro.

\section{4}

\section{Visão da União Internacional de Telecomunicações}

Na Conferência Mundial de Radiocomunicações - World Radiocommunication Conference de 1997 (WRC-97), importante evento da União Internacional de Telecomunicações (UIT), foi introduzida, pela primeira vez, a definição de sistemas adaptativos no Regulamento de Radiocomunicações.

A aplicação foi específica para a faixa de HF (3a $30 \mathrm{MHz}$ ), na qual as condições de propagação variam significativamente e os sistemas adaptativos ajustam as frequências operacionais, dinamicamente, para melhorar a qualidade da recepção.

Com o passar dos anos, novos desenvolvimentos tecnológicos ampliaram a capacidade dos sistemas adaptativos, que passaram a ser baseados emsoftware, tornando possível analisar o ambiente de rádio e ajustar as características específicas do sistema para as situações funcionais em faixas de frequências mais altas que as de HF. Essa combinação de software e rádio viabilizou propostas de novas soluções para resolver o problema do congestionamento de frequências e aumento da eficiência global da utilização do espectro. Seguindo esses avanços 
tecnológicos, dois novos conceitos foram criados [7], o de rádio definido por software (RDS) e de sistemas de rádio cognitivo (SRC), a saber:

- Rádio Definido por Software (SDR): equipamento de rádio que emprega uma tecnologia que permite a criação ou alteração de parâmetros técnicos, incluindo a faixa de frequência de operação, tipo de modulação e potência, dependendo do ambiente eletromagnético.

- Sistema de Rádio Cognitivo (SRC): um sistema de rádio que emprega uma tecnologiaque torna possível a obtenção de conhecimento de seu ambiente operacional, e define políticas e estados internos para ajustar, dinamicamente, os seus parâmetros e protocolos de acordo com o conhecimento obtido, possibilitando assim acesso e utilização dinâmica do espectro radioelétrico.

Para permitir a utilização das tecnologias RDS e SRC, há a necessidade de adequações regulamentaresque garantam a proteção dos serviços existentes de interferênciasprejudiciais que pode ser gerada por estas novas tecnologias.Dessa forma, a UIT está fomentando estudos de normas relacionadas com a aplicação do RDS e SRC, entregando esta tarefa ao Grupo de Trabalho ITU-R 1B, responsável pelos estudos de administração do espectro.

Em abril de 2010, o Grupo de Trabalho 1B definiu queRDS e SRC são tecnologias e não serviços de radiocomunicações.Estas tecnologias podem ser utilizadas em qualquer serviço de radiocomunicação, desde que atendam às disposições do Regulamento de Radiocomunicações - RadioRegulation(RR), aplicáveis ao serviço em que operam.Portanto, a introdução de SRC não deve impor restrições adicionais sobre outros serviços que venham a compartilhar a mesma faixa de frequências.

Com respeito à implantação do RDS, concluiu-se que não há alterações a serem feitas nos regulamentos para utilização desta tecnologia. Já em relação ao SRC, a situação é diferente. Existe a necessidade de novos regulamentos que permitam sua utilização. A questãoé parte da agenda da próxima Conferência Mundial de Radiocomunicações - WorldRadiocommunicationConference (WRC).

O Grupo de Estudos 1 da UIT - SG1 reuniu-se em Genebra, em janeiro de 2014, em um workshop sobre rádio cognitivo com ênfase na disciplina de 
utilização de espaços espectrais. Um dos resultados das discussões sobre o tema, foi a emissão do relatório Princípios de Gestão do Espectro e Técnicas de Engenharia para o Acesso Dinâmico ao Espectro por Sistemas Rádio que Apliquem Capacidades Cognitivas [8].Ainda como resultado das discussões, há reconhecimento dos benefícios da utilização dos sistemas de rádios cognitivos e que tais dispositivos podem ser utilizados àluz das normas existentes no Regulamento Rádio - RR.

Apesar destas constatações, são recomendadas consultas aos demais grupos de estudos da UIT da área de radiopropagação, de modo a viabilizar técnicas de proteção para os serviços que vão coexistir com a nova tecnologia.Há ainda pontos em aberto, como a detecção de sinais muito fracos e a necessidade de coibir a utilização compartilhada do espectro radioelétrico em serviços considerados críticos como os de emergência e de radioastronomia.

\section{5 \\ Organização do Trabalho}

O Capítulo 2 apresenta a tecnologia dos rádios cognitivos e explica como ela pode ser uma eficaz alternativa para aumentar o número de usuários em diversas faixas de frequências. São explorados os conceitos de serviços primários (detentores de licenças) e usuários de oportunidade, resguardadas as devidas proteções para garantir a compatibilidade eletromagnética. São explorados os conceitos de rastreamento e a utilização dos "intervalos espectrais", visando o compartilhamento das frequências. Como a inteligência necessária para os dispositivos supracitados exige que eles sejam implementados como rádios definidos por software - RDS, são apresentadas informações básicas sobre o tema.

No Capítulo 3 discute a detecção de uso espectro e detalhada as três principais técnicas utilizadas: i) detecção de energia; ii) emprego de filtros casados; e iii) detecção de ciclo estacionariedade. São apresentados os resultados das medições de ocupação do espectro realizadas em campo, utilizando a técnica de detecção de energia. Os resultados das medições são analisados, com levantamento de suas estatísticas. 
A aplicação das técnicas de predição de intervalos espectrais são abordadas no Capítulo 4, que inclui o desenvolvimento de um modelo para estimar o tamanho das janelas de predição. Novas técnicas de predição de intervalos espectrais para uso de rádios cognitivos são propostas e detalhadas, acompanhadas das informações e dados estatísticos coletados. Os sinais detectados foram armazenados em um banco de dados para permitir a simulação das técnicas propostas no estudo e a comparação do desempenho obtido com outros métodos disponíveis na literatura.

As conclusões do trabalho são apresentadas no Capítulo 5,bem como as sugestões de trabalhos futuros. 


\section{2}

\section{Tecnologia dos rádios cognitivos}

\section{1}

\section{Conceito de cognição}

A palavra cognição tem origem nos escritos de Platão e Aristóteles, conforme dito em [9]. Indica a capacidade de perceber e interpretar situações ou ambientes. Cognição está também associada ao processo de aquisição de conhecimento, envolvendo fatores diversos como o pensamento, a linguagem, a percepção, a memória e o raciocínio.

Um exemplo de uso da capacidade de cognição em uma situação prática é ilustrado na Figura 2.1, que mostra uma rua com três faixas e o percurso, marcado em vermelho, de um piloto de motocicleta que faz diversas ultrapassagens prevendo, com sua capacidade cognitiva, que poderá passar nos pontos 1, 2, 3 e 4 (círculos verdes), sem que seja atingido pelos demais veículos.

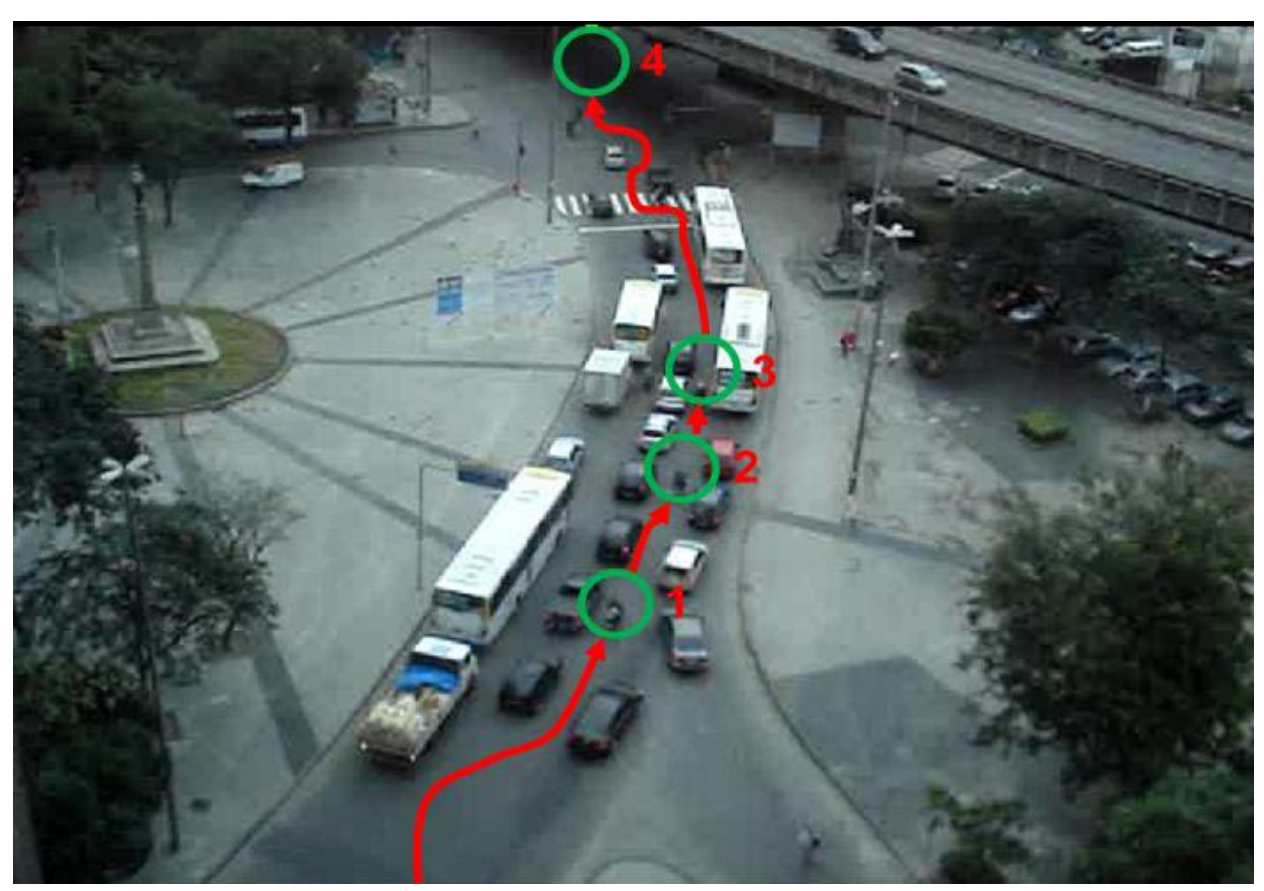

Figura 2.1 - Percurso de pilotos de motocicleta 
O piloto da moto está utilizando, intuitivamente, sua aptidão para avaliar o comportamento dos veículos que pretende ultrapassar, utilizando as informações já armazenadas em sua memória ao longo do tempo passado em que pilotou seu veículo.

As informações anteriormente registradas permitem que o piloto possa predizer em que ponto o veículo que deseja ultrapassar estará em um dado momento futuro e, consequentemente, definir qual velocidade aplicar na motocicleta, ou ainda decidir se a ultrapassagem é segura ou não.

De modo similar, fazendo uma analogia com o exemplo citado, os rádios cognitivos devem avaliar o ambiente espectral, identificar os usuários de radiofrequências, e decidir como utilizar o espectro ocupando canais momentaneamente vazios sem provocar interferências nos usuários primários.

No caso do motociclista, caso ocorra um erro de predição ou uma ação inesperada, como a aceleração muito brusca de um carro ou ônibus, o espaço predito para a motocicleta poderá estar ocupado e haverá uma colisão. A analogia no caso do rádio cognitivo, seria uma colisão na utilização do espectro radioelétrico, em que dois usuários transmitissem suas informações simultaneamente na mesma frequência gerando degradação nas informações recebidas.

O rádio cognitivo deve sensoriar o canal de um usuário primário, esperar o momento de uma pausa, ou seja, um espaço espectral, e utilizar o referido canal. Por ser um usuário secundário, o RC não pode interferir no usuário primário devendo continuar a monitoração da atividade do usuário primário e, assim que for detectada nova transmissão, cessar imediatamente a ocupação do canal de modo a minimizar a degradação do serviço principal.

\section{2}

\section{Ocupação oportunista do espectro}

A Figura 2.2 mostra, no primeiro eixo, uma faixa do espectro com canais de frequências F1 a F6. No segundo eixo são mostrados intervalos de tempo que serão utilizados como "janelas" para avaliação da ocupação do usuário primário e ocupação oportunista do rádio cognitivo. 
O RC monitora o canal F1 no primeiro intervalo e, verificando que ele está vago, insere no intervalo seguinte a transmissão oportunista. Monitora ao final do intervalo a ocupação do usuário primário e, como ainda encontra o canal vago transmite novamente. Na sequência, o quarto intervalo é monitorado e revela ocupação do primário (um chamado blackspace). O RC cessa a transmissão e passa a monitorar o canal F2 no quinto intervalo, que também se mostra ocupado. O RC continua sem transmitir e monitora o canal para F3 no sexto intervalo, identificando um novo white space e passando a transmitir no intervalo seguinte.

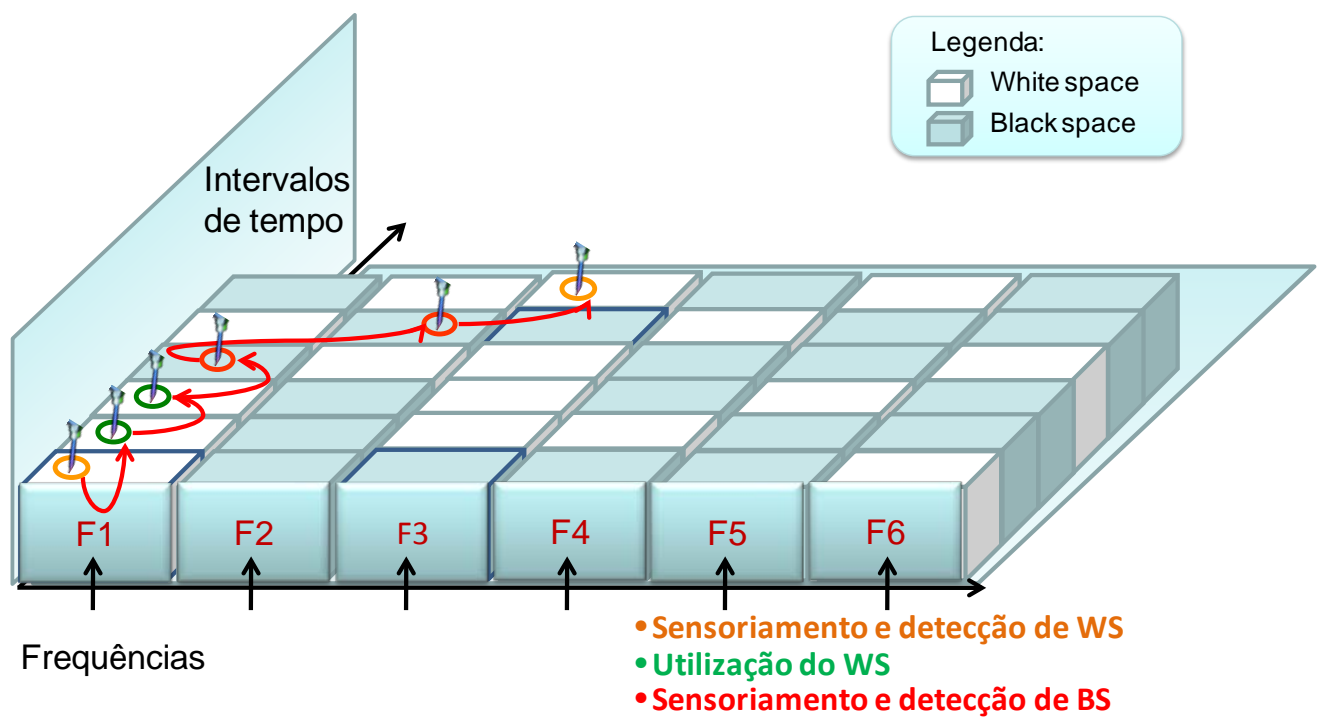

Figura 2.2 - Cognição \& exploração do espectro

Neste exemplo simplificado não foram discutidos a coordenação e os protocolos necessários para que os rádios cognitivos efetivamente transmitam e recebam as informações desejadas, utilizando os espaços espectrais livres. Tratase apenas de visão conceitual sobre como os espaços espectrais devem ser monitorados ciclicamente e as decisões a serem tomadas em função das informações adquiridas do ambiente espectral.

A Figura 2.3 mostra o esquema funcional básico de um rádio cognitivo. Ele deve possuir uma programação inicial que contenha a informações sobre outros sistemas operando na região geográfica em que será instalado obtidos da base de dados do Órgão Regulador para orientar do sensoriamento do espectro a ser realizado pelo rádio. 
Além disso, com o desenvolvimento do processo de monitoração e o armazenamento dos dados coletados vai adquirindo a informações sobre as características de ocupação do espectro pelos usuários primários monitorados.

O módulo "Cognição" processa os dados armazenados obtendo um aprendizado sobre o comportamento de ocupação dos canais pelos usuários primários. Esse conhecimento permite avaliar a probabilidade de ocorrência de espaços espectrais livres para utilização pelos usuários secundários.

Finalmente, o módulo "Algoritmo" utiliza as informações oriundas da "Cognição" e gera um modelo de ocupação dos usuários primários. Assim, podese definir quando ocupar um canal de um usuário primário, conforme a projeção estatística da probabilidade de existência de um espaço espectral. Outras funções como o protocolo de comunicação com os demais rádios cognitivos, os tempos de sensoriamento e técnicas a serem implementadas também estão contidas no módulo em questão.

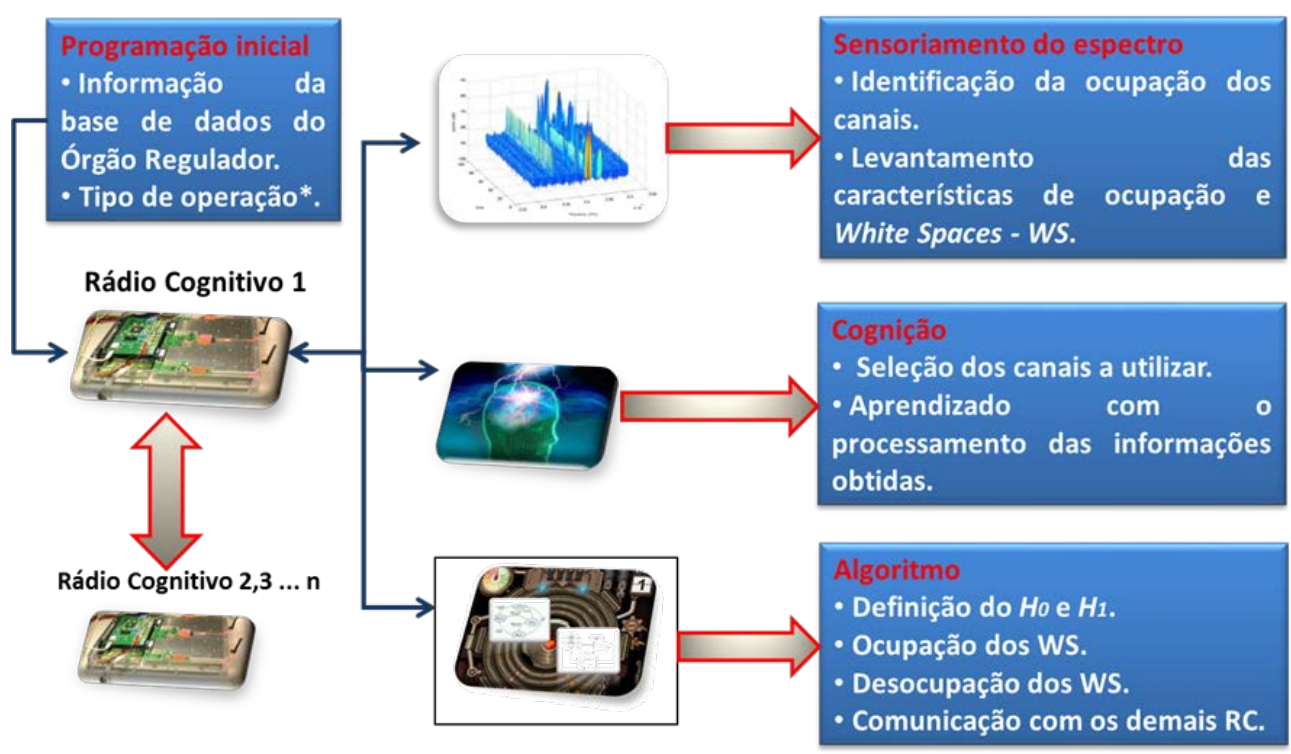

Figura 2.3 - Esquemático básico de um sistema cognitivo

O espectro é visto como um elemento crítico em qualquer novo arcabouço regulatório, conforme dito em [11]. A oferta de espectro é um elemento essencial para escolha e concorrência, e as decisões relativas ao espectro têm um impacto importante sobre a evolução do setor de telecomunicações. 


\section{3}

\section{Estrutura do Sistema Cognitivo}

A seção anterior introduziu os conceitos gerais e a descrição da tecnologia de rádios cognitivos. Nesta seção são detalhados os elementos de um sistema cognitivo segundo as propostas mais recentes. A Figura 2.4 mostra um diagrama com módulos chaves de um sistema cognitivo, adaptado de [15], que são descritos a seguir.

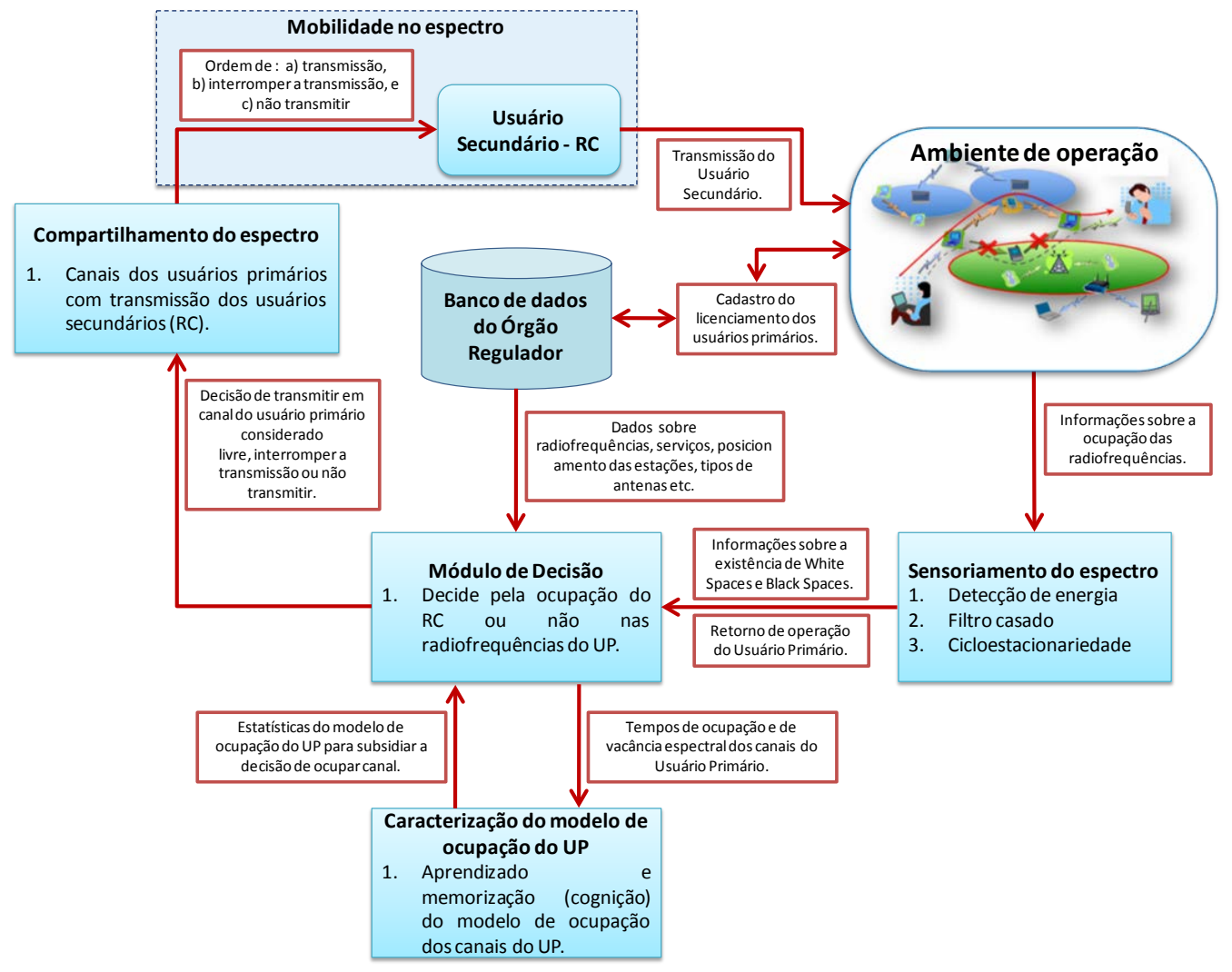

Figura 2.4 - Sistema cognitivo em desenvolvimento

\subsection{1}

\section{Ambiente de operação}

O ambiente de operação dos rádios cognitivos está representado pela caixa situada na parte direita superior da Figura 2.4. Esse ambiente representa os rádios dos usuários primários (licenciados) e os secundários que compartilham algumas faixas do espectro radioelétrico. 
Neste ambiente, os RC devem explorar a sua capacidade de conhecer as características de utilização da faixa do espectro que se deseja compartilhar. Esse compartilhamento não deve provocar interferência prejudicial nos usuários primários e, para isso, as frequências a eles alocadas devem ser monitoradas por um sensoriamento de espectro. Assim, em caráter secundário, o RC utiliza as frequências alocadas para o UP quando este está inativo e cessa sua operação quando o UP retornar suas transmissões.

\subsection{2}

\section{Sensoriamento do espectro}

O módulo de sensoriamento do espectro tem por finalidade monitorar as radiofrequências e verificarem que momento elas estão ocupadas e quando poderão ser compartilhadas entre usuários primários e secundários. Este módulo também sinaliza o retorno de operação dos usuários primários, de modo que o sistema cognitivo cesse suas transmissões caso esteja utilizando os canais dos UP.

São três técnicas de detecção de sinais mais utilizadas: a detecção de energia, o filtro casado e a ciclo estacionalidade, que serão expostas com maiores detalhes no Capítulo 3.

\subsection{3}

\section{Módulo de decisão}

Este módulo recebe as informações do setor de sensoriamento do espectro com dados sobre a existência de blackspaces ou whitespaces e decidirá pela ocupação ou não dos canais monitorados. A decisão de ocupação dos canais será tomada levando em conta as informações recebidas do sensoriamento, do módulo de caracterização do canal e também das informações extraídas do banco de dados do Órgão Regulador, que contém cadastro dos sistemas licenciados, com o posicionamento das estações, frequências utilizadas, tipos de antenas, potência de operação, serviços explorados e demais dados pertinentes. 


\subsection{4}

\section{Caracterização do modelo de ocupação}

O aprendizado do modelo de ocupação dos canais dos usuários primários deve ser registrado pelo sistema cognitivo, pois estas informações serão úteis para a definição dos momentos de compartilhamento do espectro e de interrupção das transmissões para evitar interferências. É do ambiente de operação que são obtidas as informações do processo de sensoriamento do espectro, que vão alimentar os módulos de decisão.

\subsection{5}

\section{Compartilhamento do espectro}

O compartilhamento do espectro se dá nos períodos em que se estima que o usuário primário tem vacância espectral no seu canal e o usuário cognitivo insere suas informações.

Nestes períodos, se não houver retorno da atividade do usuário primário até que o sistema cognitivo interrompa as transmissões, foi realizada uma ocupação do espectro conforme desejado, sem interferências prejudiciais. As janelas de intervalos de tempo, neste caso, foram devidamente preenchidas e liberadas, sem colisão com os usuários principais.

\subsection{6}

\section{Mobilidade no espectro}

Mobilidade no espectro é a capacidade de um rádio cognitivo desocupar o canal que está compartilhando quando um usuário licenciado é detectado. O sensoriamento de espectro engloba, além da identificação de vacâncias espectrais, a capacidade de detectar rapidamente o início do retorno da utilização do canal pelo usuário licenciado, o UP. Essa capacidade é fundamental para que o RC possa evitar ou minimizar as interferências prejudiciais nos serviços primários. 


\section{3 \\ Detecção e medições}

\section{1}

\section{Sensoriamento do espectro}

De acordo com os artigos estudados, é esperada uma grande demanda nos próximos anos para a utilização dos rádios cognitivos, que aparecem no cenário atual, como uma solução tecnológica para atender aos pleitos de diversos usuários que necessitam de mais bandas do espectro. Neste segmento, as técnicas de sensoriamento das radio frequências terão importante papel, para viabilizar a utilização compartilhada do espectro.

O uso compartilhado mencionado inclui as faixas de frequências atualmente pertencentes a usuários licenciados (os primários). Dessa forma, detectar com precisão no espectro radioelétrico a presença dos principais utilizadores, oficialmente habilitados, é uma tarefa fundamental para o rádio cognitivo, conforme indicado em [12].

\section{2}

\section{Métodos de detecção}

Considerando essa linha, no processo de sensoriamento do espectro para detecção dos WS ou BS, três técnicas de processamento de sinal são, primariamente, propostas na literatura estudada:

i) Detecção de Energia;

ii) Filtro Casado; e

iii) Detecção de ciclo estacionariedade. 


\subsection{1}

\section{Detecção de energia}

A técnica de detecção de energia é a mais simples de todas, como mencionado em [13], apresentando menores complexidades de implementação e execução. Esta técnica é baseada na teoria de Neyman-Person e detalhada em [14]. Na metodologia de detecção de energia, em geral, o nível de intensidade de campo detectado é comparado com um limiar, de acordo com as características do ambiente. Se o nível de sinal for maior do que o limiar $(\gamma)$ pré-definido, o detector de energia decide por um canal ocupado e, se o respectivo valor não for mais elevado, a decisão é de que existe uma vacância espectral.

As amostras de entrada para o detector de energia, que serão comparadas com os limiares $(\gamma)$ são representadas pela equação (3.1). A identificação de ruído é "w [n]", na verdade um canal AWGN (additive White Gaussian noise), isto é, com Ruído Branco Gaussiano Aditivo, e a do sinal é "s [n]". O espaço espectral vago (white space) é representado pela equação (3.2) e a presença do utilizador principal das radio frequências (usuário primário) é mostrada na equação (3.3). A condição de decidir por canal não ocupado é definida na equação (3.4).

Um detector de energia pode ser implementado de modo semelhante à aplicação de um analisador de espectro, pela Transformada Rápida de Fourier (FFT) utilizando a média das raias de frequências. O ganho de processamento é proporcional à FFT de tamanho $\mathrm{N}$ e da observação média de tempo $\mathrm{T}$. $\mathrm{O}$ aumento do tempo médio de $\mathrm{N}$ aumenta a resolução de frequência, o que ajuda a detecção do sinal de banda estreita.

Um detector de energia (diagrama básico) implementado no domínio do tempo, está ilustrado na Figura 3.1, também conhecido como radiômetro, realiza diretamente o cálculo da métrica T conforme a equação (3.1), e a seleção da faixa de frequência é feita com a utilização de um pré-filtro.

$$
T=\sum_{n=1}^{N}|x[n]|^{2}
$$

$n=1,2 \ldots, N$ é a quantidade de amostras.

$w[n]$ é o ruído e $s[n]$ é o sinal do usuário primário que se deseja detectar. 
Se a detecção de sinal dada por (3.1) é menor do que um o limiar $(\gamma)$ prédefinido, então a decisão será por $H_{0}$, conforme (3.2)

$$
\begin{aligned}
& H_{0}: x[n]=w[n] ; \text { não há sinal, apenas ruído. } \\
& H_{1}: x[n]=s[n]+w[n] ; \text { existe ruído e a presença do sinal. } \\
& H_{0}: x[n]=w(n) \leq \gamma
\end{aligned}
$$

Existem algumas desvantagens na utilização de detectores de energia, embora esta técnica permita uma maior simplicidade de implementação. A primeira é que um limiar utilizado para a detecção do usuário primário é suscetível a variações desconhecidas do meio ou alteração dos níveis de ruído. Assim, mesmo que o limiar seja definido adaptativamente, a presença de qualquer interferência na banda poderá confundir, em alguns casos, o detector de energia.

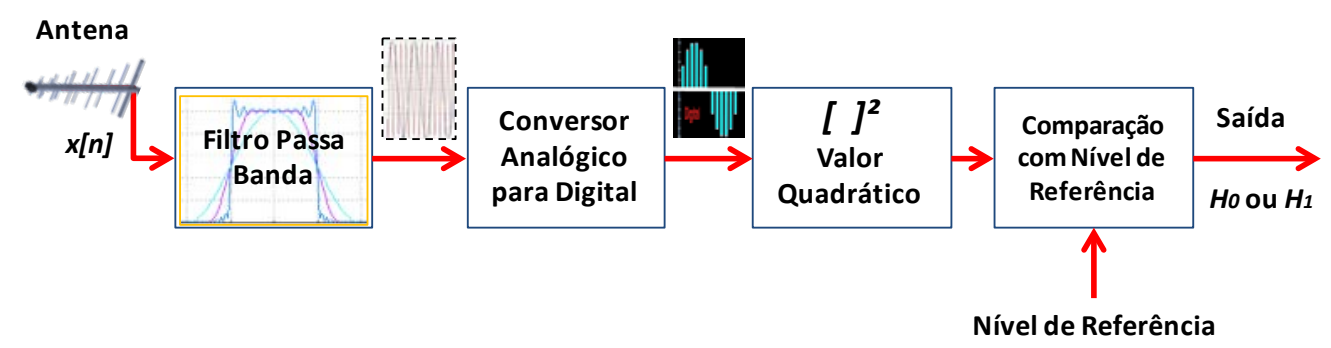

Figura 3.1 - Detector de energia

Em segundo lugar, o detector de energia não diferencia sinais modulados do ruído e de interferência, portanto, ele apresentará uma complexidade em reconhecer claramente um sinal interferente, impedindo o sistema de realizar uma avaliação de sinal mais aprimorada e concluir pela definição precisa de sensoriamento de um WS ou BS.

Por último, um detector de energia não funciona para sinais de espalhamento espectral e sinais com salto de frequência, para os quais algoritmos de processamento de sinal mais sofisticados precisam ser implementados. 


\subsection{2}

\section{Filtro casado}

O melhor método para detectar um sinal qualquer é a utilização de um filtro casado uma vez que ele maximiza a relação sinal/ruído e facilita o processamento decorrente. No entanto, a operação de um filtro casado efetivamente requer a demodulação do sinal recebido. Isso significa que o rádio cognitivo teria que possuir um conhecimento prévio das características do sinal a ser recebido na PHY (camada física) e na camada MAC (Media Access Control), como por exemplo, o tipo de modulação ou a estrutura da formatação de pulsos que compõe um pacote.

Tais informações poderão ser pré-armazenadas na memória dos RC, entretanto, a parte mais complexa é que para que ocorra uma de modulação adequada há de existir uma coerência com o sinal do usuário primário em tempo e sincronização da portadora e, até mesmo, a equalização do canal. Isto pode ser possível, considerando que a maioria dos usuários primários tem pilotos (referências do sinal), preâmbulos, bits de sincronização ou códigos de espalhamento, que podem ser utilizados para a detecção coerente. Pode-se citar como exemplos, o sinal de TV que possui uma pequena amostra de portadora para os canais de áudio e vídeo, os sistemas CDMA que têm um código para detectar o espalhamento utilizado e gerar sincronização e, os pacotes OFDM que têm preâmbulos para aquisição dos pacotes de dados.

A principal vantagem do filtro casado é que, devido à coerência na demodulação, é utilizado um menor tempo para atingir elevado ganho de processamento, uma vez que poucas amostras são necessárias para satisfazer uma determinada probabilidade de detecção. No entanto, há uma desvantagem significativa na utilização de filtro casado nos rádios cognitivos, pois seria necessário um receptor específico para cada tipo de usuário primário. 


\section{2 .3}

\section{Ciclo estacionariedade}

Outra técnica utilizada para o sensoriamento do espectro é a detecção da cicloestacionariedade do sinal. Ela é possível devido ao fato de que sinais modulados são geralmente associados a ondas portadoras senoidais, ou trens de pulso que se repetem ou se espalham no espectro, o que resulta em ciclos repetidos e assim, as suas estatísticas, média e autocorrelação, exibem periodicidade no sentido amplo. Esta tendência de periodicidade é utilizada para a análise de diversos sinais no processamento de detecção.

Este método tem como desvantagem a necessidade de implementações computacionais de alta complexidade. No entanto, como motivação do seu uso está a capacidade de detecção satisfatória em ambientes com baixos valores na relação sinal/ruído.

\section{3}

\section{Medições}

Esta seção mostra os resultados e a avaliação das medições realizadas em campo, assim como algumas conclusões e deduções, que são utilizadas na concepção dos algoritmos desenvolvidos para aprimorar a utilização do espectro, suportando a predição de futuros espaços espectrais livres, por meio dos rádios cognitivos.

\subsection{1}

\section{Resultados obtidos em Campinas - SP}

A primeira bateria de medições foi realizada na faixa de $450 \mathrm{MHz}$ a 470 MHz, na cidade de Campinas, no estado de São Paulo, em um ambiente urbano. Essa faixa é utilizada por serviços de voz, na maioria dos casos, pelas empresas de rádio taxi, concessionárias de rodovias, empresas de aviação, de transporte e refinarias. Estes são exemplos de usuários primários do Serviço Limitado Privado 
(SLP-019), autorizados pela Agência Nacional de Telecomunicações (ANATEL) para exploração desse segmento do espectro.

Neste trabalho, foi avaliada a ocupação do espectro radioelétrico na região central de Campinas, visando caracterizar os sinais existentes na localidade, nos domínios do tempo e da frequência. A instalação dos equipamentos de medição foi no topo de um prédio situado no seguinte endereço:

Instalações da PETROBRAS - Coordenação Jurídica de Campinas

Gerência Jurídica de São Paulo

Rua Barão de Paranapanema, 146, S 63/64, bloco B.

Bosque - Campinas- São Paulo

Latitude: $22^{\circ} 54^{\prime} 33,25^{\prime \prime}$ Sul

Longitude: $47^{\circ} 02^{\prime} 43,61^{\prime \prime O e s t e}$

Altitude: 667m

A Figura 3.2 mostra a localização do ponto das medições em Campinas (fonte: Google Maps). O período de coleta de dados foi das 08:00 às 18:00 horas, (horário comercial com indústria e comércio operando normalmente). O equipamento utilizado foi o analisador de espectro portátil FSH8 da Rohde \& Schwarz, conectado a uma antena J-Pole, que pode ser visualizada na Figura 3.3, sintonizada em $465 \mathrm{MHz}$ e laptop com software Lab View para automação das coletas de sinal.

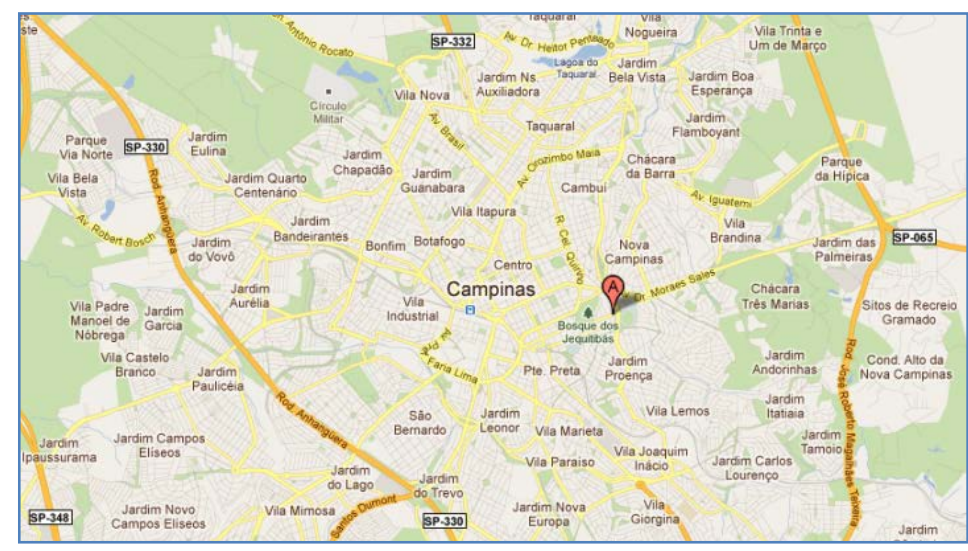

Figura 3.2 - Localização das medições em Campinas - SP 


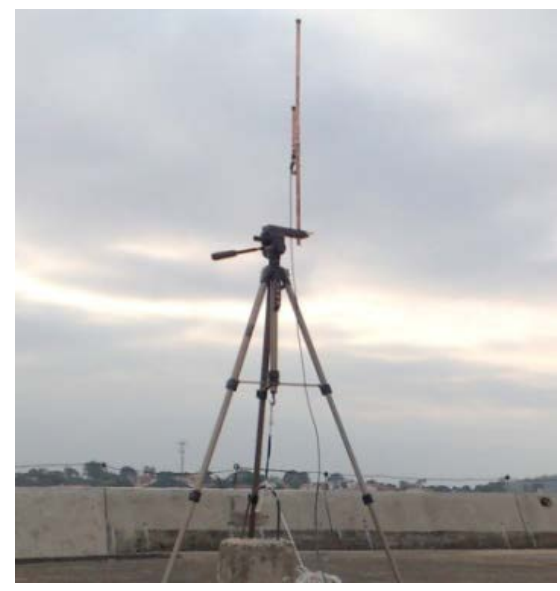

Figura 3.3 - Antena J-Pole

O nível de ruído na localidade estava em torno de $-120 \mathrm{dBm}$, como pode ser visto nas telas do analisador de espectro, da Figura 3.4, merecendo destaque que as capturas de sinal (para medição de ruído) foram realizadas no topo do prédio (Figura 3.4a) e no nível da rua (Figura 3.4b).

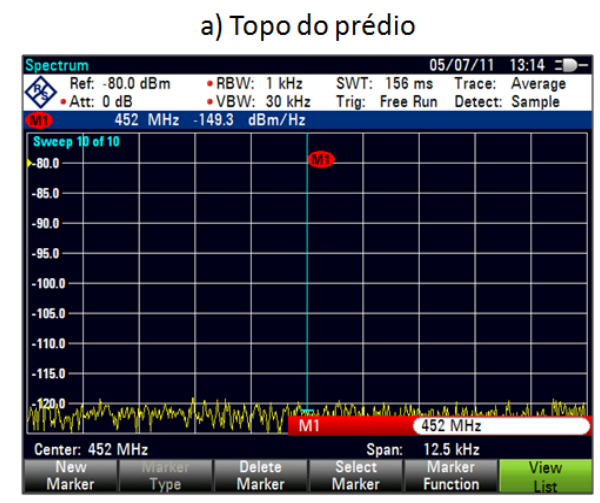

b) Nível da rua (antena a $2 \mathrm{~m}$ do solo)

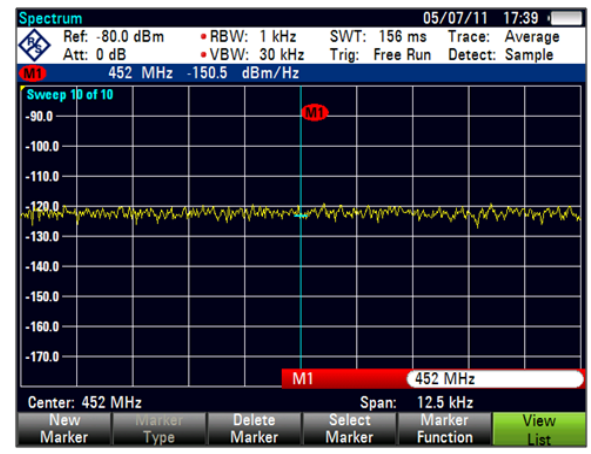

Figura 3.4 - Níveis de ruído 452 MHz - Topo do prédio e no nível da rua

A escolha da faixa de $450 \mathrm{MHz}$ deve-se aos seguintes fatores: a) É uma faixa cujos mecanismos de propagação permitem vencer alguns obstáculos típicos em áreas urbanas e também em áreas rurais, mais remotas, nas quais haja relevo acidentado; e b) Além das favoráveis características de propagação, a faixa é alta o suficiente para proporcionar uma banda de utilização que viabiliza comunicações de voz e dados com uma vazão de informações satisfatória, permitindo um elenco notável de serviços a serem implementados.

Amostras de sinal do espectro radioelétrico foram capturadas e investigadas em segmentos de $5 \mathrm{MHz}$ nos intervalos, indicados na tabela 3.1. 
Tabela 3.1 - Segmentos do espectro investigados

\begin{tabular}{|c|c|}
\hline Segmentos & Intervalo $(\mathrm{MHz})$ \\
\hline Segmento 1 & $450-455$ \\
\hline Segmento 2 & $455-460$ \\
\hline Segmento 3 & $460-465$ \\
\hline Segmento 4 & $465-470$ \\
\hline
\end{tabular}

Como um dos resultados das investigações, destaca-se o baixo percentual de utilização do espectro, na faixa de 450 a $470 \mathrm{MHz}$, com segmentos filtrados em diferentes limiares e faixas de frequências, como indicado na Figura 3.5. A ocupação percentual no tempo foi considerada baixa porque os canais, em sua grande maioria, não tinham sinal modulado continuamente. A ocupação observada foi na ordem de 10 a 50\%, com poucos canais ultrapassando a porcentagem de $40 \%$ do tempo.

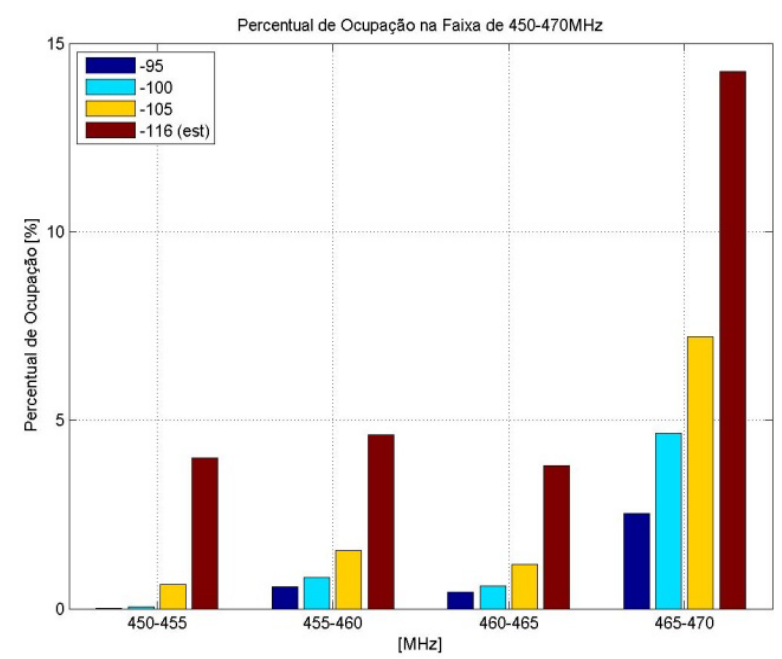

Figura 3.5 - Gráfico de ocupação espectral em função de distintos limiares

Alguns canais também foram investigados separadamente, tendo sido utilizada uma largura de $20 \mathrm{kHz}$, conforme indicado na tabela 3.2.

Tabela 3.2 - Canais investigados separadamente

\begin{tabular}{|c|c|}
\hline Canal & Intervalo $(\mathrm{MHz})$ \\
\hline 1 & $450,6400-450,6600$ \\
\hline 2 & $452,3650-452,3850$ \\
\hline 3 & $457,5275-457,5475$ \\
\hline 4 & $467,4275-467,4475$ \\
\hline 5 & $463,5400-463,5600$ \\
\hline 6 & $469,1525-469,1725$ \\
\hline
\end{tabular}


Como exemplos representativos de alguns dos resultados obtidos, a Figura 3.6 mostra o gráfico de ocupação do espectro da frequência 457, $530 \mathrm{MHz}$, em Campinas - SP, no horário de 14:19:00 às 15:00:20 horas, com uma ocupação de 34,3\% no tempo da avaliação. De modo análogo, em outro horário a frequência 463,550 MHz que também foi monitorada, apresentou uma ocupação de 33,6\% no horário de 15:18:54 às 16:00:14 horas, conforme gráfico da Figura 3.7.

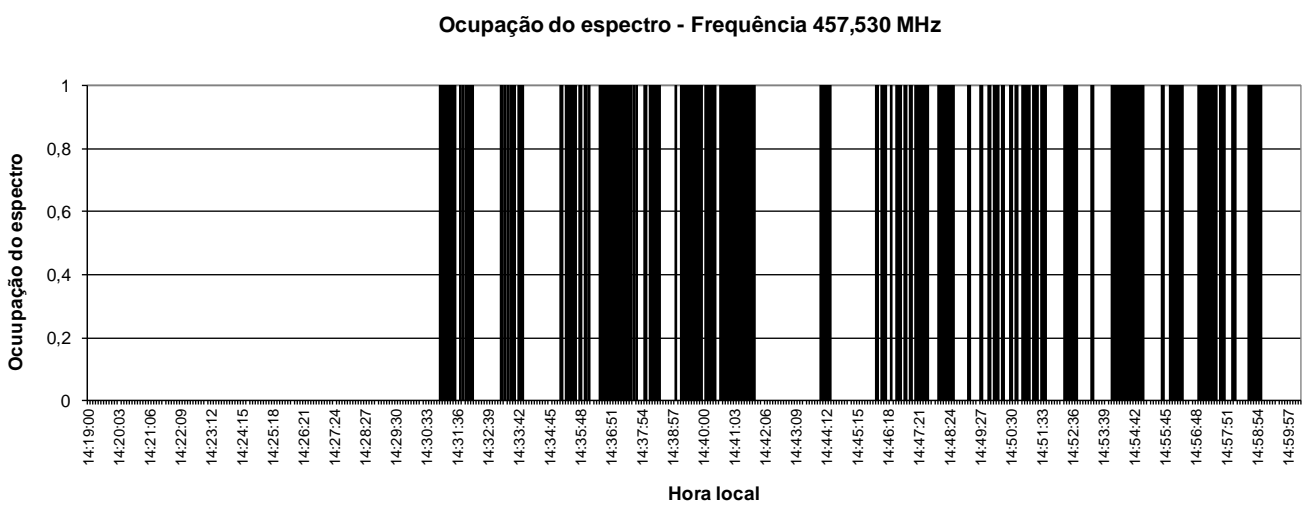

Figura 3.6 - Ocupação do espectro em Campinas - SP $-457,530 \mathrm{MHz}$

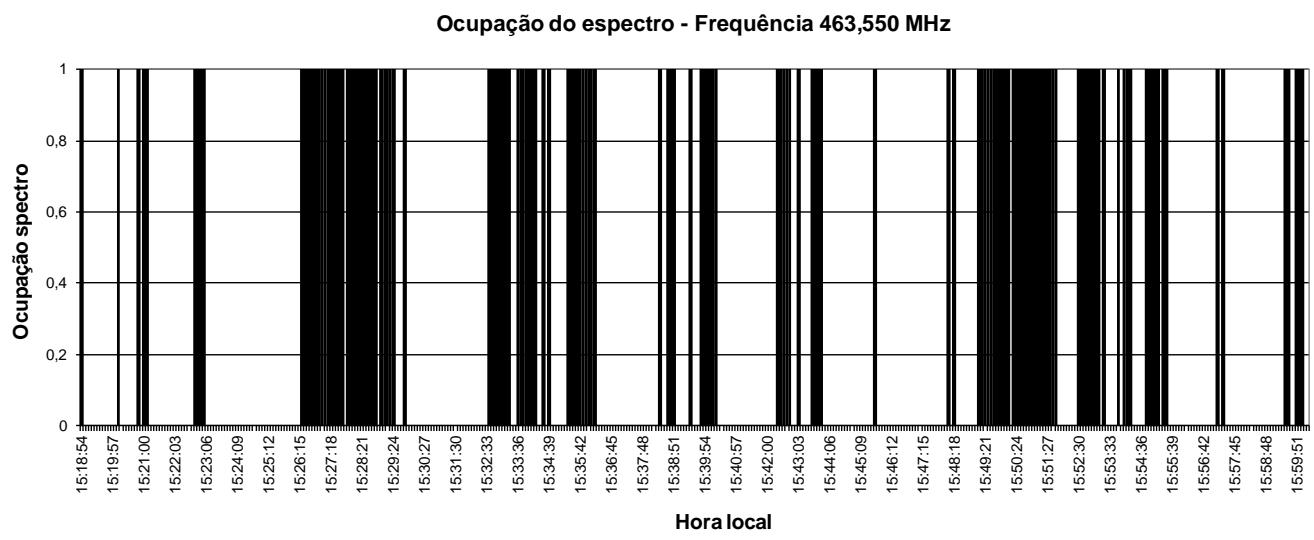

Figura 3.7 - Ocupação do espectro em Campinas - SP -463,550 MHz

O critério de escolha dos canais a serem investigados foi pela monitoração das frequências, destacando os que apresentaram maior ocupação do espectro no domínio do tempo e, depois disso, os canais selecionados foram demodulados e gravados (áudio). A modulação dos sinais era em frequência modulada (FM) com banda de $25 \mathrm{kHz}$, utilizando comunicações em voz, na maioria dos canais monitorados. O gráfico da Figura 3.8 mostra o canal com frequência central em 463,550 MHz em dois momentos ao longo do tempo, às 15:41:01 horas, com 
espaço espectral (white space) e as 15:41:18 horas com o respectivo espectro ocupado (black space). Para a automatização dos resultados, neste caso em especial, foi considerado um patamar de $-100 \mathrm{dBm}$, acima do qual o canal era considerado ocupado.

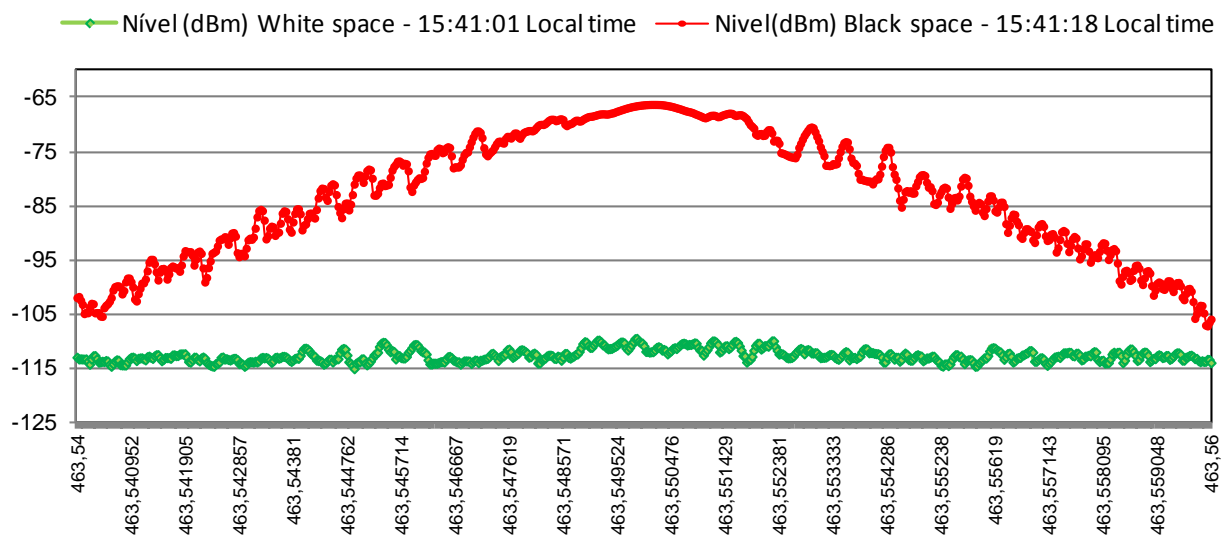

Figura 3.8 - Critério para definição de ocupação do canal

O percentual de ocupação individualizado dos canais estudados em Campinas pode ser visualizado no gráfico da Figura 3.9, com a média de ocupação na ordem de $26 \%$ do tempo, o que mostra que há grande porção do espectro ocioso, no domínio do tempo, dentro dos canais investigados.

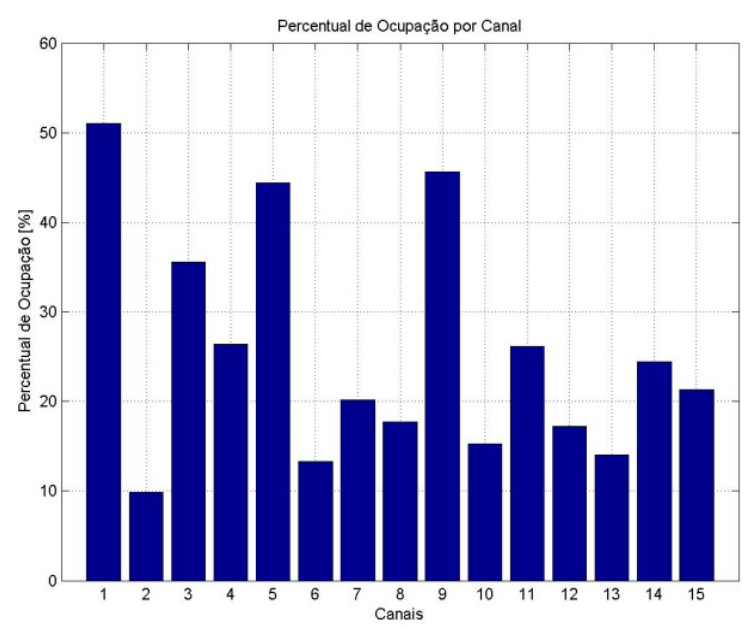

Figura 3.9 - Gráfico de porcentagem de ocupação dos canais - Campinas 
Em uma pesquisa na faixa de 450 a $470 \mathrm{MHz}$, verifica-se que estão disponíveis $20 \mathrm{MHz}$ de banda, na qual existem 1.600 canais com largura de faixa de $12,5 \mathrm{kHz}$, conforme nova normatização do órgão regulador nacional. Destaque-se que ainda existem vários usuários antigos operando com banda de 25 $\mathrm{kHz}$.

Ao redor do ponto de medição de Campinas, em um raio de 20 km, na época do trabalho, estavam autorizadas 1.563 frequências e 37 na condição de estudo na ANATEL. Das frequências mencionadas, algumas possuem irradiação em $100 \%$ do tempo, o que impediria o uso de rádios cognitivos nestes canais na mesma região. Entretanto, muitos dos canais alocados (na verdade a grande maioria) apresentam uma baixa ocupação no domínio do tempo. A Figura 3.10 mostra um momento da medição apresentando toda a faixa de 450 a $470 \mathrm{MHz}$.

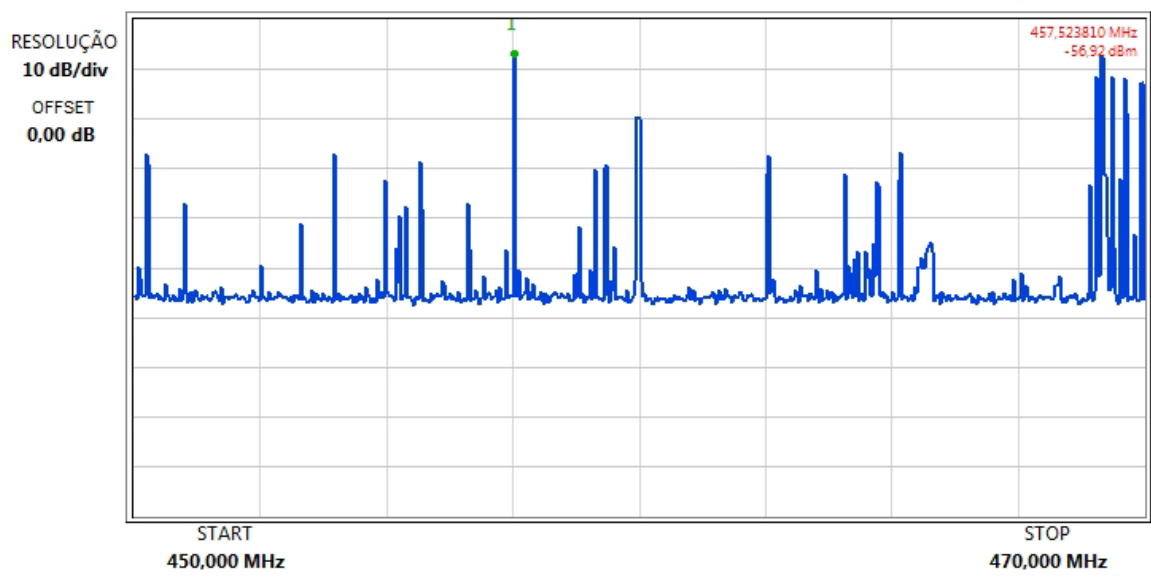

Figura 3.10 - Instantâneo do espectro de 450 a 470 MHz Campinas - SP

Evoluindo com o estudo, avaliou-se como os usuários do Serviço Limitado Privado - 019, de voz, se comportam ao longo do tempo, visando entender melhor os modelos de ocupação dos canais estudados. Além disso, a demanda nesse serviço é alta e, atualmente, considera-se o espectro congestionado, o que justifica plenamente o estudo em tela que pode resultar em uma multiplicação de uso dos canais, permitindo uma maior densidade de usuários nas regiões de interesse.

De modo a obter amostras mais precisas, no domínio do tempo, as frequências com ocupação espectral considerada significativa (dentro do conjunto de amostras obtidas) tiveram seus canais demodulados e gravados para um estudo 
minucioso do comportamento de tendências das transmissões, dos espaços espectrais existentes e de outros parâmetros.

Foram avaliadas as conversações gravadas na cidade de Campinas, São Paulo. As frequências monitoradas estão na faixa de 450 a $500 \mathrm{MHz}$. Os sinais captados foram demodulados e, posteriormente, carregados em um computador por meio de um software de processamento de áudio, o que permitiu medir com a precisão de milissegundos os momentos de ocupação do espectro e os espaços espectrais vagos, conforme a amostra avaliada na Figura 3.11.

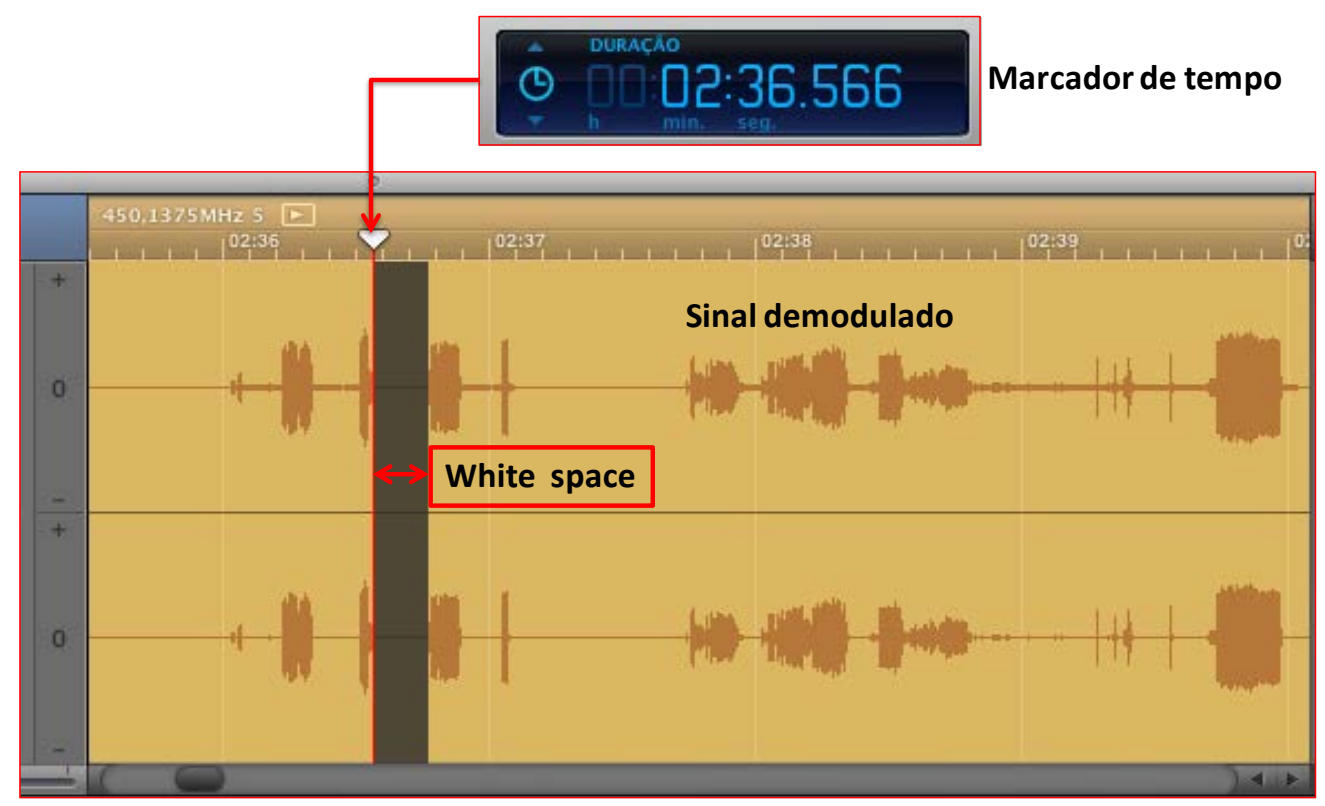

Figura 3.11 - Avaliação das conversas por meio de software de áudio

O áudio foi avaliado de modo a identificar cada sequência considerada como uma conversa, exigindo interpretação humana. Dentro de cada conversa, foram marcados os bursts de áudio (falas dos interlocutores), além disso, foram registrados também os espaços entre os referidos bursts e ainda os intervalos entre conversas. Estas conversações transcorreram em sistemas half duplex, o que permite garantir que conversas completas foram devidamente identificadas. Cabe ressaltar que os whitespaces e blackspaces foram classificados, sequencialmente, de “1” a "n”. Neste contexto, a tabela 3.3 apresenta uma legenda com a indicação dos parâmetros medidos, que foram utilizados para a caracterização das conversas e, consequentemente, da ocupação do espectro pelos usuários primários da região. 
A tabela 3.4 mostra resultados individuais dos parâmetros levantados, devidamente organizados, visando viabilizar o processamento realizado para caracterização das conversações. Os intervalos de tempo foram registrados em milissegundos.

Tabela 3.3 - Parâmetros de caracterização das conversações

\begin{tabular}{|c|l|}
\hline \multicolumn{2}{|c|}{ Legenda } \\
\hline QBC & Quantidade de bursts de falas dentro da conversação \\
\hline TECn & Tempo entre conversas. \\
\hline WS1 & Primeiro WS do ciclo. \\
\hline WSn & n-ésimo WS do ciclo. \\
\hline BS1 & Primeiro BS do ciclo. \\
\hline BSn & n-ésimo BS do ciclo. \\
\hline$n$ & n: Contador geral de segmentos TECn, BSn e WSn. \\
\hline$n$ & Início da avaliação de nova gravação. \\
\hline \multicolumn{2}{|c|}{ OBS. TEMPOS EM MILISEGUNDOS. } \\
\hline
\end{tabular}

Tabela 3.4 - Caracterização das conversações

\begin{tabular}{|c|c|c|c|c|}
\hline $\begin{array}{c}\text { Contador } \\
\text { Geral }\end{array}$ & TEC1 & BS/WS & $\begin{array}{c}\text { Duração } \\
\text { (ms) }\end{array}$ & QBC \\
\hline \multirow[t]{2}{*}{1} & TEC1 & & 49610 & \\
\hline & & & & 3 \\
\hline 2 & 1 & BS1 & 4310 & \\
\hline 3 & 1 & WS1 & 1990 & \\
\hline 4 & 1 & BS2 & 12060 & \\
\hline 5 & 1 & WS2 & 1700 & \\
\hline 6 & 1 & BS3 & 5270 & \\
\hline \multirow[t]{2}{*}{7} & TEC2 & & 188770 & \\
\hline & & & & 4 \\
\hline 8 & 2 & BS1 & 3470 & \\
\hline 9 & 2 & WS1 & 1330 & \\
\hline 10 & 2 & $\mathrm{BS} 2$ & 3700 & \\
\hline 11 & 2 & WS2 & 600 & \\
\hline 12 & 2 & BS3 & 11060 & \\
\hline 13 & 2 & WS3 & 1320 & \\
\hline \multirow[t]{3}{*}{14} & 2 & BS4 & 4350 & \\
\hline & . & & & \\
\hline & $\dot{.}$ & & & \\
\hline \multirow[t]{2}{*}{219} & TEC28 & & 15330 & \\
\hline & & & & 1 \\
\hline 220 & 28 & BS1 & 1650 & \\
\hline
\end{tabular}

Ainda com o objetivo de facilitar o entendimento dos parâmetros medidos, a Figura 3.12 esclarece como as conversas foram identificadas e extraídos os tempos de TECn, QBC, WSn e BSn. 


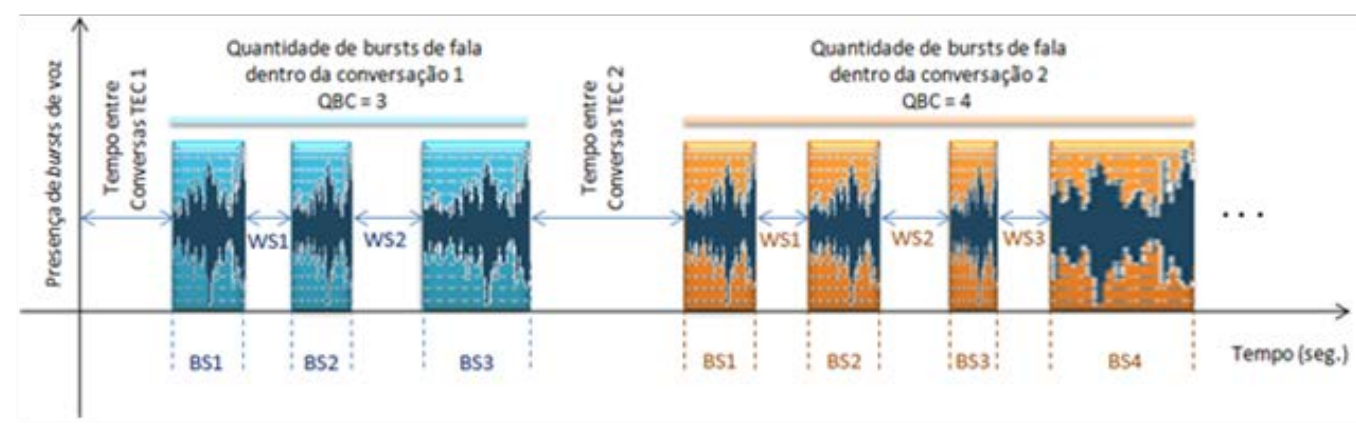

Figura 3.12 - Indicação dos parâmetros medidos

As quantidades de bursts de áudio (fala) em cada conversa variaram, basicamente, de 1 até 15, com seus resultados apresentados em ordem cronológica no gráfico da Figura 3.13. O gráfico da Figura 3.14 mostra o resultado, em ordem sequencial, nas medidas de 70 conversações avaliadas.

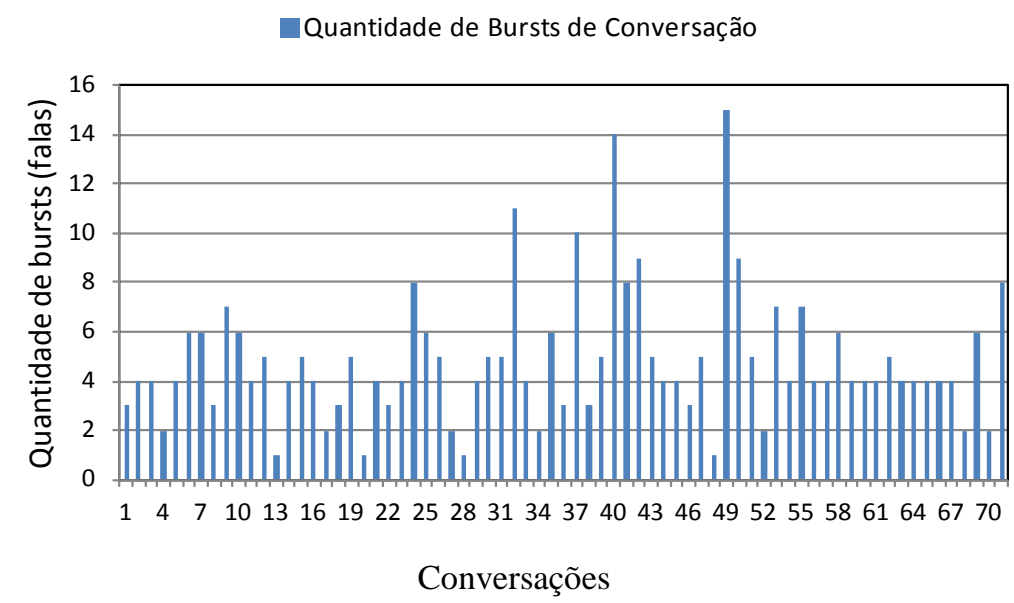

Figura 3.13 - Quantidade dos bursts de conversação (ordem de captação)

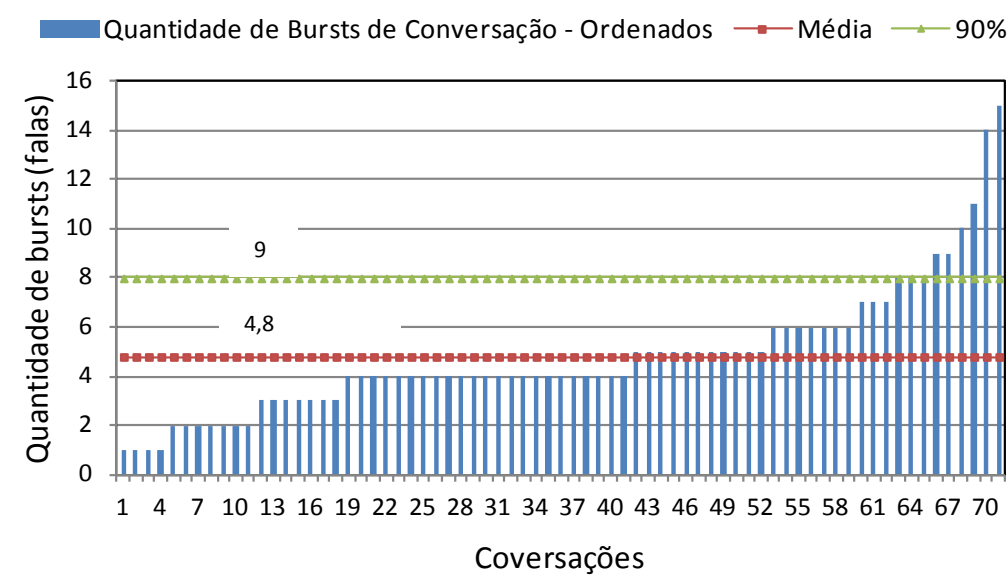

Figura 3.14 - Quantidade dos bursts de conversação em ordem crescente 
A distribuição da quantidade dos bursts de conversação está disposta no gráfico da Figura 3.15, onde nota-se uma maior concentração de dois a seis bursts de fala por conversa.

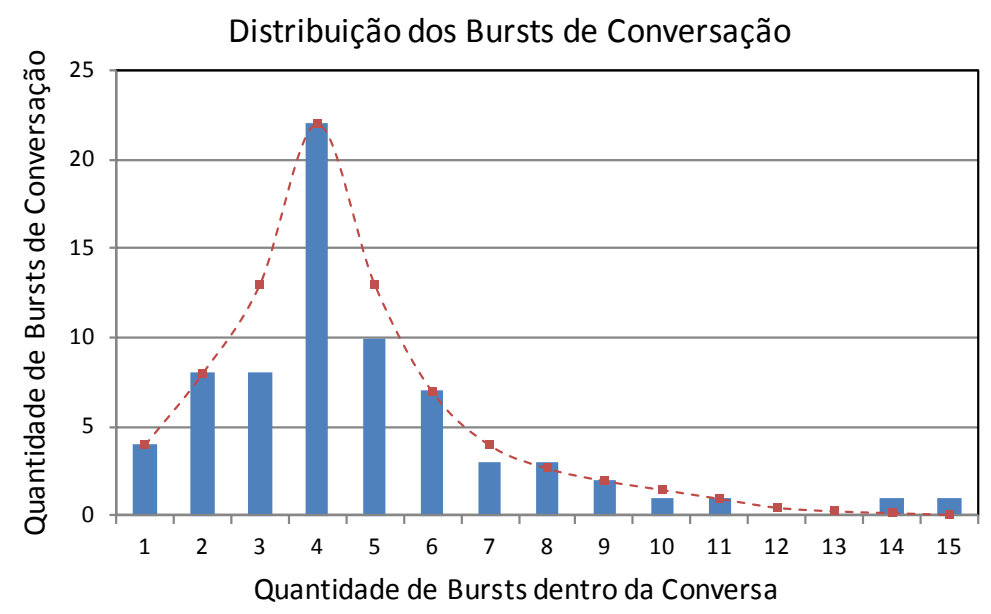

Figura 3.15 - Distribuição da quantidade dos bursts de conversação

Os tempos entre conversações (TEC) variaram entre 1.182 ms (TEC51) até 744.800 ms (TEC34), como disposto na tabela 3.5.

Tabela 3.5 - Tempos mínimo e máximo (ms) entre conversações

\begin{tabular}{|l|l|}
\hline TEC51- Mínimo & 1182 \\
\hline TEC34- Máximo & 744800 \\
\hline
\end{tabular}

Os gráficos das Figuras 3.16 e 3.17 mostram, respectivamente, os TECs na sequência de medição e em ordem crescente. 


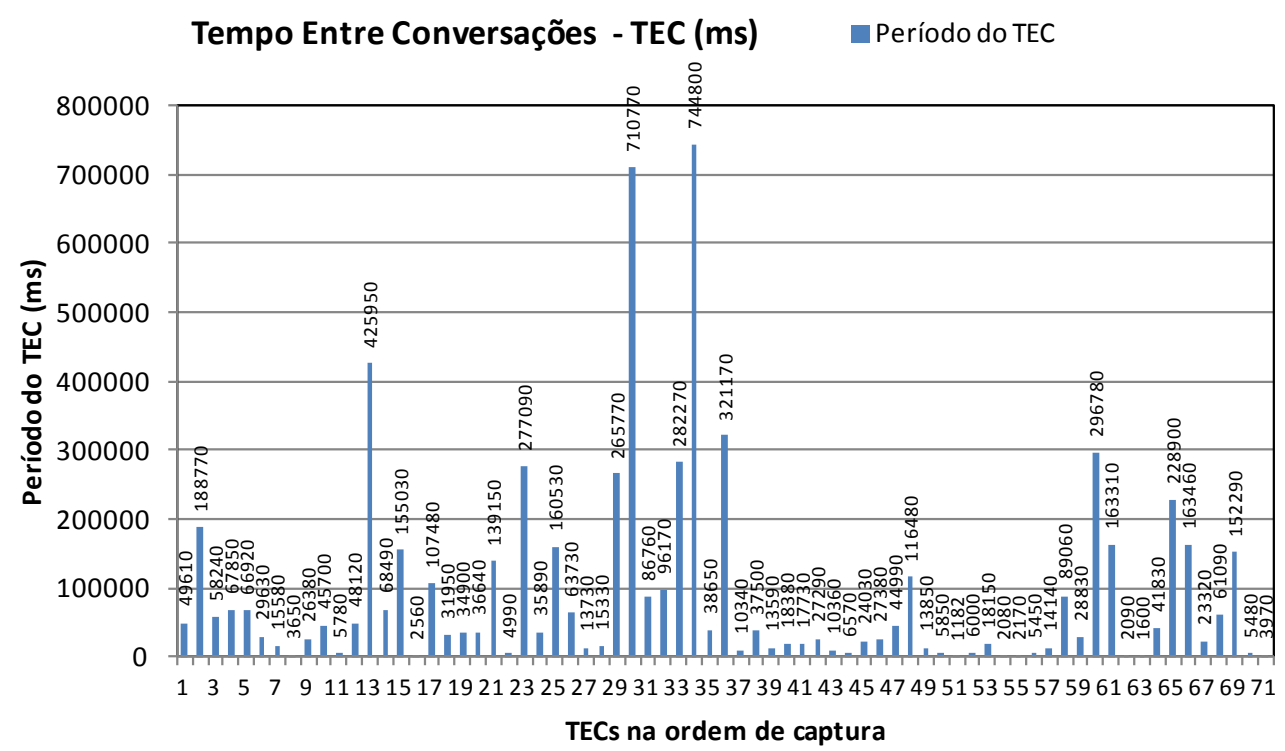

Figura 3.16 - TECs em sequência de medição

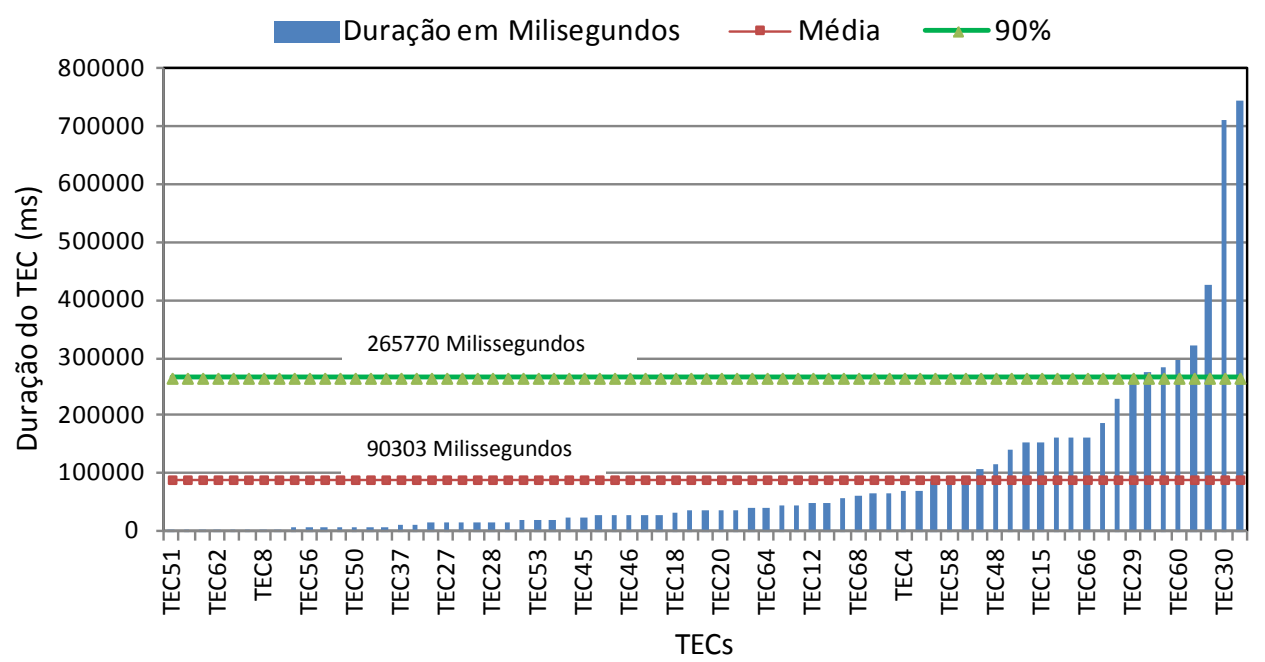

Figura 3.17 -TECs ordenados por valores crescentes

A avaliação dos black spaces indica variações interessantes a serem estudadas e muito úteis para a elaboração dos algoritmos propostos na seção seguinte. Os black spaces foram classificados em grupos de " 1 ” a " $n$ " dentro da sequência em que ocorrem em cada conversa. O gráficos das Figuras 3.18 e 3.19 mostram, respectivamente, os BS(1) obtidos nas medições em ordem cronológica, e em ordem crescente. Nas avaliações realizadas, foram estudados os comportamentos dos BS(2), BS(3) ... até BS(n), de forma similar. 


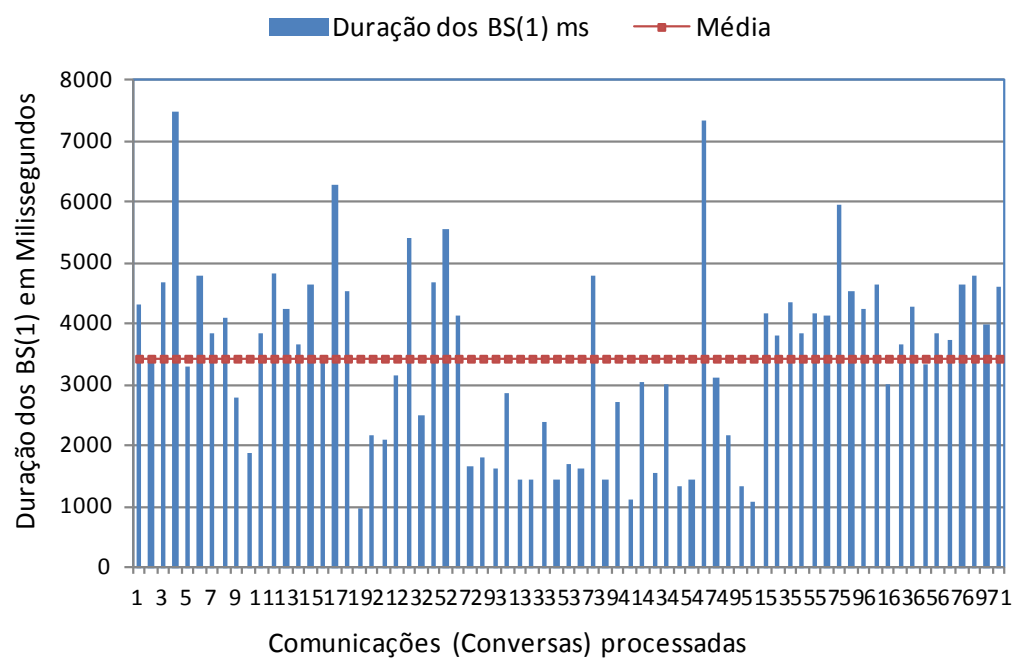

Figura 3.18 -Tempos dos BS(1) em ordem de captação

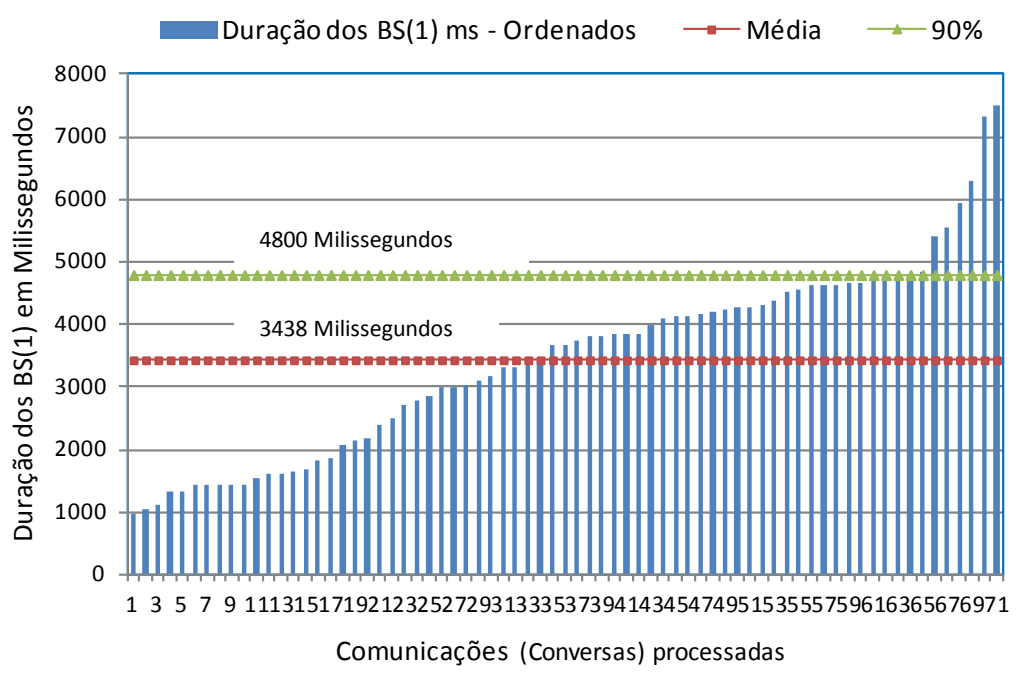

Figura 3.19 -Tempos dos BS(1) em ordem crescente, média e 90\%

Os resultados das medições dos white spaces dentro das conversas são mostrados a seguir nos gráficos das Figuras 3.20 e 3.21, respectivamente, os WS(1) em ordem cronológica e em ordem crescente. Da mesma forma que com os BS(n), nas avaliações realizadas, foram estudados os comportamentos dos WS(2), WS(3) ... até WS(n). 


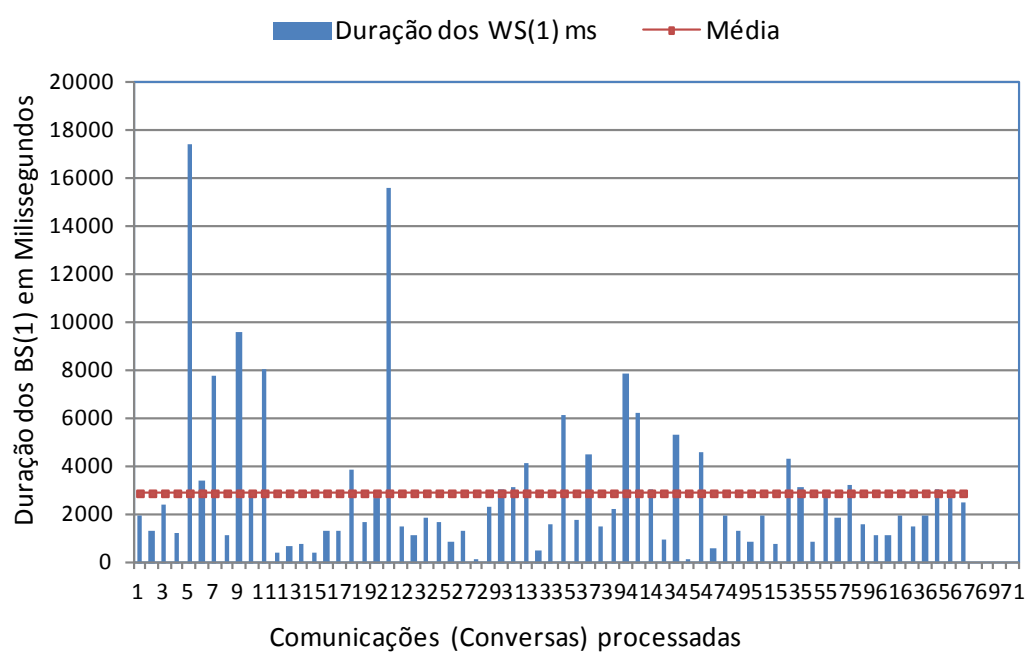

Figura 3.20 -Tempos dos WS(1) em ordem de captação

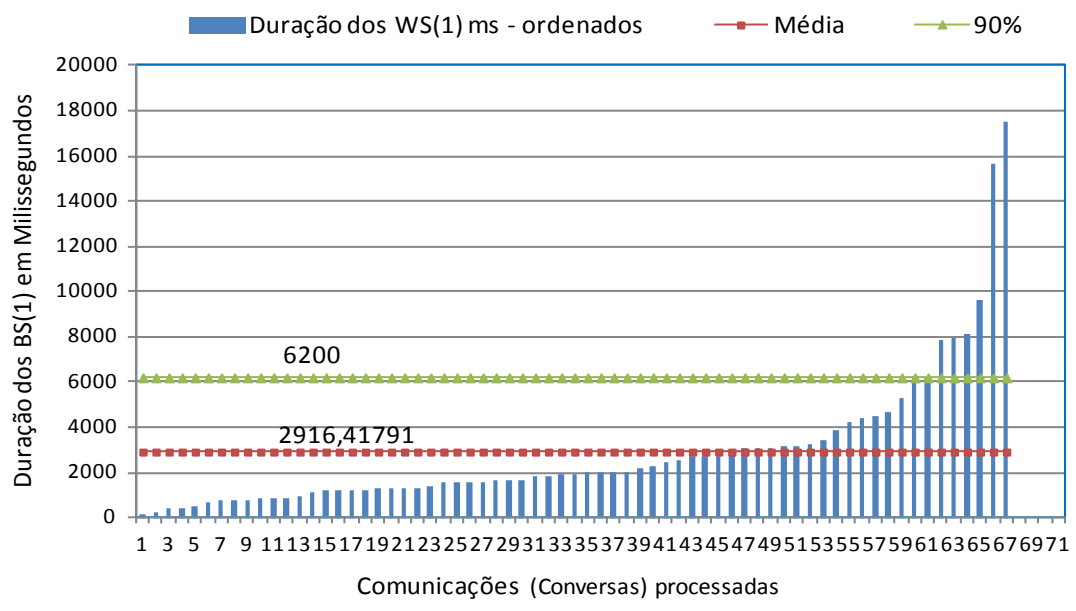

Figura 3.21 -Tempos dos WS(1) em ordem crescente, média e 90\%

O gráfico da Figura 3.22 mostra 20 ciclos gravados de conversação, nos quais pode ser observado que os tempos entre conversações - TEC são, em geral, bem maiores do que os white spaces e black spaces que compõem os ciclos monitorados.

Como observações finais desta seção, sugere-se que na medição de ocupação do espectro deve ser verificado, na região de teste, se os canais da região estão acionados continuamente com sinal ou se há white spaces regulares, pois o espaço espectral a ser explorado será dependerá da soma dos tempos ociosos detectados dentro dos canais individuais existentes na região. Nessa análise, já devem estar descartados os canais com energia contínua no tempo. Considera-se preferível que eles sejam excluídos do processamento pois, provavelmente, eles não poderão ser compartilhados por RC. 


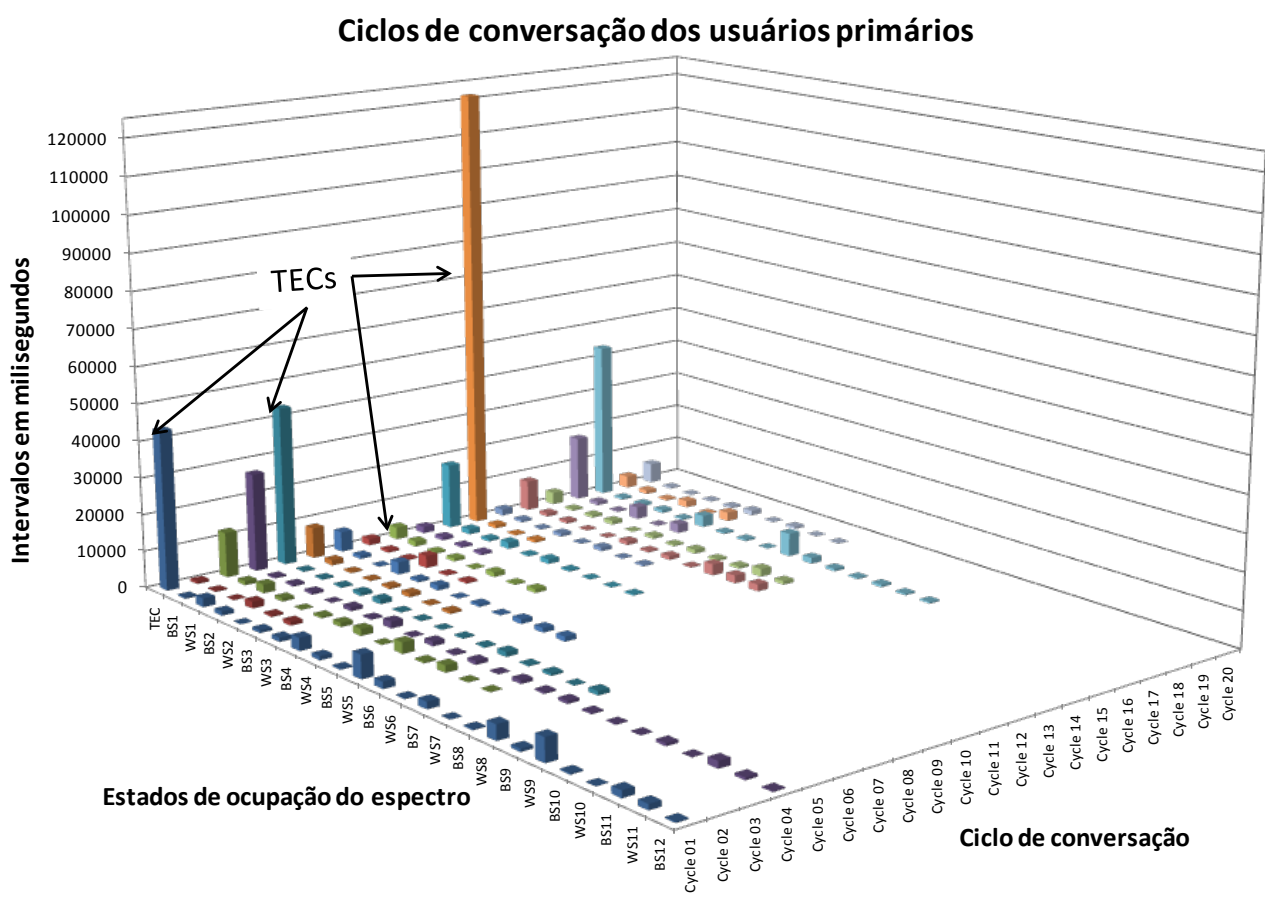

Figura 3.22 - Ciclos de conversação - TBC, BS(n) e WS(n)

Os resultados das medições apresentadas neste Capítulo foram realizadas especificamente para os estudos desta tese. Um artigo foi publicado no European Conference on Antenas and Propagation - EUCAP [49], em Gothenburg, na Suécia, em abril de 2014, que relata em detalhes as medidas realizadas.

Este estudo foi conduzido para avaliar canais com alta taxa de ocupação para tratar da investigação do desempenho dos rádios cognitivos em condições severas de operação, avaliando a robustez do sistema, nestas condições.

Assim sendo, os resultados obtidos com os algoritmos desenvolvidos em situações mais brandas serão muito mais favoráveis para viabilizar a implementação dos sistemas cognitivos.

Foram também obtidos resultados de medições realizadas no Rio de Janeiro, nas dependências da Pontifícia Universidade Católica - PUC-RJ e, em Juiz de Fora com apoio da ANATEL. Os resultados escolhidos e utilizados na tese foram somente os de Campinas por apresentarem maior ocupação do espectro em relação aos demais e, portanto, julgados mais adequados à finalidade do trabalho. 


\section{4 \\ Metodologia, Simulação e Desempenho}

Neste capítulo são descritas as metodologias utilizadas para o dimensionamento do tamanho da janela de predição e de utilização de espaços espectrais futuros. Além disso, avalia-se o processo da tomada de decisão em ocupar ou não as janelas de predição por meio dos usuários cognitivos, em função da probabilidade de colisão com os usuários primários.

É também aqui apresentada a avaliação de desempenho obtido com as técnicas discutidas nesta tese.

\section{1}

\section{Metodologia}

\subsection{1 \\ Descrição do Problema}

Neste estudo são abordadas duas situações, onde a primeira é relativa ao dimensionamento da janela de predição e a segunda é a forma de utilização da referida janela.

Como já visto, o rádio cognitivo preenche intervalos de tempo futuros no canal do usuário primário, quando houver uma indicação de alta probabilidade de que a janela que se deseja ocupar estará com vacância espectral.

Desse modo, são formuladas as seguintes questões:

a) A partir de um instante de tempo t, qual a probabilidade de que $n$ intervalos de tempo futuros estejam livres?

b) Como proceder na utilização desta janela se for sabido que a probabilidade desta janela estar totalmente livre é alta?

Em relação a primeira questão propõe-se um procedimento para o dimensionamento da janela de predição, em função da sua probabilidade de 
ocupação, utilizando o comportamento de utilização em uma janela de observação. Até onde foi possível pesquisar na literatura corrente, nenhuma referência consultada promove o cálculo desta estimativa (dimensionamento da janela de predição) exceto para modelos estocásticos de complexidade muito baixa, embora existam várias referências que propõem procedimentos para sua ocupação pelo US, em função da ocupação observada em uma janela de observação. A Figura 4.1 ilustra as janelas de observação e predição aqui discutidas.

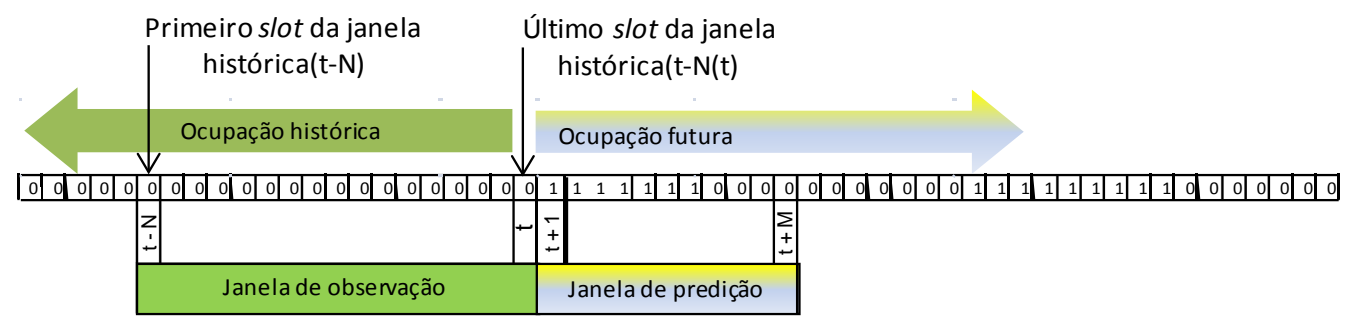

Figura 4.1 - Janelas históricas e de predição

A segunda abordagem consiste na definição de estratégias de ocupação da janela de predição a partir de estatísticas de ocupação obtidas na janela de observação, de modo a minimizar a possibilidade de colisão com o usuário primário.

Assim, o compartilhamento do espectro entre usuários primários e secundários terá seu desempenho aprimorado e, portanto, proporcionará uma utilização do espectro mais eficiente.

\subsection{2}

\section{Modelagem estatística}

Considera-se a situação em que o processo de ocupação de canal pelo usuário primário, ilustrado na Figura 4.2, seja formado por:

- Um período de silêncio cuja duração é descrita por uma variável aleatória real z.

- Uma coleção alternada de períodos de ocupação (chamados de black space - BS) e pausa (chamados de white space - WS), cujas durações são 
respectivamente descritas pelas v.a.r.su e v. A quantidade destes períodos é descrita por uma v.a.r. discreta denotada por n.

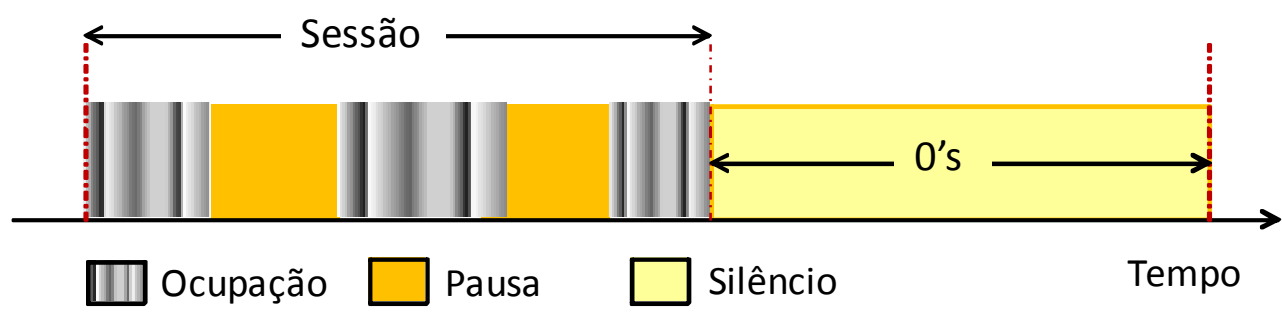

Figura 4.2 - Períodos de silêncio, ocupação e pausa

Este modelo de tráfego é tipicamente encontrado redes de comunicações tanto analógicas quanto digitais. No primeiro ocorre com frequência em situações de conversação e no segundo ocorre em redes faixa larga quando da utilização de protocolos HTTP, FTP e VoIP dentre outros. Assim este modelo utilizado não é de forma nenhuma estranha as situações de comunicações modernas.

De forma um pouco mais geral, assume-se a existência de ciclos formados por pares sessão-silêncio, onde o i-ésimo ciclo é caracterizado por:

- $\quad$ Um período de silêncio cuja duração é caracterizada pela v.a.r. zi

- Uma coleção de períodos alternados de atividade e pausa, cujas durações são descritas pelas v.a.r.'s $u_{i, 1}, v_{i, 1}, \ldots, u_{i, n_{i}-1}, v_{i, n_{i}-1}, u_{i, n_{i}}$ onde $n_{i}$ também é uma v.a.r. de natureza discreta e positiva.

Assume-se que:

- asv.a.r.'s em cada um dos grupos $\left\{z_{i}\right\},\left\{n_{i}\right\},\left\{u_{i, 1}\right\},\left\{v_{i, 1}\right\}, \ldots .,\left\{u_{i, n_{i}-1}\right\},\left\{v_{i, n_{i}-1}\right\},\left\{u_{i, n_{i}}\right\}$

são independentes e identicamente distribuídas entre si e com respectivamente as mesmas distribuições de $z, n, u_{1}, \ldots, u_{n}, v_{1}, \ldots, v_{n}$

- A v.a.r. $n$ assume valores no conjunto $\{1,2, \ldots \mathrm{N}\}$ onde $\mathrm{N}$ é conhecido, com probabilidades respectivamente iguais a $p_{1}, p_{2}, \ldots p_{N}$.

Para permitir um tratamento matemático mais simplificado, assume-se que todas as observações são feitas ao longo de janelas temporais de duração $\Delta$. Para cada uma destas janelas define-se uma coleção de processos estocásticos discretos $\mathrm{x}_{\mathrm{k}}(\mathrm{n})$ onde: 
$x_{k}(n)= \begin{cases}1 & \text { se o canal k está em atividade no periodo }\left[t_{0}+n \cdot \Delta, t_{0}+(n+1) \cdot \Delta\right) \\ 0 & \text { caso contrário }\end{cases}$

Estes processos caracterizam os canais quanto à sua atividade e no presente momento assume-se o sensoriamento perfeito, ou seja, a identificação do uso do canal é obtida sem erros. Em qualquer janela de tempo, cada um destes processos pode estar em um dentre vários estados que denominaremos de:

- $\mathrm{S} \rightarrow$ silêncio;

- WS-k $\rightarrow$ k-ésimo período de pausa (White space) dentro do período de surtos de ocupação;

- $\quad$ BS-k $\rightarrow$ k-ésimo período de atividade (black space) dentro do período de surtos de ocupação.

Além disso, tem-se:

i. O estado S produz como saída uma sequência de 0’s de tamanho definido pela v.a.r. $\bar{z}$, versão discreta da v.a.r. $\mathrm{z}$ ou seja, $P[\bar{Z}=k]=P[(k-1) . \Delta \leq z<k . \Delta]$;

ii. O estado BS-i produz como saída uma sequência de 1's de tamanho definido pela v.a.r. $\bar{u}_{i}$, versão discreta da v.a.r. $u_{i}$, ou seja, $P\left[\overline{u_{i}}=k\right]=P\left[(k-1) . \Delta \leq u_{i}<k . \Delta\right]$;

iii. O estado WS-i produz como saída uma sequência de 0's de tamanho definido pela v.a.r. $\bar{v}_{l}$, versão discreta da v.a.r. $v_{i}$, ou seja, $P\left[\overline{v_{i}}=k\right]=P\left[(k-1) . \Delta \leq v_{i}<k . \Delta\right]$;

Assim estamos diante de um Modelo de Markov Escondido (Hidden Markov Model, HMM) onde algumas de suas probabilidades de transição são da forma abaixo:

$$
\bar{p}_{k}=\frac{p_{k}}{1-\sum p_{i}}
$$

com

$$
p_{k}=P[n=k]
$$


e, representados na Figura 4.3.

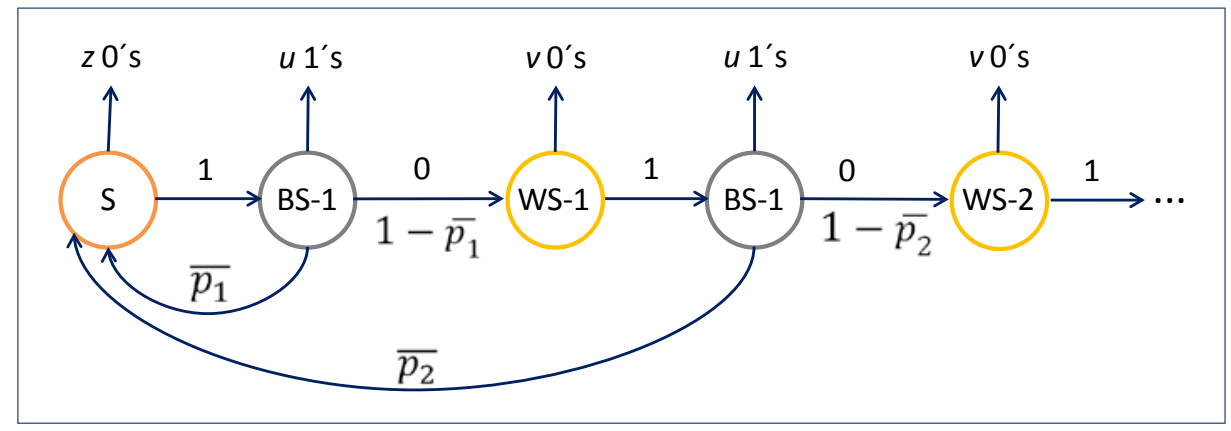

Figura 4.3 - Modelo Escondido de Markov

Embora este modelo seja interessante, pretende-se começar de forma mais simples ainda. Também assume-se que:

- $\quad z, u$, e $v$ possuem distribuições exponenciais. Então:

$$
\begin{aligned}
& P[\bar{z}=k]=P[z \in[(k-1) \cdot \Delta, k \cdot \Delta)]= \\
& =\int_{(k-1) \cdot \Delta}^{k \cdot \Delta} \lambda \cdot e^{-\lambda \cdot x} \cdot d x=[\underbrace{\left[1-e^{-\lambda \cdot \Delta}\right]}_{\alpha} \cdot \underbrace{\left.e^{-\lambda \cdot \Delta}\right]^{k-1}}_{1-\alpha}=\alpha \cdot(1-\alpha)^{k-1}
\end{aligned}
$$

revelando que $\bar{z}, \bar{u}$ e $\bar{v}$ tem distribuição geométrica conforme ilustrado em (4.4), (4.5) e (4.6):

$$
\begin{aligned}
& P[\bar{z}=k]=\alpha \cdot(1-\alpha)^{k-1} \quad \text { para } k=1,2, \ldots . . \quad \text { e } E(\bar{z})=1 / \alpha \\
& P[\bar{u}=k]=\beta \cdot(1-\beta)^{k-1} \quad \text { para } k=1,2, \ldots . . \text { e } E(\bar{u})=1 / \beta \\
& P[\bar{v}=k]=\gamma \cdot(1-\gamma)^{k-1} \quad \text { para } k=1,2, \ldots . . \text { e } E(\bar{v})=1 / \gamma
\end{aligned}
$$

Nestas condições o modelo assume uma forma HMM de 2.N estados, muito mais conveniente aos propósitos do estudo, como ilustrado na Figura 4.4. 


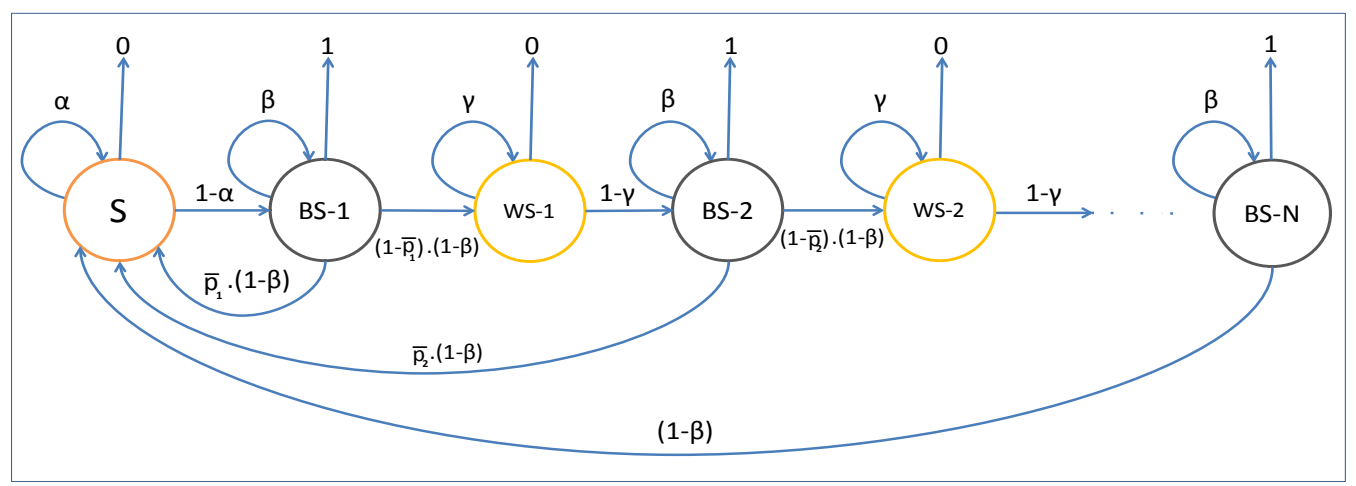

Figura 4.4 - Cadeia de Markov ajustada

Para uma análise mais realista, deve-se introduzir a possibilidade de que haja erros no sensoriamento dos estados até agora definidos. Isso pode ser facilmente modelável assumindo que qualquer um dos estados ilustrados na Figura 4.4 possa ter uma nova transição para um estado que caracteriza este erro, como ilustrado na Figura 4.5 e detalhado na seção 4.1.5.

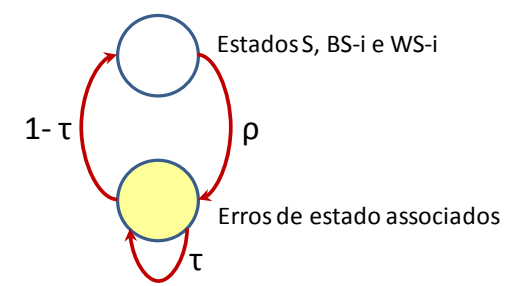

Figura 4.5 - Erros associados aos estados

Em geral, $\rho$ e $\tau$ dependem do estado de origem e são números pequenos, pois caso contrário, estaremos assumindo que a estimação da ocupação do canal é de baixa qualidade. Os valores destes parâmetros são relacionados ao valor da probabilidade de erro de sensoriamento, tratado na seção 4.1.5.

Percebe-se que novos $2 \mathrm{~N}$ estados são criados. Aqueles associados aos estados de saída 0 , isto é, estados S e WS-n produzirão saída 1, enquanto que aqueles associados aos estados de saída 1, isto é, estados BS-n produzirão saída 0 .

Cumpre destacar que as probabilidades indicadas na figura 4.4 deverão ser alteradas para acomodar estes novos estados.

Para facilidade de identificação futura, definiremos:

- estados S, WS-1,....,WS-(N-1) 1 a $\mathrm{N}$ e respectivamente identificados pelo conjunto $\mathrm{F}_{1}=\{1,2, . ., \mathrm{N}\}$. 
- estados de erro associados aos estados de 1 a $\mathrm{N}$ e respectivamente identificados pelo conjunto $\mathrm{F}_{2}=\{\mathrm{N}+1, \mathrm{~N}+2, . ., 2 \mathrm{~N}\}$.

- estados BS-1,....,BS-N e respectivamente identificados pelo conjunto $\mathrm{F}_{3}=\{2 \mathrm{~N}+1,2 \mathrm{~N}+2, . ., 3 \mathrm{~N}\}$.

- estados de erro associados aos estados $2 \mathrm{~N}+1$ a $3 \mathrm{~N}$ e respectivamente identificados pelo conjunto $\mathrm{F}_{4}=\{3 \mathrm{~N}+1,3 \mathrm{~N}+2, . ., 4 \mathrm{~N}\}$.

O Anexo1 ilustra o diagrama completo de estados.

Seja $\mathrm{O}_{\mathrm{t}}$ a observação definida como o estado do canal (0=livre, $1=$ ocupado) na janela de tempo $\mathrm{t}(\mathrm{em}$ unidades $\Delta)$.

Assim, o objetivo da primeira parte deste estudo consiste em calcular a probabilidade indicada em (4.7), que reflete a probabilidade de que os $\mathrm{H}$ slots de tempo imediatamente posteriores ao momento presente estejam não ocupados, pelo usuário primário, condicionada a informação disponível neste momento que são os estados q de ocupação de todos os slots de tempo passados.

$$
\Omega_{t}=\sum_{e_{1}=1}^{2 N} \ldots \sum_{e_{H}=1}^{2 N} P\left[q_{t+1}=e_{1}, . ., q_{t+H}=e_{H} \mid o_{t} o_{t-1} \ldots o_{1}\right]
$$

\subsection{3}

\section{Probabilidades de Permanência nos Estados em Regime Permanente}

A matriz de transição de estados da cadeia de Markov ilustrada na Figura 4.4 tem dimensão $(4 . N \times 4 . N)$ e é expressa por:

$$
P=\left[\begin{array}{cccc}
\Psi-R & R & I-\Psi & 0 \\
I-\Upsilon & \Upsilon & 0 & 0 \\
(1-\beta) \cdot Q & 0 & \beta I-\Gamma & \Gamma \\
0 & 0 & I-\mathrm{T} & \mathrm{T}
\end{array}\right] \quad\left\{\begin{array}{l}
\Psi=\operatorname{diag}(\psi) \\
R=\operatorname{diag}(\rho) \\
\Upsilon=\operatorname{diag}(\tau) \\
\Gamma=\operatorname{diag}(r) \\
\mathrm{T}=\operatorname{diag}(t)
\end{array}\right.
$$

onde: 


$$
\begin{array}{r}
Q=\left[\begin{array}{ccccc}
\bar{p}_{1} & 1-\bar{p}_{1} & 0 & \ldots & 0 \\
\bar{p}_{2} & 0 & 1-\bar{p}_{2} & \ldots & 0 \\
\vdots & \vdots & \vdots & \ldots & 0 \\
\bar{p}_{N-1} & 0 & 0 & \ldots & 1-\bar{p}_{N-1} \\
\bar{p}_{N} & 0 & 0 & \ldots & 0
\end{array}\right] \\
\text { e } \psi=\left[\begin{array}{llll}
\alpha & \gamma & \ldots & \gamma
\end{array}\right]^{T}
\end{array}
$$

O vetor $\underline{\pi}$ de probabilidade de ocorrência dos estados em regime permanente é dado pela solução do sistema $\underline{\pi}^{T}=\underline{\pi}^{T} \cdot P \quad$ onde $\underline{\pi}=\left(\begin{array}{llll}\underline{x}^{T} & \underline{y}^{T} & \underline{z}^{T} & \underline{w}^{T}\end{array}\right)^{T}, \underline{x}, \underline{y}, \underline{z}, \underline{w} \in R^{N}$. Assim, as seguintes equações devem ser obedecidas:

$$
\left.\begin{array}{l}
\underline{x}^{T} \cdot(\Psi-R)+\underline{y}^{T} \cdot(I-\Upsilon)+(1-\beta) \cdot \underline{z}^{T} \cdot Q=\underline{x}^{T} \\
\underline{x}^{T} R+\underline{y}^{T} \cdot \Upsilon=\underline{y}^{T} \\
\underline{x}^{T} \cdot(I-\Psi)+\underline{z}^{T} \cdot(\beta I-\Gamma)+\underline{w}^{T} \cdot(I-\mathrm{T})=\underline{z}^{T} \\
\underline{z}^{T} \Gamma+\underline{w}^{T} \cdot \mathrm{T}=\underline{w}^{T}
\end{array}\right\} \Leftrightarrow\left\{\begin{array}{l}
\underline{x}^{T}=(1-\beta) \underline{z}^{T} \cdot(I-\Psi)^{-1} \\
\underline{y}^{T}=\underline{x}^{T} \cdot R(I-\Upsilon) \\
\underline{z}^{T}=\underline{z}^{T} \cdot Q \\
\underline{w}^{T}=\underline{z}^{T} \Gamma \cdot(I-\mathrm{T})^{-1}
\end{array}\right.
$$

Percebe-se claramente que o vetor $\underline{z}$ é o autovetor à esquerda da matriz $Q$ associado ao autovalor 1, podendo ser determinado pelo procedimento abaixo:

$$
\begin{aligned}
& \left.\begin{array}{l}
\bar{p}_{1} \cdot z_{1}+\bar{p}_{2} \cdot z_{2}+\ldots+\bar{p}_{N-1} \cdot z_{N-1}+z_{N}=z_{1} \\
\left(1-\bar{p}_{i}\right) \cdot z_{i}=z_{i+1} \quad \text { para } i=1, \ldots, N-1
\end{array}\right\} \Rightarrow z_{i}=\eta_{i} \cdot z_{1} \quad \text { para } i=1, \ldots, N \\
& \underline{\mathrm{z}}^{T}=z_{1} \cdot \underline{\eta}^{T}
\end{aligned}
$$

onde

$$
\eta_{k}= \begin{cases}1 & \text { para } k=1 \\ \prod_{i=1}^{k-1}\left(1-\bar{p}_{i}\right) & \text { para } k=2, . ., N\end{cases}
$$

O termo $z_{1}$ da expressão acima pode ser determinado pelo procedimento a seguir apresentado: 


$$
\begin{aligned}
1 & =\left(\underline{x}^{T}+\underline{y}^{T}+\underline{z}^{T}+\underline{w}^{T}\right) \cdot \underline{1}= \\
& =\left\{\underline{x}^{T}+\underline{x}^{T} \cdot R \cdot(I-\Upsilon)^{-1}+\underline{z}^{T}+\underline{z}^{T} \cdot \Gamma \cdot(I-\mathrm{T})^{-1}\right\} \cdot \underline{1}= \\
& =\left\{\underline{x}^{T} \cdot\left[I+R \cdot(I-\Upsilon)^{-1}\right]+\underline{\underline{z}}^{T} \cdot\left[I+\Gamma \cdot(I-\mathrm{T})^{-1}\right]\right\} \cdot \underline{1}= \\
& =\left\{(1-\beta) \cdot \underline{z}^{T} \cdot(I-\Psi)^{-1} \cdot\left[I+R \cdot(I-\Upsilon)^{-1}\right]+\underline{z}^{T} \cdot\left[I+\Gamma \cdot(I-\mathrm{T})^{-1}\right]\right\} \cdot \underline{\underline{1}}= \\
& =\underline{z}^{T} \cdot\left\{(1-\beta) \cdot(I-\Psi)^{-1} \cdot\left[I+R \cdot(I-\Upsilon)^{-1}\right]+\left[I+\Gamma \cdot(I-\mathrm{T})^{-1}\right]\right\} \cdot \underline{1}= \\
& =z_{1} \cdot \underline{\eta}^{T} \cdot\left\{(1-\beta) \cdot(I-\Psi)^{-1} \cdot\left[I+R \cdot(I-\Upsilon)^{-1}\right]+\left[I+\Gamma \cdot(I-\mathrm{T})^{-1}\right]\right\} \cdot \underline{1} \\
z_{1}= & \frac{1}{\underline{\eta}^{T} \cdot\left\{(1-\beta) \cdot(I-\Psi)^{-1} \cdot\left[I+R \cdot(I-\Upsilon)^{-1}\right]+\left[I+\Gamma \cdot(I-\mathrm{T})^{-1}\right]\right\} \cdot \underline{1}}
\end{aligned}
$$

A probabilidade $\mathrm{P}_{1}$ em regime permanente de que um slot esteja ocupado, isto é, pertença a um black space vale:

$$
\begin{aligned}
P_{1}= & \left(\underline{z}^{T}+\underline{w}^{T}\right) \cdot \underline{1}=\underline{z}^{T} \cdot\left[I+\Gamma \cdot(I-\mathrm{T})^{-1}\right] \underline{1}=z_{1} \underline{\eta}^{T} \cdot\left[I+\Gamma \cdot(I-\mathrm{T})^{-1}\right] \cdot \underline{1}= \\
= & \frac{\underline{\eta}^{T} \cdot\left[I+\Gamma \cdot(I-\mathrm{T})^{-1}\right] \cdot \underline{1}}{\underline{\eta}^{T} \cdot\left\{(1-\beta) \cdot(I-\Psi)^{-1} \cdot\left[I+R \cdot(I-\mathrm{Y})^{-1}\right]+\left[I+\Gamma \cdot(I-\mathrm{T})^{-1}\right]\right\} \cdot \underline{1}} \\
= & \frac{1}{1+(1-\beta) \cdot \frac{\underline{\eta}^{T} \cdot(I-\Psi)^{-1} \cdot\left[I+R \cdot(I-\mathrm{Y})^{-1}\right] \underline{1}}{\underline{\eta}^{T} \cdot\left[I+\Gamma \cdot(I-\mathrm{T})^{-1}\right] \underline{1}}}
\end{aligned}
$$

Consequentemente a probabilidade de que, em regime permanente, $\mathrm{N}$ canais estejam ocupados no mesmo slot de tempo é da forma $P_{\text {ocup }}=\left(P_{1}\right)^{N}$, assumindo a independência estatística do comportamento de canais distintos. Se é desejado que esta probabilidade seja menor do que o valor $\rho$, isto é, $P_{\text {ocup }}<\rho$, então o número $\mathrm{N}$ de canais necessários para que isto ocorra é dado por:

$$
N>\frac{\log (\rho)}{\log \left(P_{1}\right)}
$$


Embora nesta tese seja investigada apenas a situação mono-canal, este resultado pode ser visto como oportuno caso esteja-se diante da situação de planejamento onde é possível escolher o número de canais a seremutilizados numa situação onde existem, por exemplo, vários usuários. De novo, esta linha de ação não é perseguida nesta tese.

\subsection{4}

\section{Cálculo da probabilidade de não ocupação da janela de predição pelo usuário primário}

Para efetuar uma escolha adequada do tamanho da janela de predição decidiu-se escolher como estatística de decisão a probabilidade de que, no instante $\mathrm{t}$, a janela de predição cobrindo os instantes futuros de $\mathrm{t}+1$ a $\mathrm{t}+\mathrm{H}$ esteja sem ocupação do usuário primário. É razoável supor que quanto menor for esta probabilidade, menor será a probabilidade de colisão entre usuários primário e secundário, uma vez que o cálculo exato desta última é extremamente complicado e difícil.

Assim, definindo-se $\underline{o}_{t}=\left[\begin{array}{llll}o_{t} & o_{t-1} & \ldots & o_{1}\end{array}\right]$ como a coleção de observações ruidosas do estado $o_{t}$ do canal quanto a ocupação (1) ou não (0) no slot t pelo usuário primário, tem-se que a probabilidade $\Omega_{\mathrm{t}}$ de que a janela formada pelos instantes de $\mathrm{t}+1 \mathrm{a} \mathrm{t}+\mathrm{H}$ é dada por:

$$
\begin{aligned}
& \Omega_{t}=\sum_{e_{1}=1}^{2 N} \ldots \sum_{e_{H}=1}^{2 N} P\left[q_{t+1}=e_{1}, \ldots, q_{t+H}=e_{H} \mid \underline{o}_{t}\right]= \\
& =\sum_{e=1}^{4 N} \sum_{e_{1}=1}^{2 N} \ldots \sum_{e_{H}=1}^{2 N} P\left[q_{t}=e, q_{t+1}=e_{1}, \ldots, q_{t+H}=e_{H} \mid \underline{o}_{t}\right]= \\
& =\sum_{e=1}^{4 N} \sum_{e_{1}=1}^{2 N} \ldots \sum_{e_{H}=1}^{2 N} \underbrace{P\left[q_{t}=e \mid \underline{o}_{t}\right]}_{r_{t}(e)} \cdot P\left[q_{t+1}=e_{1} \mid q_{t}=e\right] P\left[q_{t+2}=e_{2} \mid q_{t+1}=e_{1}\right] \ldots . . . P\left[q_{t+H}=e_{H} \mid q_{t+1}=e_{H-1}\right]= \\
& =\sum_{e=1}^{4 N} r_{t}(e) \cdot \sum_{e_{1}=1}^{2 N} P\left(e, e_{1}\right) \sum_{e_{2}=1}^{2 N} P\left(e_{1}, e_{2}\right) \ldots \ldots . \sum_{e_{H-1}=1}^{2 N} P\left(e_{H-2}, e_{H-1}\right) \cdot \underbrace{2 N} P\left(e_{H-1}, e_{H}\right)=
\end{aligned}
$$

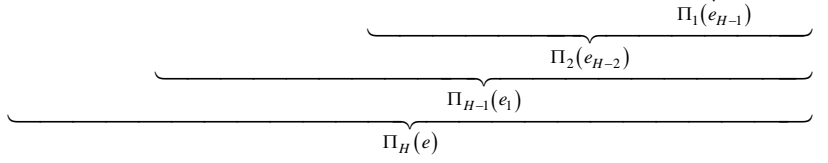

$$
\begin{aligned}
& =\sum_{e=1}^{4 N} r_{t}(e) \cdot \Pi_{H}(e)
\end{aligned}
$$




$$
\Omega_{\mathrm{t}}=\sum_{e=1}^{4 N} r_{t}(e) \cdot \prod_{H}(e)
$$

Defina-se:

$$
P_{11}=\left[\begin{array}{cc}
\Psi-R & R \\
I-\Upsilon & \Upsilon
\end{array}\right], P_{21}=\left[\begin{array}{cc}
(1-\beta) \cdot Q & 0 \\
0 & 0
\end{array}\right], \underline{r}_{t}=\left(r_{t}(1), \ldots, r_{t}(4 \mathrm{~N})\right)^{T}
$$

Logo:

$$
\begin{array}{r}
\underline{\Pi}_{H}=\left[\begin{array}{l}
P_{11} \\
P_{21}
\end{array}\right] .\left(P_{11}\right)^{H-1} \cdot\left[\begin{array}{l}
\underline{1} \\
\underline{1}
\end{array}\right] \\
\Omega_{t}=\underline{r}_{t}^{T} \underline{\Pi}_{H}
\end{array}
$$

Podemos ainda determinar uma lei de recorrência para $\underline{r}_{t}$

$$
\left.\begin{array}{rl}
r_{t+1}(k) & =P\left[q_{t+1}=k \mid \underline{o}_{t+1}\right]=\sum_{j=1}^{4 N} P\left[q_{t+1}=k, q_{t}=j \mid \underline{o}_{t}, o_{t+1}\right]= \\
& =\sum_{j=1}^{4 N} \underbrace{P\left[q_{t}=j \mid \underline{o}_{t}\right]}_{r_{t}(j)} \cdot \underbrace{P\left[q_{t+1}=k \mid q_{t}=j, o_{t+1}\right]}_{m_{j k}\left(o_{t+1}\right)}= \\
& =\sum_{j=1}^{4 N} r_{t}(j) \cdot m_{j k}\left(o_{t+1}\right)
\end{array}\right\} \Rightarrow \underline{r}_{t+1}^{T}=\underline{r}_{t}^{T} \cdot M\left(o_{t+1}\right)
$$

Vamos analisar o caso $o_{t+1}=0$.

$q_{t}=j \in F_{1} \Rightarrow q_{t+1}=j$ com probabilidade 1

$q_{t}=N+j \in F_{2} \Rightarrow q_{t+1}=j$ com probabilidade 1

$q_{t}=2 N+j \in F_{3} \Rightarrow q_{t+1}=\left\{\begin{array}{l}1 \\ j+1 \quad \text { com probabilidades } \\ 3 N+j\end{array}\left\{\begin{array}{l}\bar{p}_{j} \cdot\left(\frac{1-\beta}{1-\beta+r_{j}}\right) \\ \left(1-\bar{p}_{j}\right) \cdot\left(\frac{1-\beta}{1-\beta+r_{j}}\right) \\ 1-\left(\frac{1-\beta}{1-\beta+r_{j}}\right)\end{array}\right.\right.$ $q_{t}=3 N+j \in F_{4} \Rightarrow q_{t+1}=3 N+j$ com probabilidade 1

\section{Logo:}


$M(0)=\left[\begin{array}{cccc}I_{N} & 0_{N} & 0_{N} & 0_{N} \\ I_{N} & 0_{N} & 0_{N} & 0_{N} \\ B . Q & 0_{N} & 0_{N} & I_{N}-B \\ 0_{N} & 0_{N} & 0_{N} & I_{N}\end{array}\right] \quad$ onde $B=\left(I+\frac{\Gamma}{1-\beta}\right)^{-1}=\operatorname{diag}\left[\frac{1-\beta}{1-\beta+r_{i}}\right]$

Vamos analisar o caso $o_{t+1}=1$.

$q_{t}=j \in F_{1} \Rightarrow q_{t+1}=\left\{\begin{array}{l}N+j \\ 2 N+j\end{array}\right.$ com probabilidades $\left\{\begin{array}{l}\frac{\rho_{j}}{1-\alpha+\rho_{j}} \text { se } j=1, \frac{\rho_{j}}{1-\gamma+\rho_{j}} \text { caso contrário } \\ \frac{1-\alpha}{1-\alpha+\rho_{j}} \text { se } j=1, \frac{1-\gamma}{1-\gamma+\rho_{j}} \text { caso contrário }\end{array}\right.$

$q_{t}=N+j \in F_{2} \Rightarrow q_{t+1}=N+j$ com probabilidade 1

$q_{t}=2 N+j \in F_{3} \Rightarrow q_{t+1}=2 N+j$ com probabilidade 1

$q_{t}=3 N+j \in F_{4} \Rightarrow q_{t+1}=2 N+j$ com probabilidade 1

Logo:

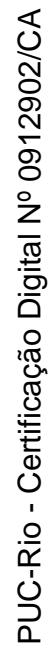

$M(1)=\left[\begin{array}{cccc}0_{N} & I_{N}-A & A & 0_{N} \\ 0_{N} & I_{N} & 0_{N} & 0_{N} \\ 0_{N} & 0_{N} & I_{N} & 0_{N} \\ 0_{N} & 0_{N} & I_{N} & 0_{N}\end{array}\right]$

onde $A=\left[I+R \cdot(I-\Psi)^{-1}\right]^{-1}=\operatorname{diag}\left[\frac{1-\alpha}{1-\alpha+\rho_{1}}, \frac{1-\gamma}{1-\gamma+\rho_{2}}, \ldots, \frac{1-\gamma}{1-\gamma+\rho_{N}}\right]$

Logo:

$\Omega_{t}=\underline{r}_{t}^{T} \cdot \underline{\Pi}_{H}=\underline{r}_{t-1}^{T} M\left(o_{t}\right) \cdot \underline{\Pi}_{H}=\underline{r}_{t-2}^{T} M\left(o_{t-1}\right) \cdot M\left(o_{t}\right) \underline{\Pi}_{H}=\ldots . .=$

$=\underline{r}_{0}^{T} M\left(o_{1}\right) \ldots \ldots . M\left(o_{t-1}\right) \cdot M\left(o_{t}\right) \underline{\Pi}_{H}$

Observe-se que $M(0)$ e $M(1)$ são matrizes idempotentes, o que significa dizer que $\underline{r}_{t}$ permanece constante ao longo de períodos onde $o_{t}$ é constante, só sofrendo transições nos casos onde $\left(o_{t}, o_{t+1}\right)=(0,1)$ ou $(1,0)$. Além disso, estaremos assumindo que o estado inicial é $S$, o que implica que $\underline{r}_{0}^{T}=\left[\begin{array}{llll}1 & 0 & \ldots & 0\end{array}\right]$.

Devemos ainda notar que: 
Se $o_{t}=0$

$$
\begin{aligned}
\underline{r}_{t}^{T} & =\underline{r}_{0}^{T} \cdot[M(0)]^{m_{1}} \cdot[M(1)]^{n_{1}} \cdot[M(0)]^{m_{2}} \cdot[M(1)]^{n_{2}} \cdots \cdots \cdot \cdot[M(0)]^{m_{K}} \cdot[M(1)]^{n_{K}}[M(0)]^{m_{K+1}}= \\
& =\underline{r}_{0}^{T} \cdot[M(0) \cdot M(1)]^{K} \cdot M(0)
\end{aligned}
$$

Se $o_{t}=1$

$$
\begin{aligned}
\underline{r}_{t}^{T} & =\underline{r}_{0}^{T} \cdot[M(0)]^{m_{1}} \cdot[M(1)]^{n_{1}} \cdot[M(0)]^{m_{2}} \cdot[M(1)]^{n_{2}} \cdots \ldots . \cdot[M(0)]^{m_{K}} \cdot[M(1)]^{n_{K}}= \\
& =\underline{r}_{0}^{T} \cdot[M(0) \cdot M(1)]^{K}
\end{aligned}
$$

Em ambos os casos $\mathrm{K}$ é o número de 1-surtos em $\underline{o}_{t}$, e $\mathrm{m}_{\mathrm{k}} \mathrm{e} \mathrm{n}_{\mathrm{k}}$ são respectivamente as durações dos k-ésimos0-surtos e 1-surtos.

Note que:

$$
M_{01}=M(0) \cdot M(1)=\left[\begin{array}{cccc}
0_{N} & I_{N}-A & A & 0_{N} \\
0_{N} & I_{N}-A & A & 0_{N} \\
0_{N} & B \cdot Q \cdot\left(I_{N}-A\right) & B \cdot Q \cdot A+I_{N}-B & 0_{N} \\
0_{N} & 0_{N} & I_{N} & 0_{N}
\end{array}\right]
$$

Note que $M_{01}$ é uma matriz estocástica, o que implica que seus q $(\mathrm{q} \leq 4 \mathrm{~N})$ autovalores distintos $\left\{\lambda_{1}, \lambda_{2}, \ldots, \lambda_{q}\right\}$ de multiplicidades $\left\{m_{1}, m_{2}, \ldots, m_{q}\right\}$ localizam-se no interior do círculo unitário no plano complexo a exceção de um que vale 1 e tem multiplicidade 1 . Sem perda de generalidade assumiremos $\lambda_{1}=1$. Assim:

$$
1=\lambda_{1}>\lambda_{2}>\ldots>\lambda_{q}>0 \text { e } \lambda_{i}=0 \text { para } q+1 \leq i \leq 2 N
$$

Resultados de Cálculo Funcional nos permitem dizer que $\left(M_{01}\right)^{K}=\sum_{i=0}^{4 N-1} \sigma_{4 N-i}(K) \cdot\left(M_{01}\right)^{i}$ para $K \geq 4 N \quad$ onde $\quad\left\{\sigma_{i}(k), i=0, . ., 4 N-1\right\}$ são soluções do seguinte conjunto de equações lineares:

$$
\left.\frac{d^{(i)}}{d \lambda^{i}}\left[\sum_{n=0}^{4 N-1} \sigma_{4 N-1-n}(K) \cdot \lambda^{n}\right]\right|_{\lambda=\lambda_{j}}=\left.\frac{d^{(i)}}{d \lambda^{i}}\left[\lambda^{K}\right]\right|_{\lambda=\lambda_{j}} \quad \text { para }\left\{\begin{array}{l}
i=1, . ., m_{j} \\
j=1, . ., q
\end{array}\right.
$$

No caso específico da matriz $\mathrm{M}_{01}$, tem-se como solução:

$$
\begin{array}{ll}
\sum_{n=0}^{q-1} \sigma_{n}(K) \cdot \lambda_{i}^{4 N-1-n}=\lambda_{i}^{K} & \text { para } i=1, . ., q \\
\sigma_{j}(K)=0 & \text { para } j=q, . ., 4 N-1
\end{array}
$$


Logo:

$$
\begin{aligned}
& \sum_{n=0}^{q-1} \sigma_{n}(K) \cdot \lambda_{i}^{4 N-1-n}=\lambda_{i}^{K} \quad \text { para } i=1, . ., q \\
& \sum_{n=0}^{q-1} \sigma_{n}(K) \cdot \lambda_{i}^{4 N-q-1+q-n}=\lambda_{i}^{K} \quad \text { para } i=1, . ., q \\
& \sum_{n=0}^{q-1} \sigma_{n}(K) \cdot \lambda_{i}^{q-n}=\lambda_{i}^{K-(4 N-q-1)} \quad \text { para } i=1, . ., q \\
& {\left[\begin{array}{cccc}
\lambda_{1}^{q-1} & \lambda_{1}^{q-2} & \cdots & \lambda_{1}^{0} \\
\lambda_{2}^{q-1} & \lambda_{2}^{q-2} & \cdots & \lambda_{2}^{0} \\
\vdots & \vdots & & \vdots \\
\lambda_{q}^{q-1} & \lambda_{q}^{q-2} & \cdots & \lambda_{q}^{0}
\end{array}\right]} \\
& \underbrace{\left[\begin{array}{c}
\sigma_{0}(K) \\
\sigma_{1}(K) \\
\vdots \\
\sigma_{q-1}(K)
\end{array}\right]}_{\Lambda} \underbrace{\left[\begin{array}{c}
\lambda_{1}^{K-(4 N-q-1)} \\
\lambda_{2}^{K-(4 N-q-1)} \\
\vdots \\
\lambda_{q-1}^{K-(4 N-q-1)}
\end{array}\right]}_{\underline{\sigma(K)}}
\end{aligned}
$$

$$
\Lambda . \underline{\sigma}(K)=\underline{\lambda}(K) \Rightarrow \underline{\sigma}(K)=\Lambda^{-1} \cdot \underline{\lambda}(K)
$$

Como $\left[\begin{array}{c}1 \\ \lambda_{2}^{K-(4 N-q-1)} \\ \vdots \\ \lambda_{q}^{K-(4 N-q-1)}\end{array}\right] \longrightarrow{ }_{K \rightarrow \infty}^{\longrightarrow}\left[\begin{array}{c}1 \\ 0 \\ \vdots \\ 0\end{array}\right]$ então $\underline{\sigma}(\infty)$ é a primeira coluna de $\Lambda^{-1}$.

Logo:

$$
\begin{gathered}
M_{01}(\infty)=\sum_{n=0}^{q-1} \sigma_{n}(\infty) \cdot\left(M_{01}\right)^{4 N-1-n}=\left(M_{01}\right)^{4 N-q} \cdot \sum_{n=0}^{q-1} \sigma_{n}(\infty) \cdot\left(M_{01}\right)^{q-1-n} \\
\Omega_{t}=\underline{r}_{t}^{T} \cdot \underline{\Pi}_{H} \Rightarrow\left\{\begin{array}{l}
\Omega_{\infty}(0)=\underline{r}_{0}^{T} \cdot M_{01}(\infty) \cdot M(0) \cdot \underline{\Pi}_{H} \\
\Omega_{\infty}(1)=\underline{r}_{0}^{T} \cdot M_{01}(\infty) \cdot \underline{\Pi}_{H}
\end{array}\right.
\end{gathered}
$$

Como em geral, $\underline{r}_{0}^{T}=\left[\begin{array}{llll}1 & 0 & \cdots & 0\end{array}\right]$.

Os resultados obtidos sugerem que na primeira oportunidade onde $\mathrm{O}_{\mathrm{t}}$ for zero, deve-se tentar ocupar o canal por $\mathrm{H}$ slots de tempo onde $\mathrm{H}$ é escolhido de modo que $\Omega_{\infty}(H, 0)$ seja superior a um limiar prefixado. Esta é a essência do algoritmo a ser desenvolvido em seções posteriores onde alguns detalhes adicionais são incluídos na tentativa de mitigar efeitos indesejáveis lá discutidos. 


\subsection{5}

\section{Modelagem do Erro de Estimação de Estado}

Para tornar a situação um pouco mais realista, assume-se que existe um erro inerente à estimação do estado em cada time-slot de modo que podemos estabelecer que a probabilidade de ocorrência deste erro seja $\mathrm{p}<1 / 2$.

Avaliando novamente a Figura 4.4, é desejado que a emissão de observação relativa aos estados S e WS-n tenha distribuição de Bernoulli onde $\mathrm{P}\left(\mathrm{o}_{\mathrm{t}}=1\right)=\mathrm{p}$ enquanto que para os estados BS-n esta emissão também tenha distribuição de Bernoulli onde $\mathrm{P}\left(\mathrm{o}_{\mathrm{t}}=0\right)=\mathrm{p}$.

A proposta do estudo foi acrescentar para cada um dos estados S, BS-n e WS-n um estado de erro com probabilidades de transição especificadas. Seria interessante determinar tais probabilidades fazendo com que estas duas situações sejam equivalentes em algum sentido.

Inicialmente, consideram-se os estados S e WS-n. Suas formas originais e modificadas, respectivamente correspondentes as situações sem estado de erro e com estado de erro são ilustradas nas figuras 4.6 e 4.7.

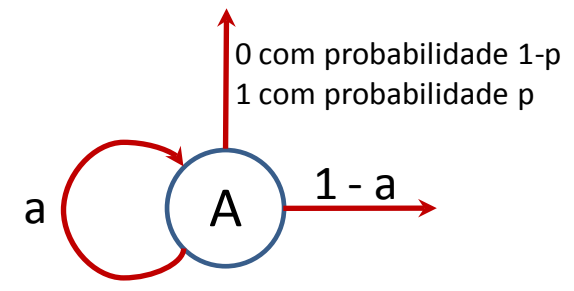

Figura 4.6 - Observação sem estado de erro

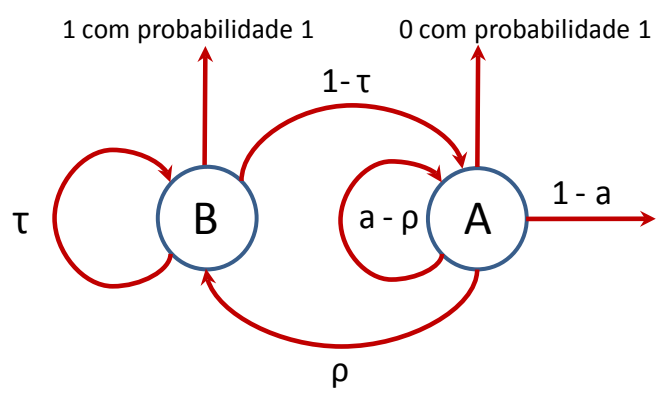

Figura 4.7 - Observação com estado de erro 
Nestas figuras, $\mathrm{a}=\alpha$ quando o estado é $\mathrm{S}$ e $\mathrm{a}=\beta$ quando o estado é WS-n. Entenderemos como equivalência entre as formas acima, quando:

1. a probabilidade de emitir 1 na forma modificada assumir o valor p. Em regime permanente, tem-se que:

$$
[1-p \quad p] \cdot\left[\begin{array}{rr}
1-\frac{\rho}{a} & \frac{\rho}{a} \\
1-\tau & \tau
\end{array}\right]=\left[\begin{array}{ll}
1-p & p
\end{array}\right] \Rightarrow p \cdot(1-\tau)=(1-p) \cdot \frac{\rho}{a} \Rightarrow \rho=a \cdot \underbrace{\left[\frac{p}{1-p}\right]}_{\delta} \cdot(1-\tau)
$$

2. o tempo de permanência nos dois grupos for o mesmo.

Aqui teremos que fazer algumas simplificações em benefício das contas e simplicidade.

Os tempos médios de permanência no estado A nas formas original e modificada valem respectivamente $N_{0}=\frac{1}{1-a}$ e $N_{1}=\frac{1}{1-a+\rho}$ enquanto que o tempo médio de permanência no estado B vale $N_{1}=\frac{1}{1-\tau}$. Entretanto, na forma modificada a situação é um pouco mais complicada. Não é difícil de perceber que o tempo de permanência nesta forma pode ser aproximadamente considerado como uma v.a.r. que assume valores da forma $(k+1) \cdot N_{1}+k \cdot N_{2}$ com probabilidades dadas por $(1-\rho) . \rho^{k}$ para $\mathrm{k}=0,1, \ldots .$. Assim, o tempo médio de permanência nesta forma é dado por:

$$
\begin{aligned}
\bar{N}_{0} & =\sum_{k=0}^{\infty}\left[(k+1) \cdot N_{1}+k \cdot N_{2}\right] \cdot \rho^{k} \cdot(1-\rho)=(1-\rho) \cdot\left[N_{1} \cdot \sum_{k=0}^{\infty}(k+1) \cdot \rho^{k}+N_{2} \cdot \sum_{k=0}^{\infty} k \cdot \rho^{k}\right]= \\
& =(1-\rho) \cdot\left[N_{1} \cdot \frac{1}{(1-\rho)^{2}}+N_{2} \cdot \frac{\rho}{(1-\rho)^{2}}\right]=\frac{1}{1-\rho} \cdot\left[N_{1}+\rho \cdot N_{2}\right]
\end{aligned}
$$

Assim $N_{0}=\bar{N}_{0}$ implica em:

$$
\begin{gathered}
\frac{1}{1-\rho} \cdot\left[\frac{1}{1-a+\rho}+\frac{\rho}{1-\tau}\right]=\frac{1}{1-a} \Rightarrow h(\rho)=\frac{1-\rho}{1-a}-\frac{1}{1-a+\rho}=a \cdot \delta \\
\Downarrow \\
\rho^{2}-\underbrace{a \cdot[1-\delta \cdot(1-a)]}_{b} \cdot \rho+\underbrace{\delta \cdot a \cdot(1-a)^{2}}_{c}=0
\end{gathered}
$$

O discriminante da equação quadrática acima vale: 


$$
\Delta=b^{2}-4 c=a \cdot\left[\delta^{2} \cdot a^{3}-2 \cdot \delta \cdot(1+\delta) \cdot a^{2}+\left(\delta^{2}+6 \delta+1\right) \cdot a-4 \cdot \delta\right]
$$

E tem o seguinte aspecto, mostrado na figura 4.8:

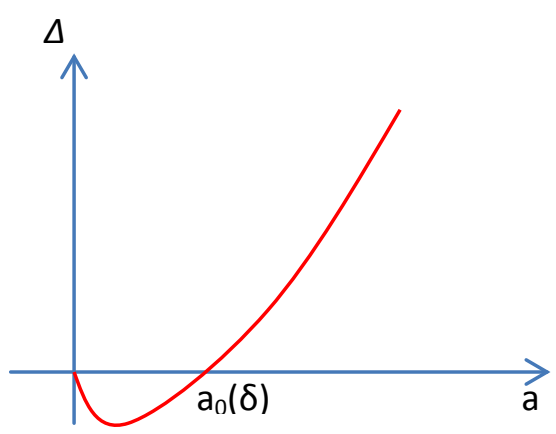

Figura 4.8 - Discriminante

Assim para a $>a_{0}(\delta)$ tem-se dois valores para $\rho, a$ saber, $\rho_{1}=\frac{1}{2}(b-\sqrt{\Delta})$ e $\rho_{2}=\frac{1}{2}(b+\sqrt{\Delta})$

Como $\tau=1-\frac{\rho}{a . \delta}$ tem-se que $\rho<a . \delta$. Entretanto $\mathrm{p}<1 / 4 \rightarrow \mathrm{b} / 2>\mathrm{a} . \delta \rightarrow$ só a primeira raiz é de interesse.

Logo $\rho=\frac{1}{2}(b-\sqrt{\Delta})$ e $\tau=1-\frac{\rho}{a . \delta}$ implicando que as matrizes $R$ e $\Upsilon$ sejam diagonais onde todos os elementos da diagonal são iguais, exceto seu primeiro elemento.

Considerando agora os estados BS-n, as suas formas originais e modificadas, isto é, respectivamente nas situações sem e com erro são abaixo ilustradas nas figuras 4.9 e 4.10 .

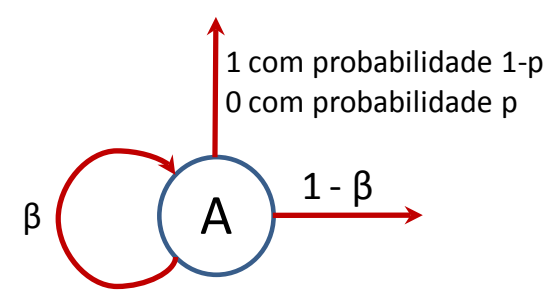

Figura 4.9 - Observação sem estado de erro 


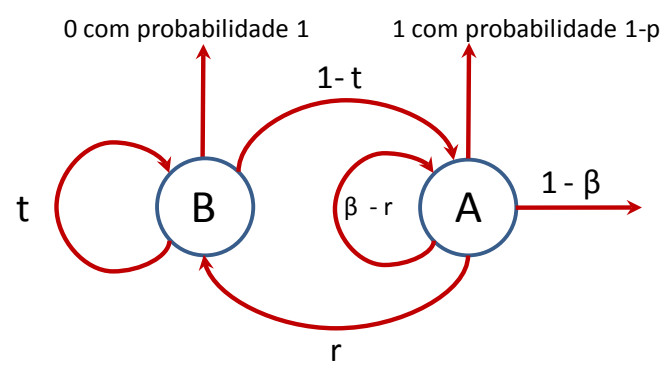

Figura 4.10 - Observação com estado de erro

Esta situação é absolutamente idêntica ao caso anterior onde a, $\rho$ e $\tau$ são respectivamente substituídos por $\beta, \mathrm{r}$ e t e as matrizes $\Gamma$ e $\mathrm{T}$ são da forma:

$$
\begin{aligned}
& \Gamma=r_{0} . I \\
& \mathrm{~T}=t_{0} . I
\end{aligned}
$$

\subsection{6 \\ Dimensionamento da janela de predição para um caso específico}

De modo a produzir um caso real para avaliação da aplicação de um sistema de rádio cognitivo, uma bateria de medidas foi realizada na faixa de 450 a $470 \mathrm{MHz}$ na cidade de Campinas, no estado de São Paulo, em um ambiente urbano. A motivação para a escolha da faixa de frequências, o horário das medições e outros detalhamentos estão disponíveis no Capítulo 3.

Uma ilustração do processo de captura dos dados é ilustrada na figura 4.11. A unidade de tempo aplicada foi em frames de 1 milissegundo. 
Indicação dos parâmetros medidos

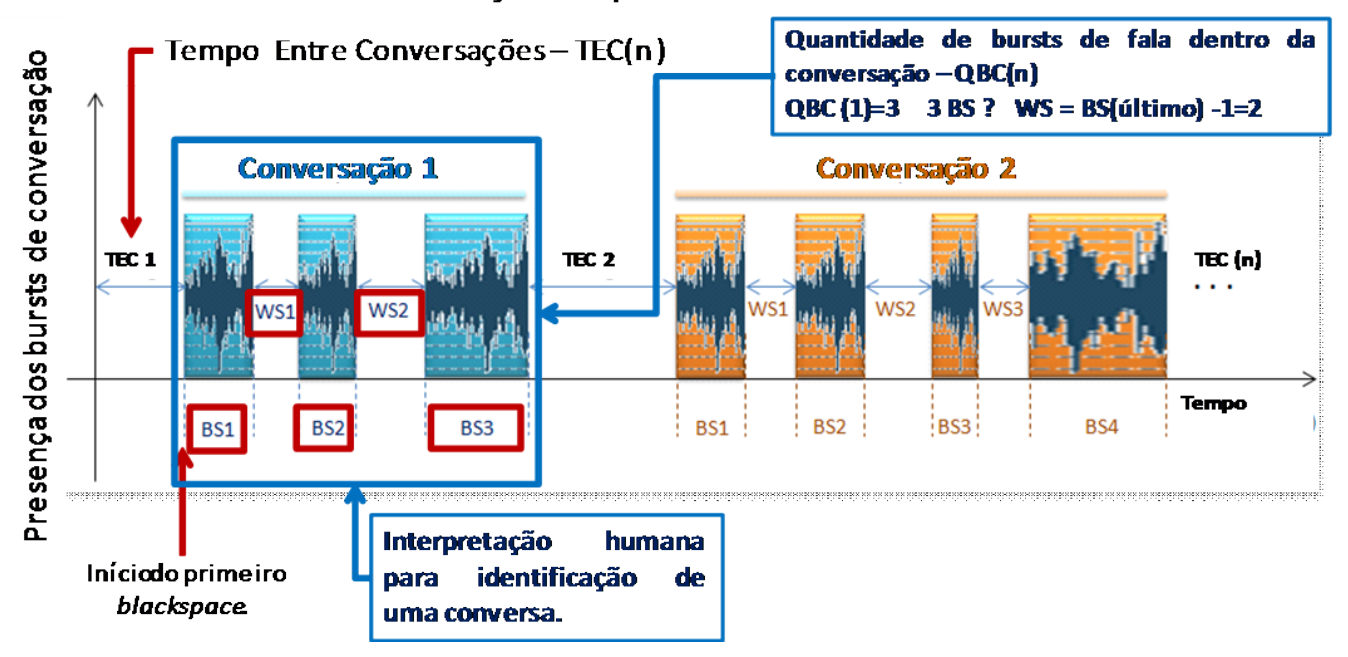

Figura 4.11 - Parâmetros medidos

Recomenda-se neste ponto a leitura do ANEXO 2para que se tenha a real dimensão de como os dados utilizados nas estimações e simulações aqui implementadas foram produzidos.

Os parâmetros estatísticos $(\alpha, \beta, \gamma, \underline{p})$ foram então estimados a partir dos dados coletados na campanha de medidas mencionada e revelaram que a durações médias do silêncio, atividade e pausa foram respectivamente90.303 milissegundos, 3.769 milissegundos e 2.814 milissegundos. As respectivas probabilidades de não haver colisões em regime permanente $\Omega_{\infty}(0)$ e $\Omega_{\infty}(1)$ são avaliadas como uma função do tamanho da janela de decisão H e mostradas, respectivamente, nas figuras 4.12-4.13 e 4.14-4.15 para vários valores de probabilidade de erro de sensoriamento do espectro, tais como $0 \%, 1 \%$, $5 \%$ e $10 \%$.

Pela figura 4.13 observa-se que no caso específico de janela de predição de tamanho 600, a probabilidade de que ela seja formada apenas de white spaces é de 30\% quando a observação no instante t revela canal livre $\left(\mathrm{O}_{\mathrm{t}}=0\right)$.

Similarmente pela figura 4.15 observa-se que no caso específico de janela de predição de tamanho 600, a probabilidade de que ela seja formada apenas de white spaces é de 0,009\% quando a observação no instante t revela canal ocupado $\left(\mathrm{O}_{\mathrm{t}}=1\right)$. 


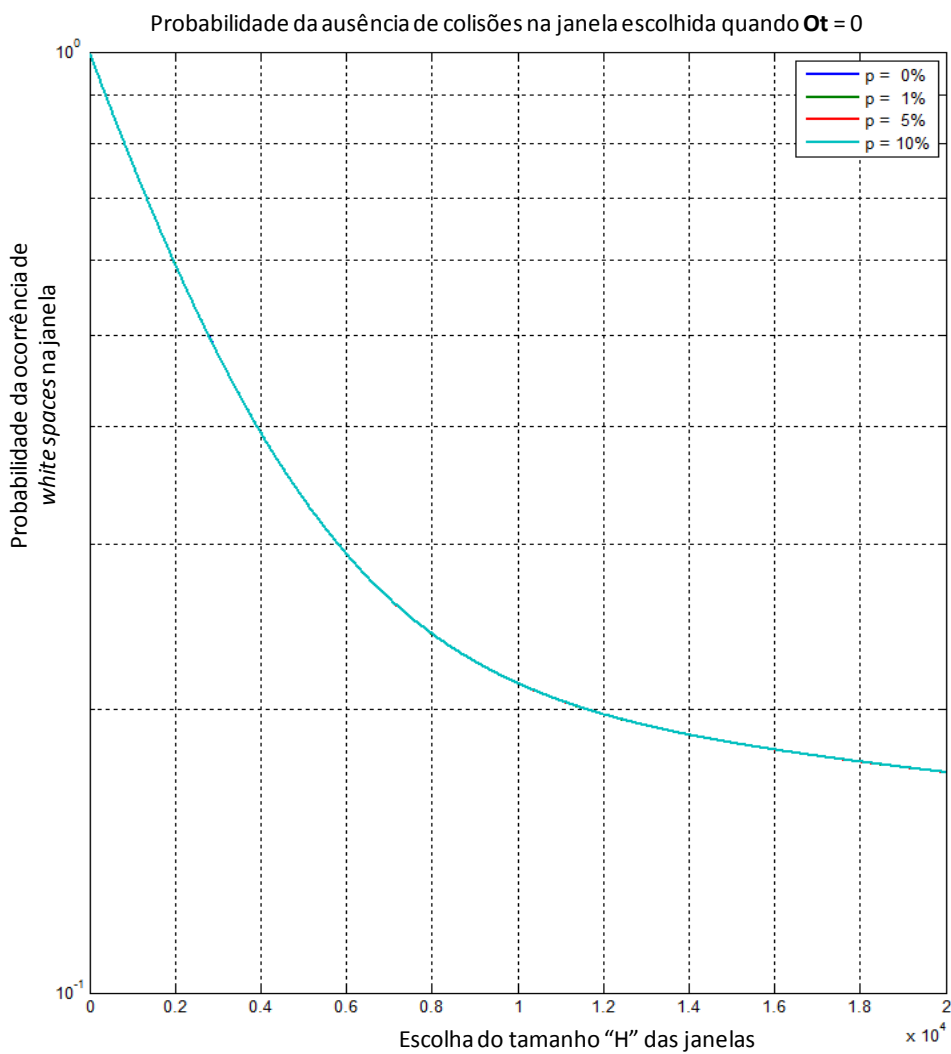

Figura 4.12 - Probabilidade da ausência de colisões com Ot $=0$

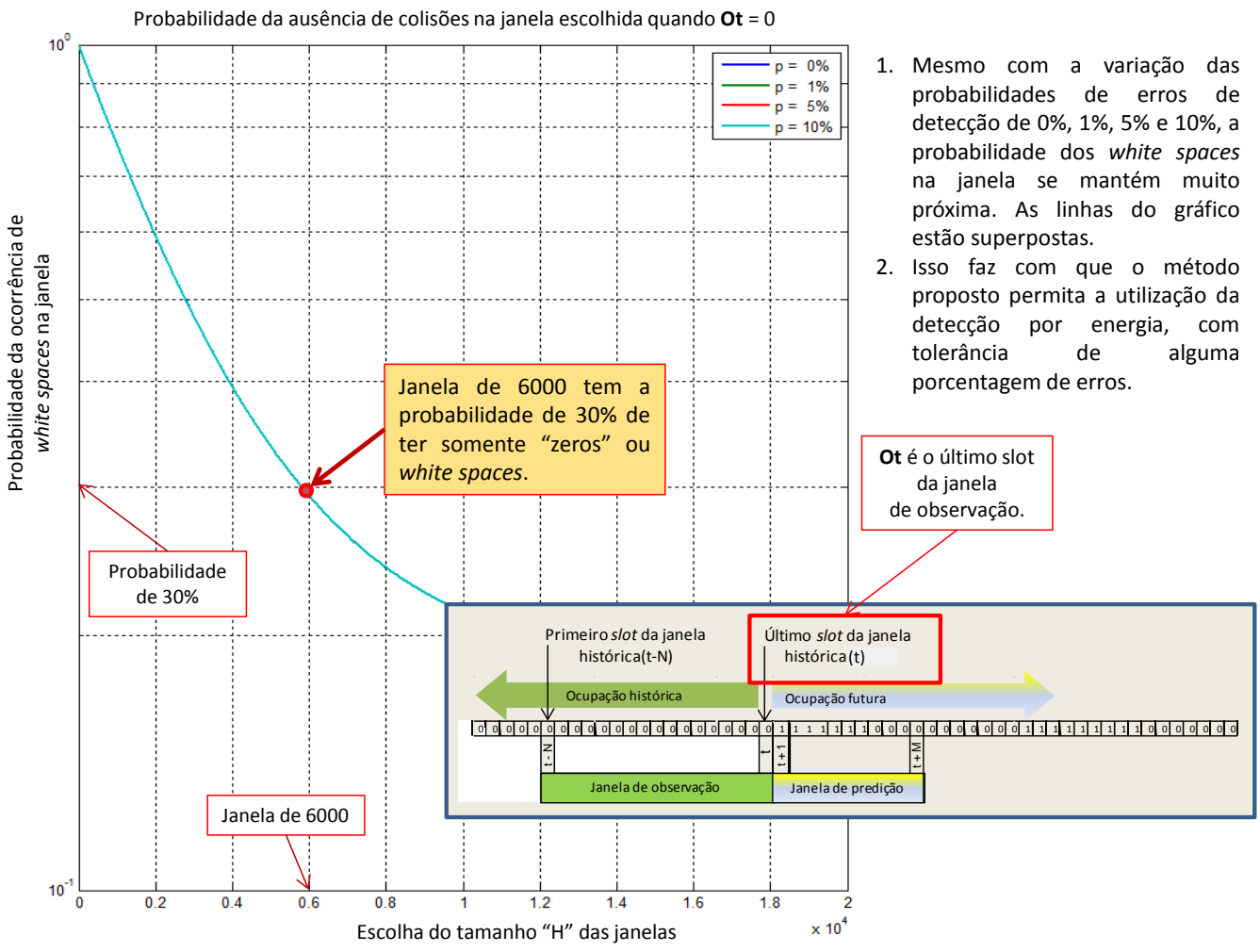

Figura 4.13 - Probabilidade da ausência de colisões com Ot $=0$ - Detalhado 


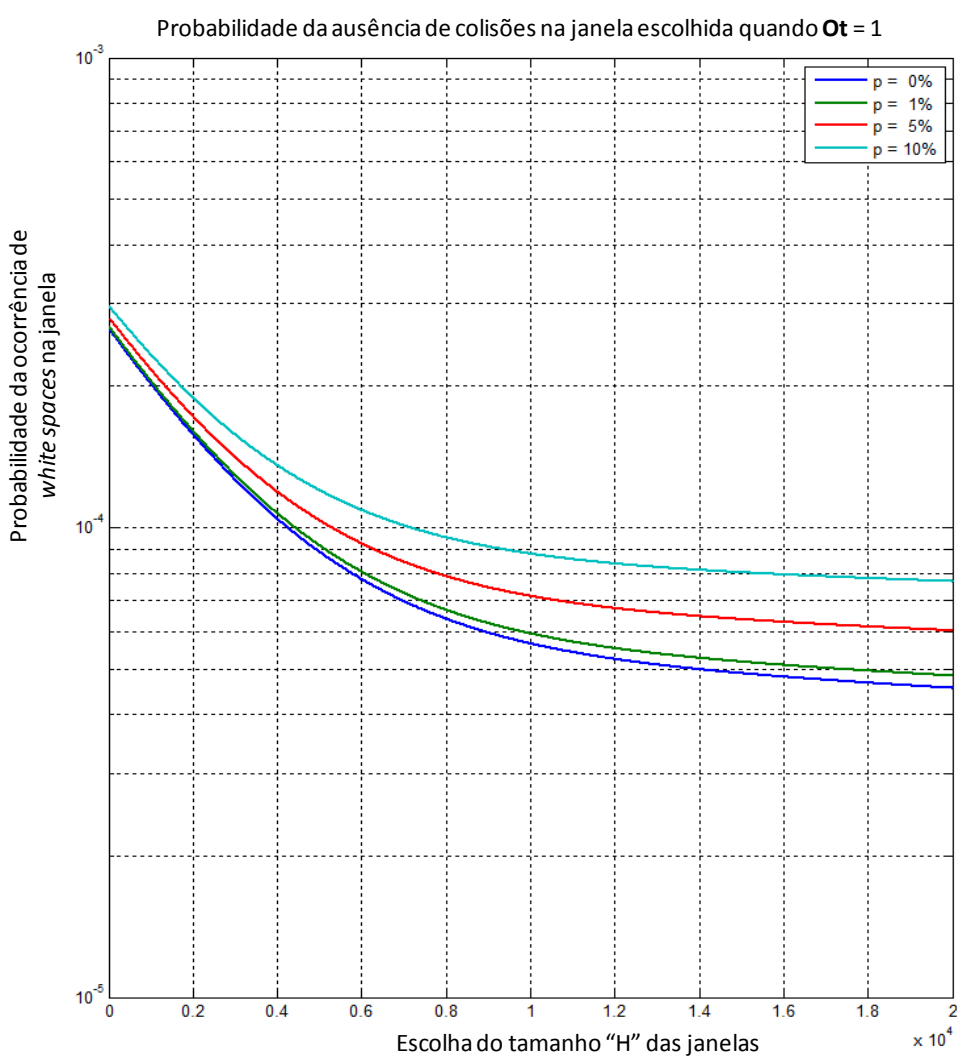

Figura 4.14 - Probabilidade da ausência de colisões com Ot = 1

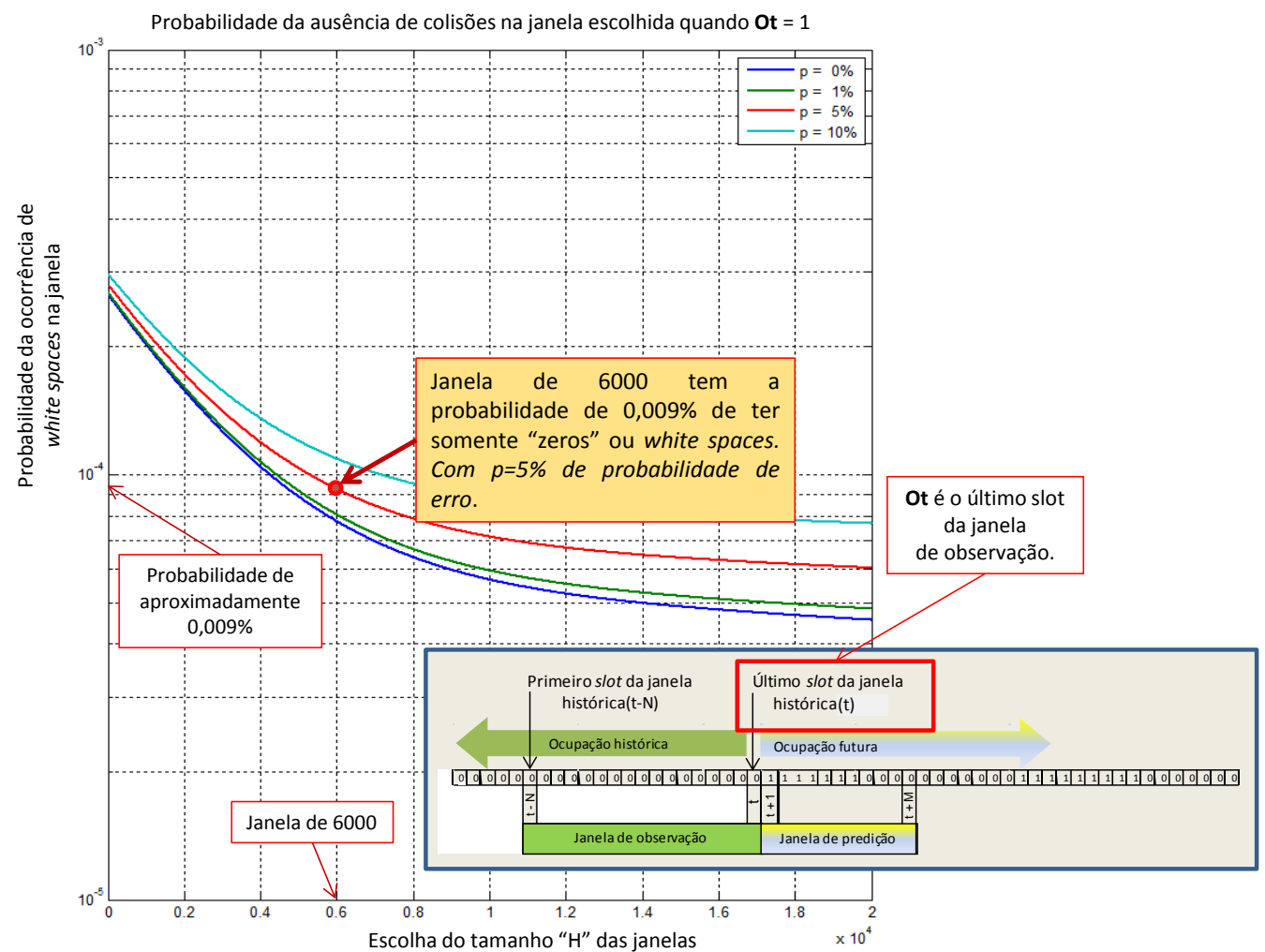

Figura 4.15 - Probabilidade da ausência de colisões com Ot = 1 - Detalhado 
É facilmente observado na figura 4.14 do gráfico de $\Omega_{\infty}(1)$ que, aparentemente contrária a nossa intuição, essa probabilidade aumenta com a probabilidade de erro de sensoriamento de espectro para uma dada janela de tamanho $\mathrm{H}$.

Isso pode ser explicado observando-se que quando se assume que o canal está ocupado, tal erro possa ter sido causado pelo erro na detecção do espectro enquanto que o canal está livre de fato. Se esta oportunidade é utilizada pelo usuário secundário, há uma grande chance de se observar um número muito pequeno de colisões.

Embora não seja fácil de verificar na figura 4.13, o oposto ocorre com as probabilidades de ausência de colisão, mas agora em acordo com a nossa intuição. Entretanto, a explicação correta é a mesma do caso anterior.

Talvez a mais interessante consequência nestas curvas seja que a decisão quanto ao tamanho das janelas H pode ser tomada com base no risco de colisão que o usuário secundário quer se expor. Janelas de predição grandes, associadas à probabilidade de ausência de colisões eliminam a grande tarefa de sensoriamento do espectro durante a utilização do canal pelo usuário secundário.

Como última observação, deve ser notado que o modelo de ocupação de canal "ocupado-livre" mencionado no início deste trabalho, é uma situação particular do modelo apresentado e corresponde ao caso de $\mathrm{N}=1$. A figura 4.16 mostra esse desempenho em termos de ausência de colisões versus a decisão do tamanho da janela $\mathrm{H}$. 


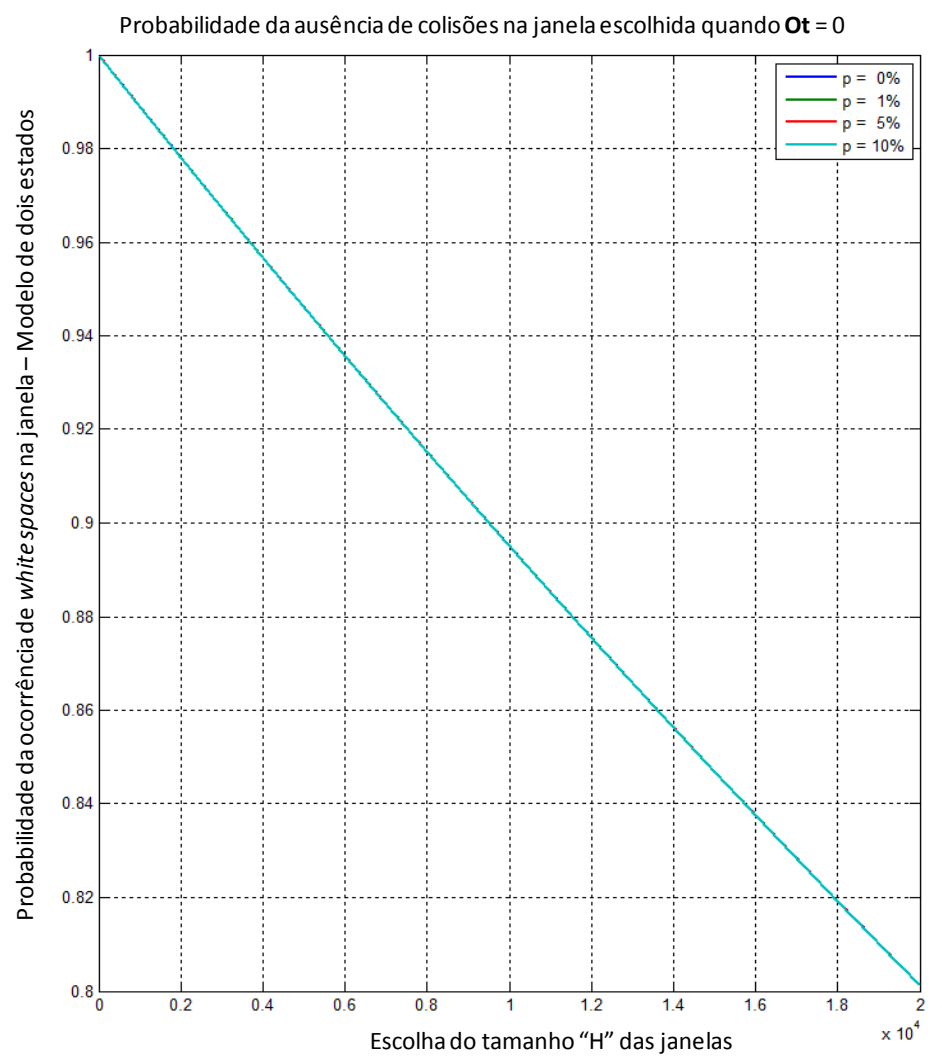

Figura 4.16 - Ausência de colisões versus tamanho da janela H

Daí pode-se verificar que este modelo simples tende a ser muito otimista. Se for definido o risco como 90\% para a ausência de colisões, a figura 4.16 nos mostra que uma janela de decisão de tamanho 950 é satisfatória. Entretanto, se o modelo for realmente mais complexo como o desenvolvido neste estudo, o tamanho da janela (conforme a figura 4.12) de 950 corresponderá a 75 \% para a ausência de colisões, provavelmente, um risco muito alto para ser adotado.

\section{2}

\section{Predição de intervalos espectrais}

Os rádios cognitivos foram concebidos para solucionar problemas relacionados ao congestionamento do espectro e por esta razão, diversos estudos estão atualmente em progresso na comunidade científica. Pesquisas estão sendo desenvolvidas no intuito de aprimorar as tecnologias que são utilizadas para efetivar o compartilhamento eficiente do espectro entre usuários primários e secundários. Nesse compartilhamento do espectro, é importante que os usuários 
secundários monitorem as transmissões dos usuários primários e aguardem a ocorrência de um white space para poder utilizar o respectivo canal.

Quando o usuário secundário está utilizando o canal e ocorre o retorno do usuário primário, a operação exige que os usuários secundários interrompam as suas transmissões e evitem as colisões que degradam as comunicações. Todo esse processo nos sistemas cognitivos envolve um dispêndio grande de energia e coordenação, requerendo muito tempo de processamento, que tem como inconveniente a geração de latência. Portanto, a predição de espaços espectrais é extremamente útil para minimizar a latência supracitada.

Logo, pode ser dito que a predição do estado de janelas espectrais pode reduzir a latência e aumentar o desempenho dos rádios cognitivos, merecendo destaque e investigação. Entretanto, esse segmento ainda é um desafio a ser vencido. Por essa razão, este estudo apresenta uma nova técnica para realizar a predição dos espaços espectrais e compara os resultados com outros trabalhos disponíveis na literatura técnica. Os resultados obtidos mostram vantagens em relação a outros estudos publicados.

\subsection{1}

\section{Estudos afins}

O trabalho de Mohammad Taqi e outros [3] descreve as atividades requeridas pelos usuários secundários, tais como o sensoriamento do espectro e a utilização de um critério de decisão de utilização do canal do UP de modo a minimizar alguma medida de interferência sobre o usuário primário. Este estudo foca principalmente nas ações de handoff dos usuários secundários e sugere a avaliação do comportamento dos usuários primários, com base na cadeia de Markov escondida para predição dos espaços espectrais. Esta técnica permite que os usuários secundários ocupem mais intervalos de tempo continuamente sem realizar o handoff, reduzindo a latência do sistema. Convém salientar que este trabalho utiliza o modelo clássico on-off (usado como comparação na seção 4.2.5) para a cadeia de Markov escondida, o que reputamos ser de simplicidade exagerada e não capaz de considerar as peculiaridades do processo de ocupação de canais pelo usuário primário. 
De acordo com o trabalho de Tao Jing's [4], a predição da ocupação do espectro possui um grande potencial para reduzir a interferência nos usuários primários (PU), quando estes estão ativos. O estudo em tela investiga a predição de espectro cooperativa e local. Na predição de espectro local, contida no trabalho, cada usuário secundário realiza sua predição, realizando um sensoriamento com base na cadeia de Markov escondida para realizar a predição dos estados futuros dos canais de forma totalmente semelhante ao caso anterior. O estudo ainda apresenta uma predição do espectro realizada de forma cooperativa, estruturada em teoria de jogos de coalisão. Nesta situação os usuários secundários são considerados como jogadores e tentam formar coalizões para, de forma cooperativa, realizar a predição dos estados futuros dos canais. Os resultados indicaram que a acurácia da predição pode ser melhorada no sistema cooperativo.

D. Barnes e B. T. Maharaj publicaram em [5], um método é proposto para aprimorar o desempenho de rádios cognitivos, aumentando a vazão de dados dos usuários secundários e reduzindo a degradação dos dados enviados pelo usuário primário, por meio da implementação de sistema de predição. Um simulador de comutação de canal foi desenvolvido para avaliar o desempenho dos usuários primários, no qual a cadeia de Markov escondida (novamente do tipo on-off) foi implementada para modelar e predizer o comportamento do UP, a partir do qual alocações de canais proativas puderem ser realizadas.

De acordo com o artigo, o desempenho do sistema cognitivo pode ser aprimorado se o comportamento do UP for adequadamente modelado, porque o usuário secundário utiliza estas informações para realizar a predição da ocupação do espectro, permitindo aplicar decisões de comutação de canais proativas. Desse modo, utilizando um modelo de predição, são obtidos significativos ganhos no desempenho do sistema, particularmente em condições de tráfego mais intenso, quando foi observado aumento da vazão de dados do usuário secundário e redução à metade da degradação do usuário primário. 


\subsection{2}

\section{Esquema proposto para predição de uso do espectro}

O módulo de decisão relativa a utilização do espectro possui uma das mais importantes funcionalidades dos sistemas de rádio cognitivo, porque ele afeta diretamente o desempenho das redes como um todo, em especial a transferência de informações dos usuários secundários.

Assume-se que o usuário secundário pode sensoriar o espectro e estimar se um slot de tempo específico está em uso ou não, onde a probabilidade de erro nesta estimação vale $\mathrm{P}_{\text {est }}$.

A coleção dos slots de tempo sensoriados pelo usuário secundário é chamada de janela histórica $\left(\mathrm{W}_{\mathrm{H}}\right)$ e o seu tamanho é $\mathrm{L}_{\mathrm{H}}$. A partir destas observações, o usuário secundário decidirá como utilizará os slots de tempo futuros em uma janela de predição $\left(\mathrm{W}_{\mathrm{P}}\right)$, com o tamanho $\mathrm{L}_{\mathrm{P}}$.

O desempenho do esquema de utilização da janela de predição é usualmente avaliado pela medição de dois parâmetros, que são descritos a seguir:

- System Utility (SU) - É a razão entre o número de white spaces utilizados pelo usuário secundário e o número total de white spaces existentes na janela de predição. Seu valor idealizado é de $100 \%$.

- Disturbance Ratio (DR) - É a razão entre o número de black spaces utilizados pelo usuário secundário e o número total de black spaces existentes na janela de predição. Seu valor idealizado é de $0 \%$.

O elemento motivador do algoritmo aqui desenvolvido consiste em estimar a existência de sequencias de 0's (slots livres) ou de 1's (slots ocupados) numa vizinhança imediatamente anterior ao instante $t$ onde a decisão sobre ocupação deve ser feita. Um número grande de 1's ou 0’s é um forte indicador de que o canal respectivamente está ou não sendo ocupado pelo usuário primário, o que sugeriria ao usuário secundário não ocupa-lo ou não.

A seção seguinte tem por objetivo colocar estas ideias num plano mais formal que possa permitir a definição de um algoritmo de ocupação da janela de predição. 


\subsection{3}

\section{Formulação do Problema}

Considera-se a situação na qual o usuário secundário (US) pretende utilizar, de forma oportunística, um canal, normalmente atribuído a um usuário primário (UP). Considerando t como o momento presente, o US observa o estado do canal nos intervalos de tempo t, t-1,..., t-N (janela de observação) e avalia o seu conteúdo para decidir como se comportar nos slots de tempo $t+1, t+2$, ....,t+M (janela de predição), como ilustrado na figura 4.18.

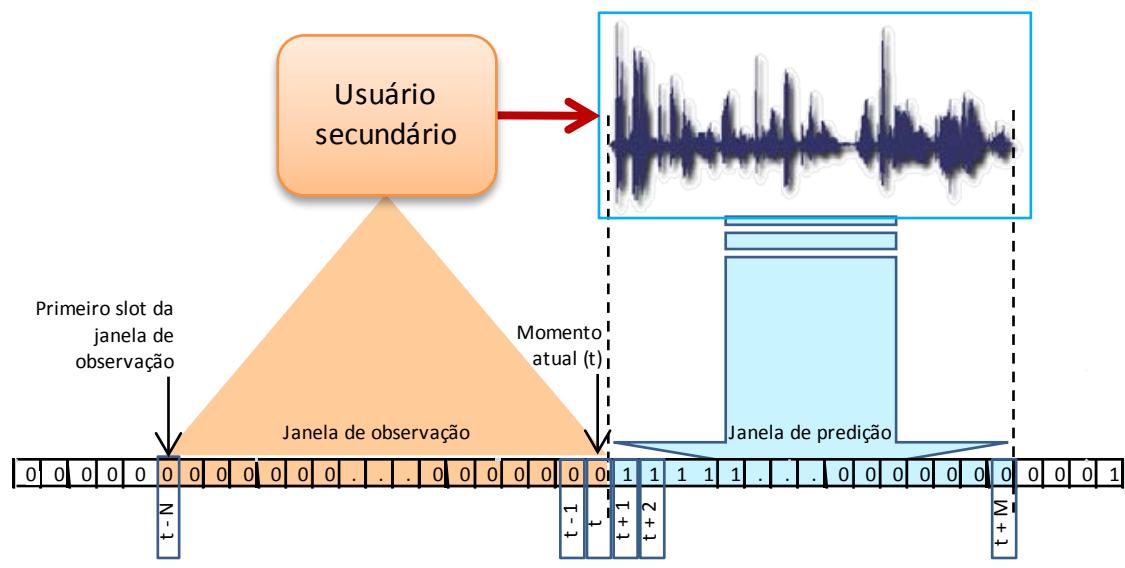

Figura 4.17 - Avaliação da janela histórica

Inicialmente assume-se que $\mathrm{M}$ e $\mathrm{N}$ são pequenos quando comparados aos tempos médios de atividade e pausa dos usuários primários de modo que se possa assumir que na janela de observação é muito pouco improvável a ocorrência de mais de um black space ou white space. Denotando-se por $\mathrm{x}_{\mathrm{k}}$ o estado do canal devido à atividade de PU ("0 = ocioso" e "1 = ocupado") e na ausência de erros de estimativa, há dois casos possíveis para a janela de observação:

Caso $1: \mathrm{x}_{\mathrm{t}-\mathrm{k}}=0$ para todo $\mathrm{k}$ em $\{0,1, \ldots \mathrm{L}-1\}$ e $\mathrm{x}_{\mathrm{t}-\mathrm{k}}=1$ para todo $\mathrm{k}$ em $\{\mathrm{L}, \mathrm{L}+1, \ldots \mathrm{N}-1\}$

Caso $2: \mathrm{x}_{\mathrm{t}-\mathrm{k}}=1$ para todo $\mathrm{k}$ em $\{0,1, \ldots \mathrm{L}-1\}$ e $\mathrm{x}_{\mathrm{t}-\mathrm{k}}=0$ para todo $\mathrm{k}$ em $\{\mathrm{L}, \mathrm{L}+1, \ldots \mathrm{N}-1\}$ 
Entretanto em situações reais existe a ocorrência de erros. Assume-se então que cada elemento da sequência $\left\{\mathrm{x}_{\mathrm{t}-\mathrm{k}}, \mathrm{k}=\{0,1, \ldots \mathrm{N}-1\}\right\}$ pode ser corrompido por ruído de tal forma que a inversão do estado ocorra com uma probabilidade fixa não superior a $1 / 2$.

Essa consideração permite concluir que os elementos da sequência mencionada anteriormente, podem ser tratados como uma sequência de v.a.r.'s independentes onde $\left\{\mathrm{x}_{\mathrm{t}-\mathrm{k}}, \mathrm{k}=\{0,1, \ldots \mathrm{L}-1\}\right\}$ são Bernoulli(p) enquanto $\left\{\mathrm{x}_{\mathrm{t}-\mathrm{k}}\right.$, $\mathrm{k}=\{\mathrm{L}, \mathrm{L}+1, \ldots \mathrm{N}-1\}\}$ são Bernoulli(1-p).

O "Caso 1" corresponde a situação onde $\mathrm{p}<1 / 2$ enquanto que o "Caso 2" corresponde a situação onde $\mathrm{p}>1 / 2$.

Então o problema que se deseja resolver pode ser assim formulado: levando em conta que a janela de observação acima definida produziu valores $\left\{\mathrm{X}_{\mathrm{t}}, \mathrm{X}_{\mathrm{t}-1}, \ldots, \mathrm{X}_{\mathrm{t}-(\mathrm{N}-1)}\right\}$ para os estado de ocupação do canal, pretende-se estimar os valores de p e L que então serão utilizados no esquema de decisão na utilização da janela de predição.

\subsection{4}

\section{Solução proposta}

Em resumo, a ideia inicial aqui é avaliar a probabilidade de ocorrência da sequência observada $\left\{X_{t}, X_{t-1}, \ldots, X_{t-(N-1)}\right\}$ em função de $L$ e p e, em seguida, encontrar valores para esses parâmetros que levam a maximização desta probabilidade de ocorrência.

A verossimilhança da sequência observada $\underline{X}_{t}^{N}=\left(X_{t}, X_{t-1}, \ldots, X_{t-(N-1)}\right)$ pode ser expressa por:

$$
\begin{aligned}
L\left(\underline{X}_{t}^{N}\right) & =\left[\prod_{i=0}^{L-1}(1-p)^{\left(1-X_{t-i}\right)} \cdot p^{X_{t-i}}\right] \cdot\left[\prod_{i=L}^{N-1} p^{\left(1-X_{t-i}\right)} \cdot(1-p)^{X_{t-i}}\right]= \\
& =\left[(1-p)^{\left(L-S_{L}^{-}\right)} \cdot p^{S_{L}^{-}}\right] \cdot\left[p^{\left(N-L-S_{L}^{+}\right)} \cdot(1-p)^{S_{L}^{+}}\right]= \\
& =p^{N-\left(L-S_{L}^{-}+S_{L}^{+}\right)} \cdot(1-p)^{\left(L-S_{L}^{-}+S_{L}^{+}\right)}= \\
& =p^{N-\varphi(L)} \cdot(1-p)^{\varphi(L)}
\end{aligned}
$$


Onde:

$$
\begin{aligned}
& S_{L}^{-}=\sum_{i=0}^{L-1} X_{t-i} \\
& S_{L}^{+}=\sum_{i=L}^{N-1} X_{t-i}=\sum_{i=0}^{N-1} X_{t-i}-\sum_{i=0}^{L-1} X_{t-i}=S-S_{L}^{-} \\
& \varphi(L)=L-S_{L}^{-}+S_{L}^{+}=L+S-2 . S_{L}^{-}
\end{aligned}
$$

Observe que:

- Se $\varphi(L)=N$ então $L\left(\underline{X}_{t}^{N}\right)$ é máximo quando $p=0$

- Se $\varphi(L)=0$ então $L\left(\underline{X}_{t}^{N}\right)$ é máximo quando $p=1$

- Se $\varphi(L) \notin\{0, N\}$ então $L\left(\underline{X}_{t}^{N}\right)$ é máximo quando $p=1-\frac{\varphi(L)}{N}$

Do exposto acima, podemos concluir que $L\left(\underline{X}_{t}^{N}\right)$ é máximo quando $p=1-\frac{\varphi(L)}{N}$ e de modo a evitar a saturação típica da escala linear em problemas semelhantes, a função de verossimilhança passa a ser definida na sua forma logarítmica:

$$
L_{\text {opt }}\left(\underline{X}_{t}^{N}\right)=(N-\varphi(L)) \cdot \log \left(1-\frac{\varphi(L)}{N}\right)+\varphi(L) \cdot \log \left(\frac{\varphi(L)}{N}\right)
$$

por meio da qual o valor máximo de L pode ser encontrado utilizando "força bruta" mas com baixo esforço computacional.

Entretanto, quando L é pequeno, a sensibilidade do estimador de p é frequentemente alta. Para mitigar este efeito indesejado, quando o valor estimado de $\mathrm{L}$ for inferior ao de um limiar $\mathrm{L}_{\text {bound }}$ (tipicamente 20),decide-se por estimar através de frequência de erros empírica ao longo de toda a sequência.

Mesmo sabendo que isso ocorra raramente, é possível que mais de um ciclo de atividade e pausa ocorra dentro de uma janela de observação. Novamente, este efeito pode ser mitigado reaplicando a estimação de (L, p) em uma sub janela de observação $\left(X_{t}, X_{t-1}, \ldots, X_{t-\left(L^{*}-1\right)}\right)$ onde $\mathrm{L}^{*}$ foi encontrado na primeira fase. De um ponto de vista formal, o algoritmo de estimação proposto (L, p),indicado na Figura 4.19, pode ser descrito como indicado a seguir: 


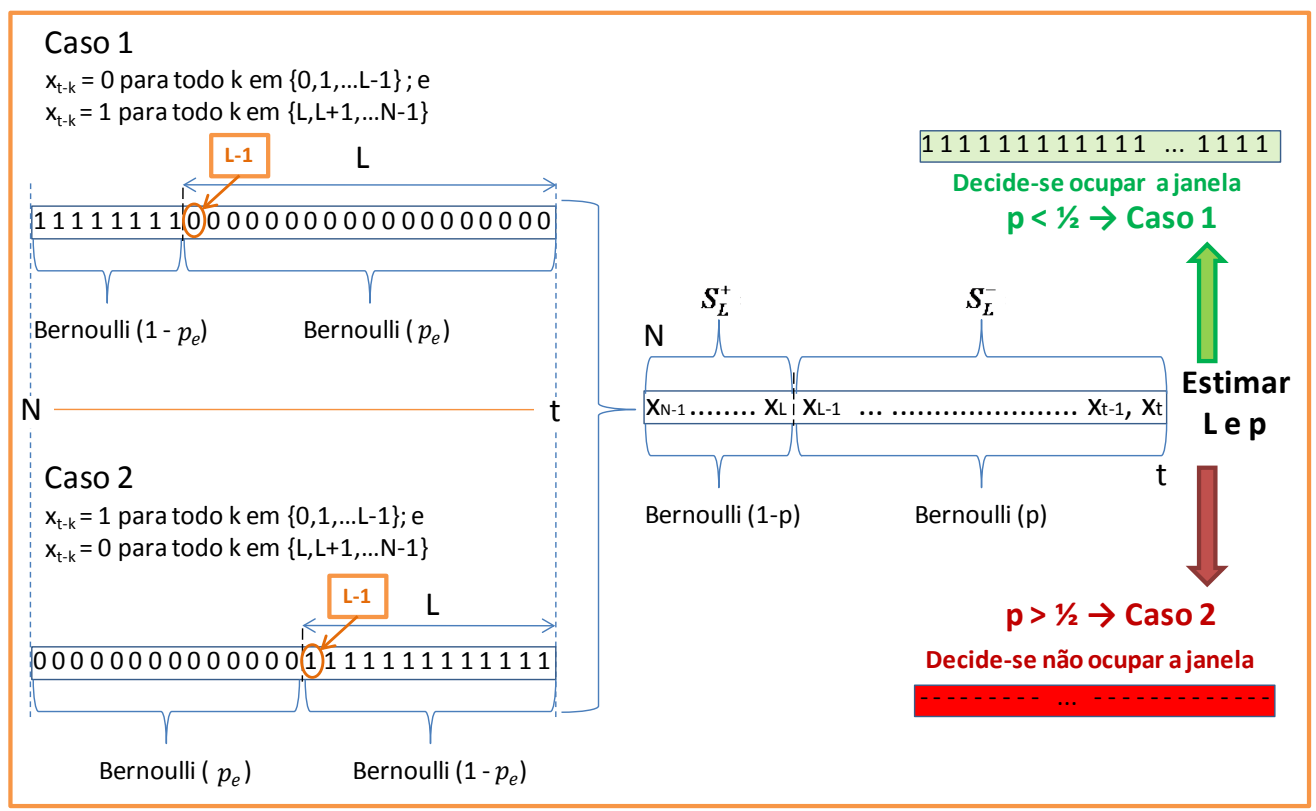

Figura 4.18 - Representação do algoritmo de estimação

Algoritmo para estimação do par (L,p) em função da observação na da janela

$$
\underline{X}_{t}^{N}=\left(X_{t}, X_{t-1}, \ldots, X_{t-(N-1)}\right)
$$

1. Calcular

$$
\varphi(L)=L+\sum_{i=0}^{N-1} X_{t-i}-2 \cdot \sum_{i=0}^{L-1} X_{t-i} \text { for } L \in\{1,2, \ldots, N\}
$$

2. Calcular $L^{*}$ que maximiza

$$
L_{\text {opt }}\left(\underline{X}_{t}^{N}\right)=(N-\varphi(L)) \cdot \log \left(1-\frac{\varphi(L)}{N}\right)+\varphi(L) \cdot \log \left(\frac{\varphi(L)}{N}\right)
$$

3. Se $L^{*}<L_{\text {bound }}$ então $p^{* *}=\frac{1}{N} \sum_{i=0}^{N-1} X_{t-i} \quad L^{* *}=L_{\text {bound }}$

4. Senão, para $\boldsymbol{L} \in\left\{\mathbf{1}, \mathbf{2}, \ldots, \boldsymbol{L}^{*}\right\}_{\text {calcular } L^{* *} \text { que maximiza }}$

$$
L_{o p t}\left(\underline{X}_{t}^{N}\right)=\left(L^{*}-\varphi(L)\right) \cdot \log \left(1-\frac{\varphi(L)}{L^{*}}\right)+\varphi(L) \cdot \log \left(\frac{\varphi(L)}{L^{*}}\right)
$$


5. Fazendo

$$
p^{* *}=1-\frac{\varphi\left(L^{* *}\right)}{L^{*}} \quad \text { Retorna ao par }\left(L^{* *}, p^{* *}\right)
$$

O algoritmo aqui proposto utiliza o valor final estimado de p para decidir sobre a utilização ou não da janela de predição. Se $\mathrm{p}^{* *}$ for menor do que $1 / 2$ esta janela é integralmente utilizada pelo usuário secundário enquanto que se $\mathrm{p}^{* *}$ for maior ou igual a 1⁄2 esta janela é não é utilizada pelo usuário secundário.

\section{2 .5}

\section{Experimentos}

De modo a avaliar a qualidade da estimação proposta foi desenvolvido um programa de computador que:

i) randomicamente seleciona valores para $\mathrm{N}, \mathrm{L}$ e p;

ii) Gera uma sequência binária com essas características, e

iii) Estima L e p por meio do método proposto.

Uma série de 10000 casos foi gerada, e para cada um deles o erro relativo das estimações de $\mathrm{L}$ e de $\mathrm{P}$ foram avaliados. A figura 4.19apresenta esses resultados. 

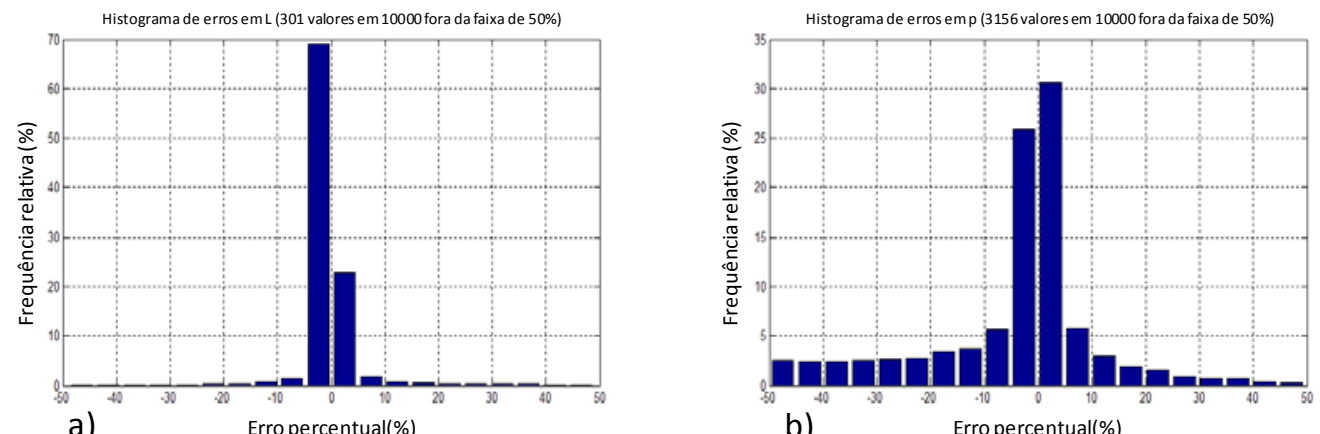

b)
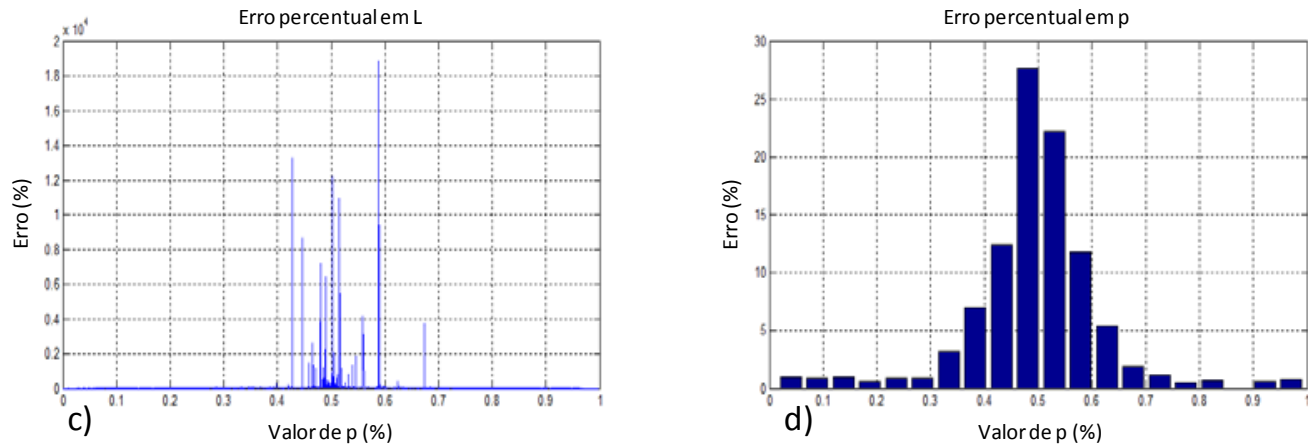

Figura 4.19 - Resultados da simulação

Em (a) pode ser visto que em 92\% dos casos, o erro relativo em L (aqui denominado de L-erro), definido por $1-L_{\text {estimado }} / L_{\text {real }}$, não excedeu $5 \%$, enquanto que em (b) o erro relativo em $\mathrm{P}$ (aqui denominado de P-erro), definido por $1-P_{\text {estimado }} / P_{\text {real }}$, não excedeu $10 \%$ dos casos em $68 \%$ dos casos apenas.

É importante destacar que de certa forma o P-erro é pouco relevante uma vez que o que importa é que ambas as percentagens $\mathrm{P}_{\text {estimado }}$ e $\mathrm{P}_{\text {real }}$ estejam simultaneamente abaixo ou acima de 1/2. De acordo com a figura 4.19 (d) se não houver medições de erros superiores a30\%, não mais do que $10 \%$ dos casos violam a incongruência mencionada.

\subsection{6}

\section{Resultados obtidos e comparação com outros trabalhos}

Os resultados obtidos pelo algoritmo proposto nesta tese estão expostos nesta seção e, além disso, eles são comparados com outros em estudos similares. O trabalho de Uyanik Gulnur, e outros [46], versa sobre predição do espectro. O trabalho destaca que a capacidade de predição do espectro é uma funcionalidade importante que pode melhorar o desempenho dos sistemas cognitivos (usuários 
secundários), reduzindo a latência gerada pelos sistemas mais convencionais apresentados na literatura.

O estudo em questão propõe três mecanismos de predição, que são comentados na sequência, desta seção. A avaliação de desempenho destes três mecanismos é avaliada pelas estatísticas do System Utility (SU) e do Disturbance Ratio (DR).

- Método 1 - Predição baseada no coeficiente de correlação Pearson

Este esquema de predição é baseado no coeficiente de correlação de Pearson [43], que é medido na janela histórica observada. Se este coeficiente for superior a um determinado limiar, a janela de predição é preenchida com o valor da última amostra da janela histórica. Caso contrário, a janela de predição é preenchida com o resultado da maioria dos estados observados na janela histórica.

- Método 2 - Predição baseada em regressão Linear

Este esquema é baseado na regressão linear entre os dados de ocupação da janela histórica e o vetor índice. Se o coeficiente angular desta regressão for superior a um limiar $\gamma_{1}$, esta regressão é estendida a janela de predição onde um segundo limiar $\gamma_{2}$ é utilizado para promover a binarização dos valores desta reta e por consequência definir o processo de ocupação desta janela pelo usuário secundário.

- Método3 - Predição baseada em autocorrelação

Este esquema de predição baseia-se no fato de que o segundo máximo local da função autocorrelação dos dados de ocupação da janela histórica reflete a periodicidade deste sinal. Se este valor for suficientemente grande (maior do que um limiar), assume-se a existência da periodicidade e completa-se a janela de predição seguindo-se a periodicidade observada. Caso contrário, a janela de predição não é utilizada pelo usuário cognitivo.

A seguir são apresentados os resultados das simulações utilizando os três métodos mencionados em conjunto com o método proposto nesta tese.

As figuras 4.20, 4.21 e 4.22 apresentam o desempenho dos quatro métodos por meio da relação do parâmetro System Utility (SU) em função da 
probabilidade de erro na estimação do estado do canal. Foi utilizada uma janela histórica de tamanho1000, sendo que os gráficos estão associados respectivamente a janelas de predição de tamanhos 600, 700 e 1000.

Pode-se observar que o método proposto superou os demais, no que tange respeito a estatística escolhida, principalmente para maiores valores de probabilidade de erro, revelando robustez de desempenho.

Para que se perceba a relevância estatística destas conclusões, convém salientar que todos os dados estimados estão ilustrados com seus respectivos intervalos de confiança ao nível de significância de 95\%.

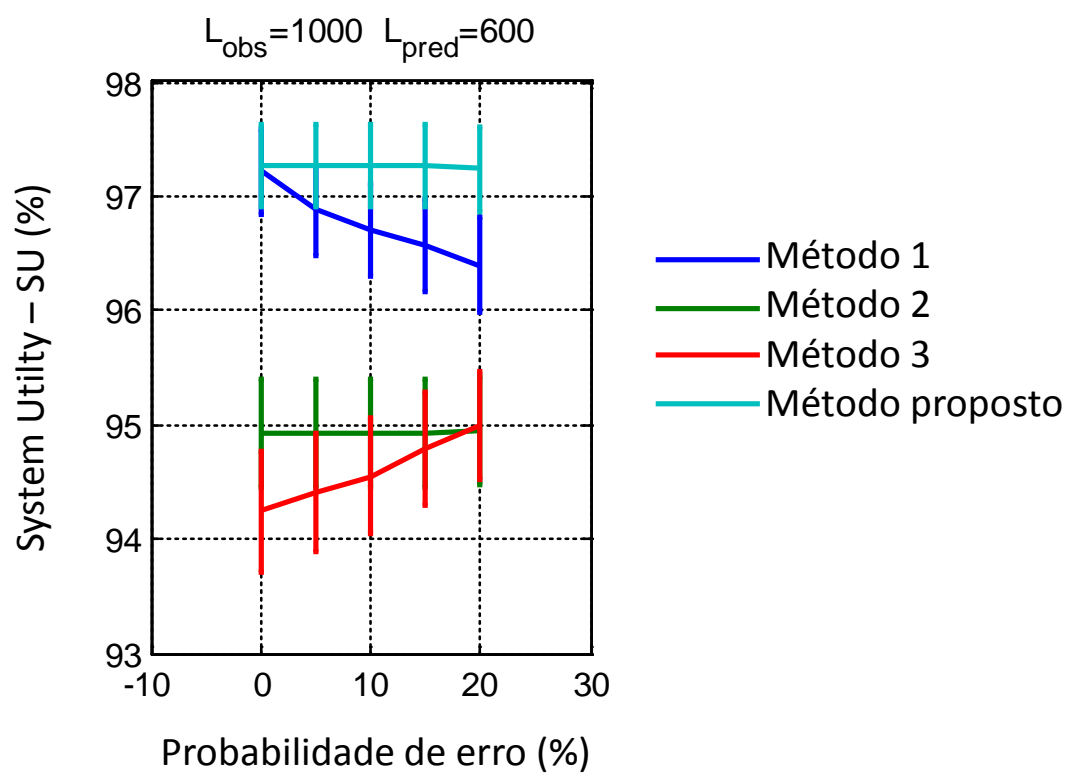

Figura 4.20 - System Utility - Janelas: observação: 1000, predição: 600 


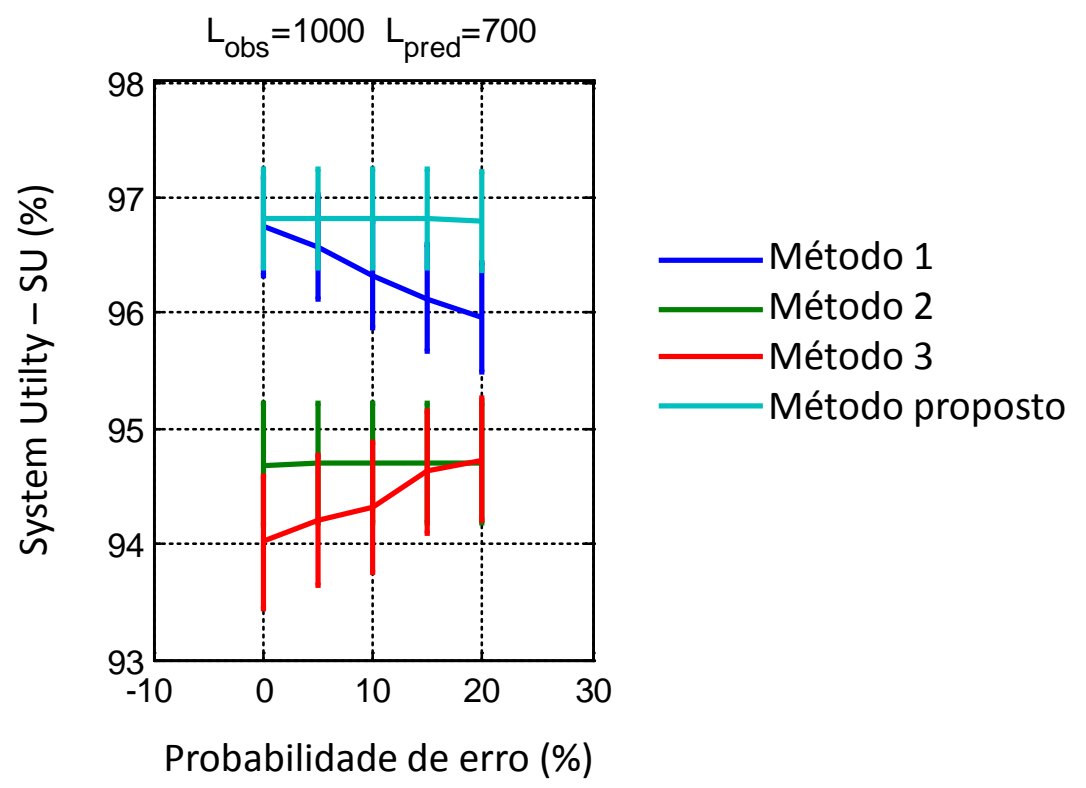

Figura 4.21 - System Utility - Janelas: observação: 1000, predição: 700

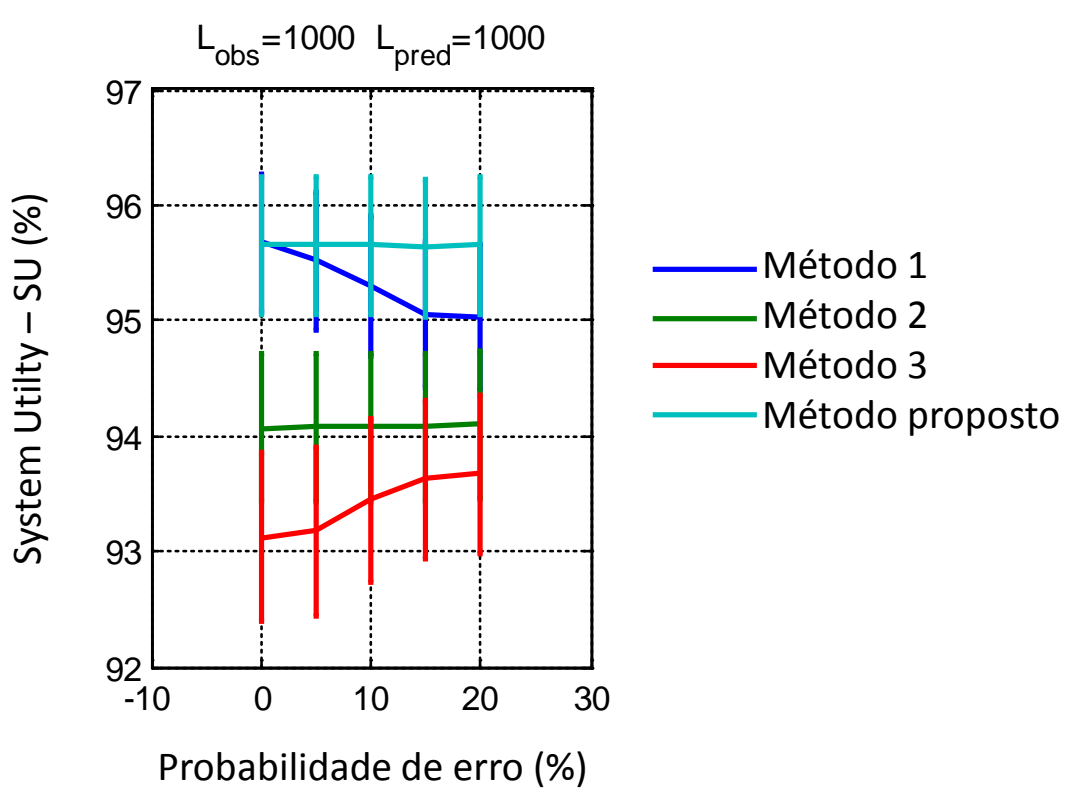

Figura 4.22 - System Utility - Janelas: observação: 1000, predição: 1000

As figuras 4.23, 4.24 e 4.25 apresentam, de forma semelhante ao caso anterior e para os mesmos tamanhos de janelas, o desempenho dos quatro métodos por meio da relação do parâmetro Disturbance Ratio (DR)em função da probabilidade de erro na estimação do estado do canal. 
Pode-se observar que o método proposto continuou superando os demais no que tange respeito a estatística escolhida, principalmente para maiores valores de probabilidade de erro, revelando novamente robustez de desempenho.

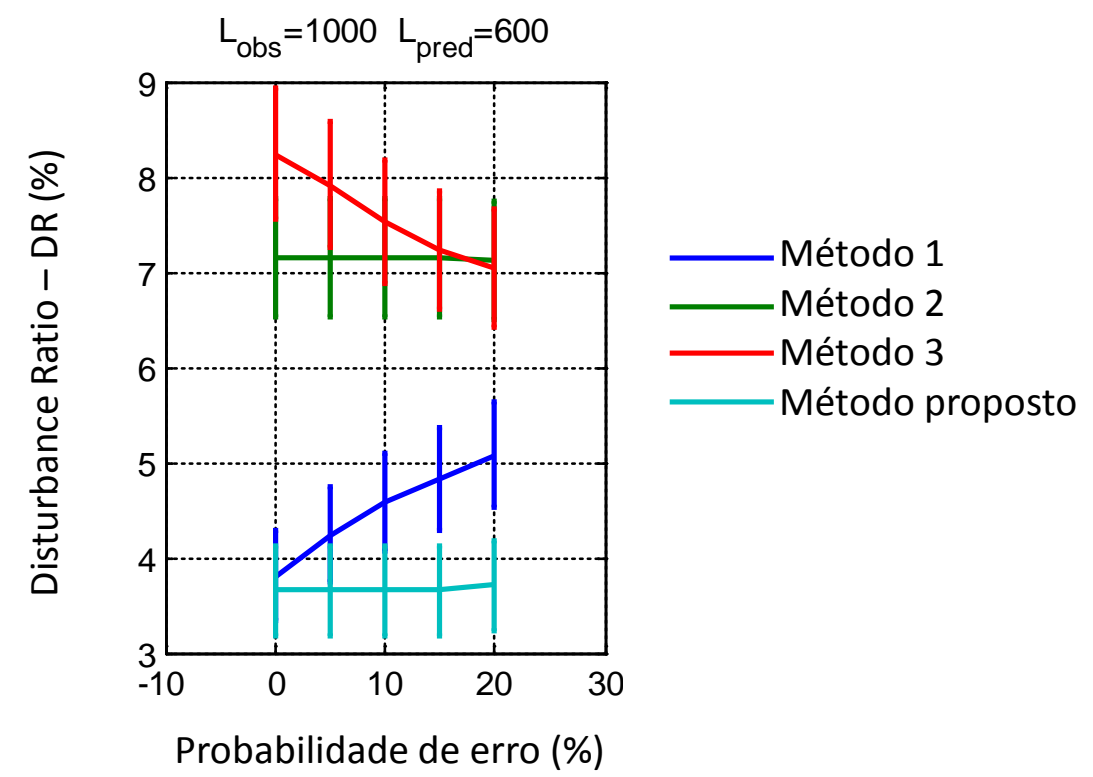

Figura 4.23 - Disturbance Ratio - Janelas: observação: 1000, predição: 600

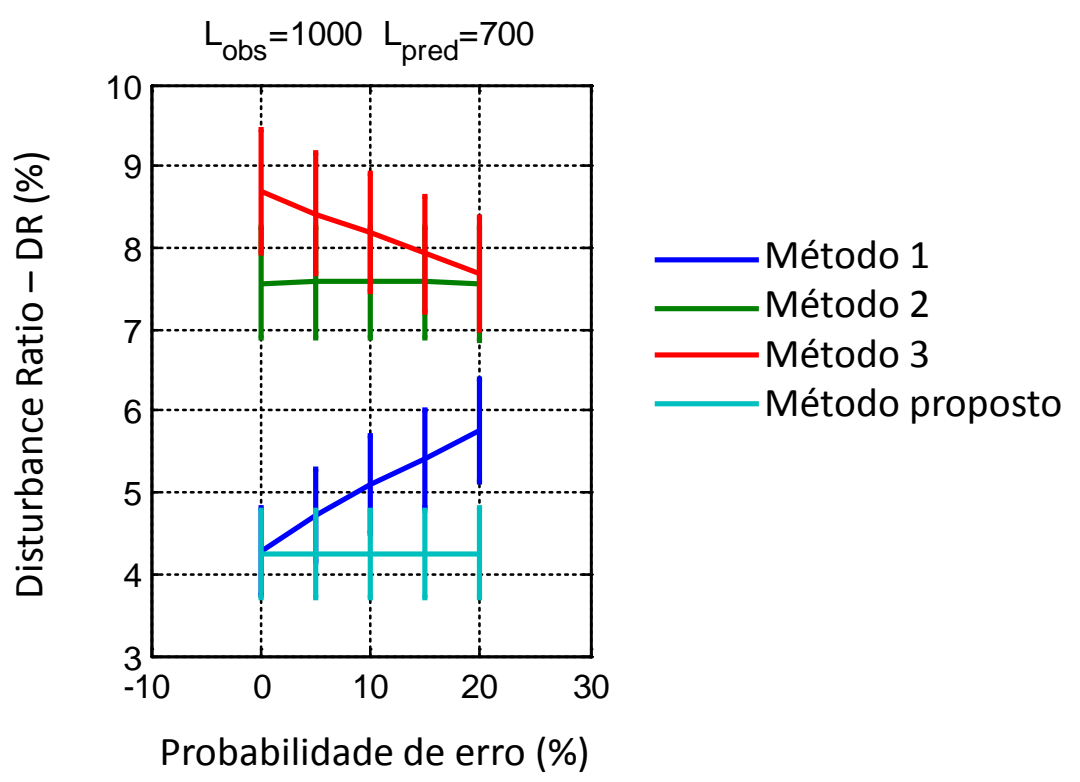

Figura 4.24 - Disturbance Ratio - Janelas: observação: 1000, predição: 700 


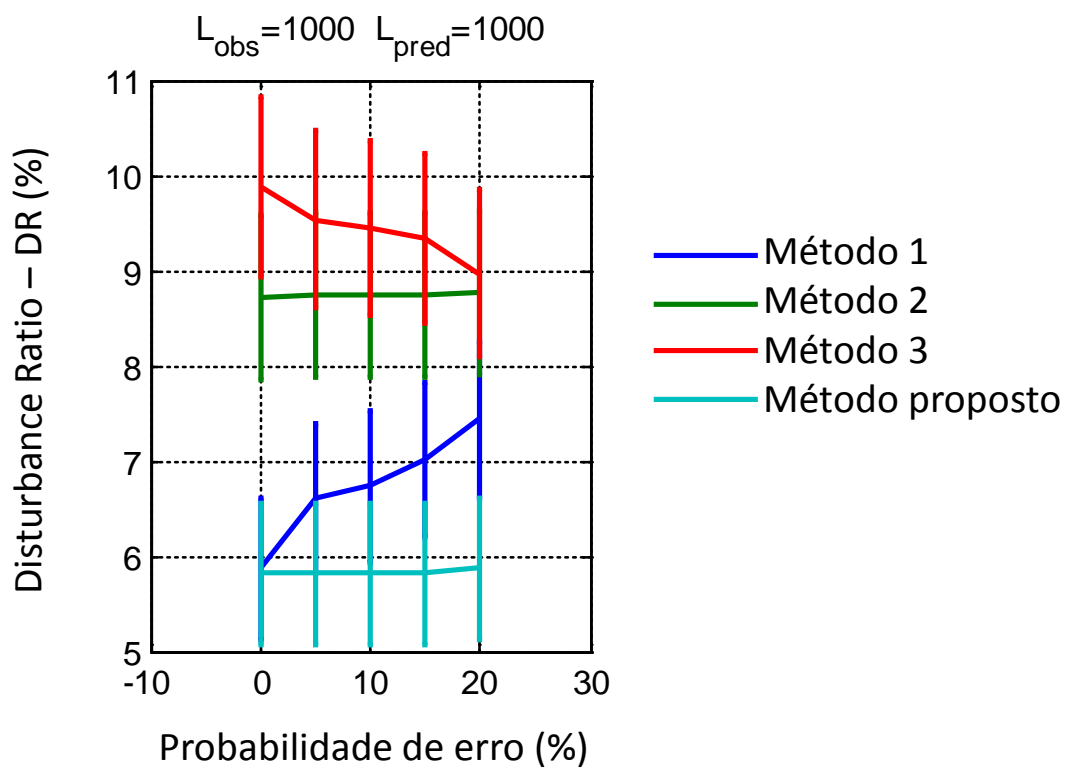

Figura 4.25 - Disturbance Ratio - Janelas: observação: 1000, predição: 1000

Os resultados completos destas simulações estão disponíveis no Anexo 3.

Com o intuito de avaliar e ilustrar o desempenho do método proposto em relação aos tamanhos da janela de predição foram escolhidos para esse parâmetros os valores 1.000, 1.500, 2.000, 2.500 e 3.000, porém mantendo-se a janela histórica de tamanho 1000. Foram ainda escolhidos dois cenários respectivamente associados aos valores de $0 \%$ e $20 \%$ para a probabilidade de erro de estimação do estado do canal de modo a ilustrar o comportamento dos algoritmos em situações com erro.

As figuras 4.26 e 4.27 ilustram o comportamento das duas estatísticas de interesse (SU e DR) num cenário ideal onde não há erros de estimação do canal. Percebe-se uma pequena superioridade do método proposto em relação aos Métodos 2 e 3, porém com desempenho similar ao do Método 1. 


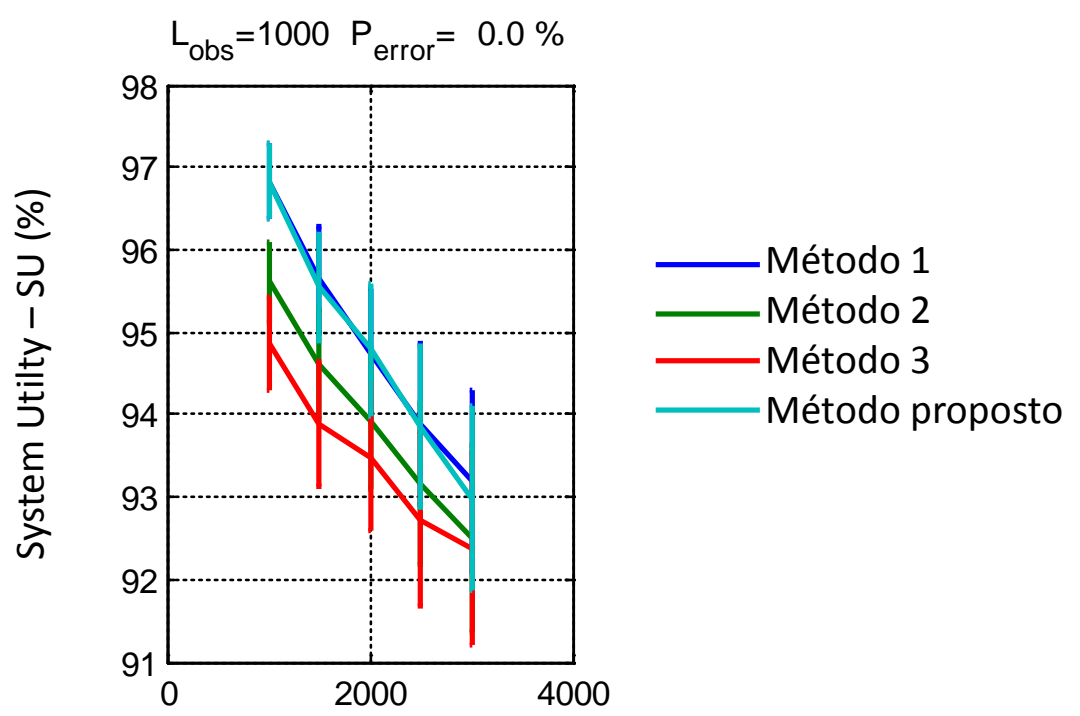

Tamanho da janela de predição

Figura 4.26 - System Utility - Janelas de predição de 1.000 até 3.000

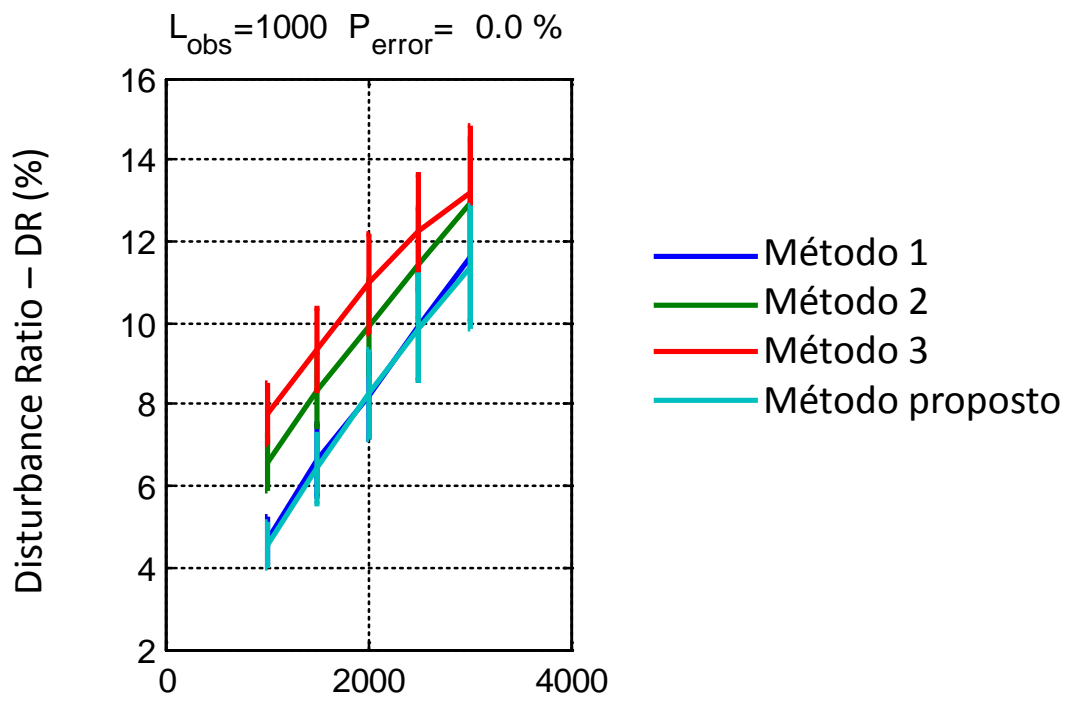

Tamanho da janela de predição

Figura 4.27 - Disturbance Ratio - Janelas de predição de 1.000 até 3.000 - Erro 0\%

Entretanto, quando a probabilidade de erro de estimação do canal é de $20 \%$, passa-se a perceber no comportamento das estatísticas escolhidas, uma leve superioridade do método proposto, como ilustrado nas figuras 4.28 e 4.29. 


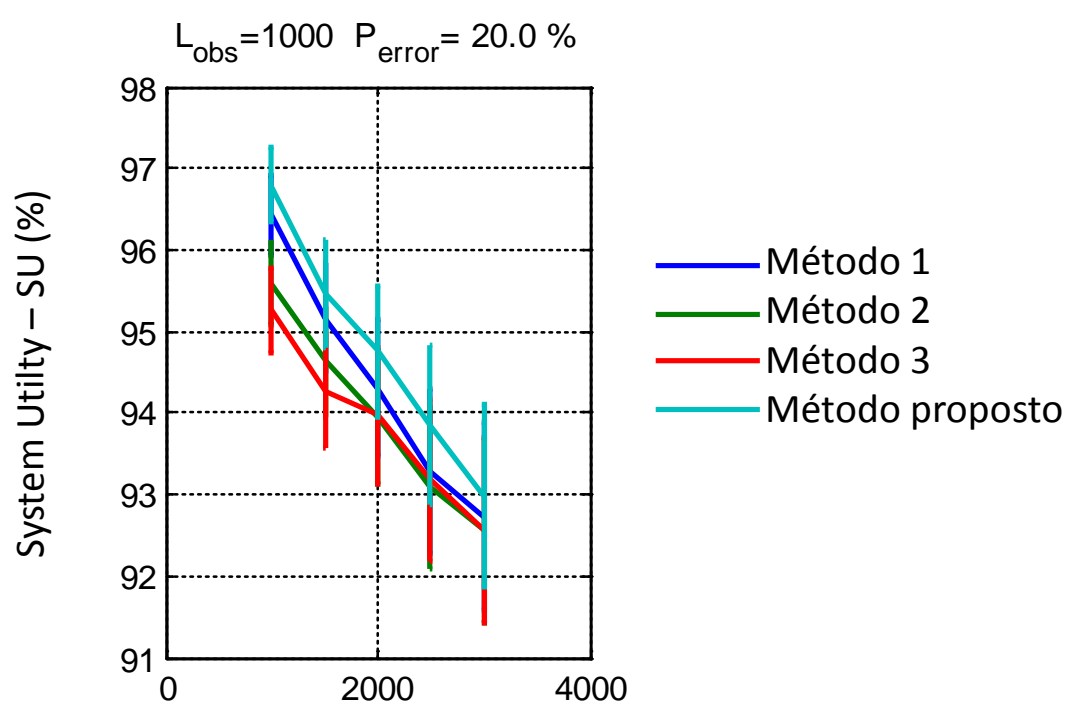

Tamanho da janela de predição

Figura 4.28 - System Utility - Janelas pred. de 1.000 até 3.000 - Erro 20\%

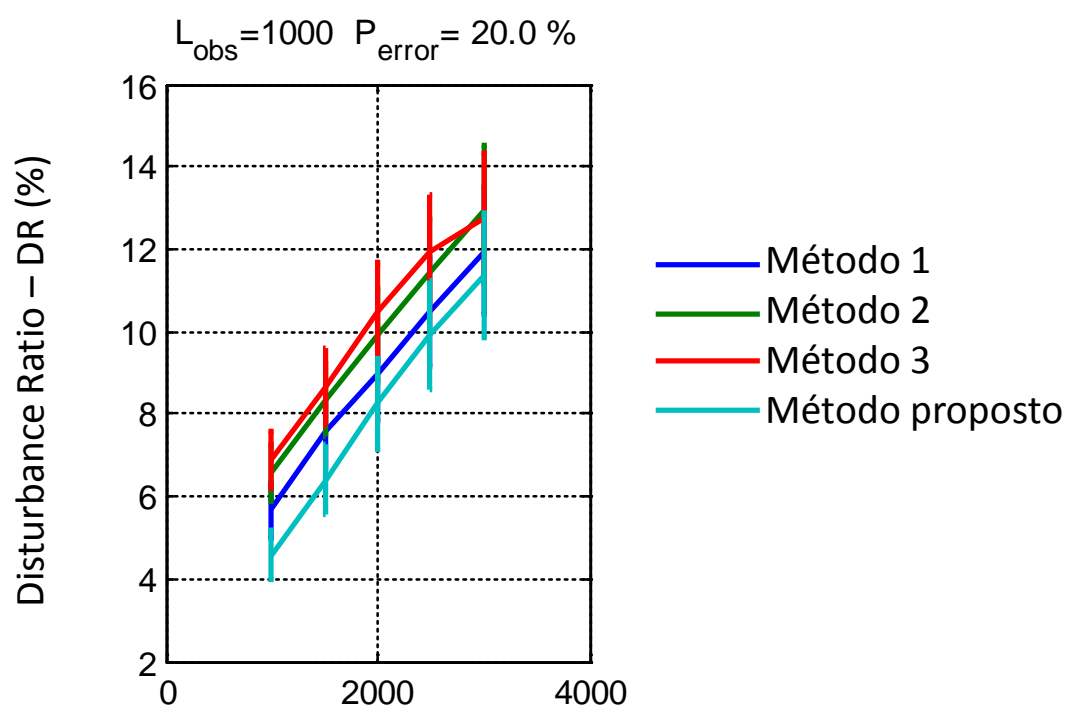

Tamanho da janela de predição

Figura 4.29 - Disturbance Ratio - Janelas pred. de 1.000 até 3.000 - Erro 20\% 


\section{Conclusões}

Nos capítulos anteriores foram descritas as características dos sistemas de rádios cognitivos, ilustrando-se em diagramas os módulos chaves dessa nova tecnologia, relatando-se as suas nuances regulatórias hoje existentes e as alterações normativas necessárias para a implementação de sua plena capacidade, com o objetivo de vislumbrar a exploração de novos serviços no cenário atual de telecomunicações, explorando novos serviços.

Foi ainda foi apresentada, segundo a ótica da União Internacional de Telecomunicações, algumas opções de utilização desta tecnologia, além de estudos em andamento para promover melhorias na utilização e acesso dinâmico do espectro eletromagnético.

As medições apresentadas no Capítulo 3 foram idealizadas pelo autor do trabalho e realizadas em diversas localidades, como Juiz de Fora - MG, Rio de Janeiro - RJ e Campinas - SP, sendo esta última a mais utilizada nesta tese, devido a sua intensa ocupação do espectro e consequentemente de grande utilidade para os estudos desenvolvidos.

As medições em Campinas - SP foram utilizadas para a determinação das estatísticas relevantes para a caracterização do comportamento do usuário primário, o que permitiu por meio de bootstraping estatístico, a geração de diversas medidas sintéticas de comportamento estatístico do usuário primário, intensamente utilizadas nesta tese.

Os métodos de sensoriamento de radio frequências mais utilizados foram aqui conceitualmente apresentados assim como as metodologias empregadas em sua utilização. A aquisição dos dados obtidos nas campanhas de medida mencionadas seguiu uma destas metodologias.

Foram aqui estudados e desenvolvidos soluções para dois problemas de interesse típico no contexto de rádio cognitivo, a saber, a definição do tamanho da janela de predição e o procedimento para sua utilização. O primeiro foi efetuado num contexto muito mais amplo do que aqueles discutidos na literatura corrente e o segundo propiciou um método que, numa primeira análise, tem 
desempenho da ordem ou superior a alguns apresentados na literatura corrente também.

\section{1}

\section{Comentários}

Ainda existem diversas questões em aberto para o desenvolvimento efetivo dos rádios cognitivos, mas é claro que as propostas discutidas nesta tese podem ser consideradas como um bom começo para a mitigação do problema de congestionamento do espectro.

A utilização dos recursos de comunicação em sua plena capacidade exige inovações regulatórias que não devem tardar para que as demandas de serviços de telecomunicações possam ser atendidas.

\section{2}

\section{Soluções apresentadas}

Sugere-se a aplicação dos métodos propostos no Capítulo 4 para dimensionamento da janela de predição e para predição da referida janela para compartilhamento do espectro entre usuários primários e secundários. Com as metodologias sugeridas deve-se obter uma maior eficiência de uso do espectro radioelétrico de modo robusto e seguro.

Merecem ser destacadas as contribuições desta tese conforme indicado a seguir:

a. Foi levantada em campo uma base de dados de ocupação do espectro que pode ser utilizada em outros trabalhos sobre rádio cognitivo para aplicação de outras soluções e desenvolvimento de algoritmos de ocupação do espectro;

b. Foi desenvolvido um método inédito, por meio do qual é possível estimar o tamanho das janelas de ocupação, a serem utilizadas por sistemas cognitivos, em função de estatísticas de vacâncias espectrais.

c. Desenvolvimento de um algoritmo de utilização do espectro destinado a um usuário primário em função da avaliação do comportamento do usuário primário em janelas históricas. A partir da decisão de utilização das janelas, elas são preenchidas com dados do usuário secundário (cognitivo). O método 
foi testado em comparação com outros relevantes, disponíveis na literatura técnica, demonstrando um melhor desempenho.

\section{3}

\section{Estudos Futuros}

Deixa-se como recomendação para estudos correlatos aos que foram aqui realizados, os abaixo mencionados:

a. Investigação de métodos alternativos de predição de intervalos espectrais para cenários de estatística diferente do aqui apresentado para fins de comparação de desempenho e ampliação do universo de aplicação;

b. Realização de campanhas de medições em campo em situações realísticas e sua consequente modelagem estatística de modo a atender a outros serviços de telecomunicações, candidatos a compartilhamento de espectro, em busca de uma utilização mais eficiente do espectro radioelétrico.

c. Avaliação de aplicações de rádio cognitivo em diversas faixas de frequências que ofereçam oportunidades, em especial em áreas urbanas onde existem demandas reprimidas para utilização do espectro que impedem a implantação de novos serviços de telecomunicações.

d. Aperfeiçoamento dos métodos propostos, visando um aumento de desempenho com variações das dimensões das janelas de predição e de observação, ou mesmo com o desenvolvimento de novos algoritmos para aprimoramento da eficiência do espectro. 
Referências bibliográficas

[1] MITOLA, J. III. Cognitive Radio an Integrated Agent Architecture for Software Defined Radio. PhD thesis, KTH Royal Institute of Technology, Stockholm, Sweden, 2000.

[2] SILVA, M.W.R. da; CARDOSO, Kleber V.; MOURA, David F. C.;GALDINO, Juraci F.; SALLES, Ronaldo M.; REZENDE, José Ferreira de; Avaliação do Compartilhamento Espectral em Redes Cognitivas Utilizando Jogos Evolucionários. XXVI Simpósio Brasileiro de Telecomunicações- SBRT’08, 02 a 05 de setembro de 2008, Rio de Janeiro, RJ.

[3] SHARMA, V.; JAYAPRAKASAM, A.K. An Efficient Algorithm for Cooperative Spectrum Sensing in Cognitive Radio Networks. Indian Institute of Science, Bangalore, 2008.

[4] THOMAS, G. Fast detection of spectral white spaces for cognitive radio networks. Military Communications Conference, 2009. MILCOM 2009. IEEE. - Univ. of Louisiana at Lafayette, Lafayette, LA, USA - October, 2009.

[5] KIM, J. \& JEFFREY, G. Andrews Sensitive White Space Detection with Spectral Covariance Sensing. IEEE Transactions on Wireless Communications, Vol. 9, No. 9, September, 2010.

[6] HAYKIN, S. Cognitive Radio: Brain-Empowered Wireless Communications. IEEE Journal on Selected Areas in Communications, Vol. 23, No. 2, February, 2005.

[7] Report International Telecommunication Union - ITU-R SM.2152 (09/2009). Definitions of Software Defined Radio (SDR) and Cognitive Radio System (CRS).

[8] Report International Telecommunication Union - UIT-R (01/2014) SM.[DYNAMIC ACCESS] Spectrum management principles and spectrum engineering techniques for dynamic access to spectrum by radio systems employing cognitive capabilities.

[9] MARQUES, V. Fonoaudiologia, neurofisiologia - Linguagem e Cognição capturado em mídia de Internet em maio de 2014.

[10] Plano de Atribuição, Destinação e Distribuição de Faixas de Frequências no Brasil da Agência nacional de telecomunicações - ANATEL - Edição 2013 http://www.anatel.gov.br/. 
[11] Seção: Tutoriais Operação - Telecom e Internet: Desafios e Perspectivas capturado em mídia de Internet em agosto de 2012 http://www.teleco.com.br/

[12] MEHTA, T.; KUMAR, N.; SAINI, S.S. Comparison of Spectrum Sensing Techniques in Cognitive Radio Networks- IJECT Vol. 4, Issu Espl - 3, April - June 2013, ISSN : 2230-7109 (Online) | ISSN : 2230-9543 (Print), Dept. of ECE, UIET, Panjab University, Chandigarh, UT, India 3Sr. Scientist, CSIR - Central Scientific Instruments Organization (CSIR-CSIO), Chandigarh, UT, India.

[13] MAHARJAN, S.; TAKADA, K.P. and J. Experimental Study of Energy Detector Prototype for Cognitive Radio System, IEICE Technical Report, SR-2007-52(2007-11), Hiroshima International University, Hiroshima, Japan.

[14] NEYMAN, J. and PEARSON, E.S. On the Problem of the Most Efficient Tests of Statistical Hypotheses. Phil. Trans. R. Soc. Lond. vol. A231, pp 289-337, February 16, 1933.

[15] MASONTA, M.T.; MZYECE, M. \& NTLATLAPA, N. Spectrum Decision in Cognitive Radio Networks: A Survey - IEEE COMMUNICATIONS SURVEYS \& TUTORIALS, VOL. 15, NO. 3, THIRD QUARTER 2013.

[16] [MITOLA_99] Joseph Mitola III. Cognitive radio for flexible mobile multimedia Communications. In Sixth International Workshop on Mobile Multimedia Communications (MoMuC’99), San Diego, CA, 1999.

[17] [MAGUIRE_99] Joseph Mitola III and Gerald Maguire Jr. Cognitive radio: Making software radio more personal. IEEE Personal Communications, 6:13-18, august 1999.

[18] [MITOLA_92] Jospeh Mitola III. Software radios-survey, critical evaluation and future directions. In IEEE National Telesystems Conference, pages 13/15-13/23, New York, 1992.

[19] MITOLA J. III, Cognitive radio: An integrated agent architecture for software define radio. $\mathrm{PhD}$ thesis, Royal Institute of Technology (KTH), Stockholm, Sweden, May 2000.

[20] KIM, J. \& JEFFREY, G. Andrews Sensitive White Space Detection with Spectral Covariance Sensing. IEEE Transactions on Wireless Communications, Vol. 9, No. 9, September, 2010.

[21] SHARMA, V. \& JAYAPRAKASAM, A.K. An Efficient Algorithm for Cooperative Spectrum Sensing in Cognitive Radio Networks. Cornell University Library - Computer Science Information Theory. - September, 2008. 
[22] HAYKIN, S. Cognitive Radio: Brain-Empowered Wireless Communications. IEEE Journal on Selected Areas in Communications, Vol. 23, No. 2, February, 2005.

[23] JONDRAL F.K. Software-Defined Radio-Basics and Evolution to Cognitive Radio. - EURASIP Journal on Wireless Communications and Networking 2005:3, 275-283 - August, 2005.

[24] SRINU, S. \& SABAT, S.L. FPGA implementation of Spectrum Sensing based on Energy detection for Cognitive Radio. Communication Control and Computing Technologies (ICCCCT), 2010 IEEE International Conference - October, 2010.

[25] LIANG, M. \& ZHU, Q. A New Algorithm of Spectrum Allocation for Cognitive Radio Based on Cooperative Game. Wireless Communications Networking and Mobile Computing (WiCOM), 2010 6th International Conference on - September, 2010.

[26] JAYAPRAKASAM, A.K. \& SHARMA, V. Cooperative Robust Sequential Detection Algorithms for Spectrum Sensing in Cognitive Radio. Ultra Modern Telecommunications \& Workshops, 2009, ICUMT 09 International Conference. - October, 2009.

[27] BANERJEE, T.; KAVITHA, V. \& HARMA, V. Energy Efficient Change Detection Over a Mac Using Physical Layer Fusion. - Acoustics, Speech and Signal Processing, 2008 ICASSP. IEEE International Conference on April, 2008.

[28] UNNIKRISHNAN, J. \& VEERAVALLI, V.V. Cooperative Spectrum Sensing and Detection for Cognitive Radio. - Global Telecommunications Conference, 2007. GLOBECOM '07. IEEE - November, 2010.

[29] NGUYEN-THANH, N. \& KOO, I. An Enhanced Cooperative Spectrum Sensing Scheme Based on Evidence Theory and Reliability Source Evaluation in Cognitive Radio Context. - Communications Letters, IEEE July, 2009.

[30] STEVENSON, C.R.; CHOUINARD, G.; LEI, Z.; HU, W.; SHELLHAMMER, S. J. \& CALDWELL, W. IEEE 802.22: The First Cognitive Radio Wireless Regional Area Network Standard. Communications Magazine, IEEE - January, 2009.

[31] CABRIC, D.; MISHRA, S.M.; BRODERSEN, R.W. Signals, Systems and Computers, 2004. Conference Record of the Thirty-Eighth Asilomar Conference on - November, 2004.

[32] SPOONER, C.M. Multi-Resolution White-Space Detection for Cognitive Radio. Military Communications Conference, 2007 MILCOM 2007 IEEE. North West Research Associates. - October, 2007. 
[33] MATHESON, R.J. Principles of Flexible-Use Spectrum Rights. Journal of Communications and Networks, Vol. 8, No. 2 - June, 2006.

[34] CHAKRABORTY, M.; BERA, R.; PRADHAN, P. \& SUNAR, S. Spectrum sensing and Spectrum shifting implementation in a Cognitive Radio based IEEE 802.22 Wireless Regional Area Network.(IJCSE) International Journal on Computer Science and Engineering Vol. 02, No. 1477-1481 - April, 2010.

[35] ATAPATTU, S.; TELlAMBURA, C.; \& JIANG, H. Relay Based Cooperative Spectrum Sensing in Cognitive Radio Networks. Global Telecommunications Conference, 2009. GLOBECOM 2009. IEEE December, 2009.

[36] CHEN, K.-C.; FELLOW; IEEE; TU, Sheng-Yuan \& YU, Chung-Kai. Statistical Inference in Cognitive Radio Networks. - Communications and Networking in China, 2009. China COM 2009. Fourth International Conference on - August, 2009.

[37] Question ITU-R 241-1/5 - ITU Radiocommunication - Working Party 5A. Cognitive radio systems in the mobile service. International Telecommunication Union - December, 2007.

[38] Working Party 5A. Cognitive radio systems in the land mobile service. Document 5A/601-E - ITU Radiocommunication - November, 2010.

[39] ZHANG, W.; MALLIK, R. K. \& LETAIEF, K.B. Optimization of Cooperative Spectrum Sensing with Energy Detection in Cognitive Radio Networks. - Acoustics, Speech and Signal Processing, 2008 ICASSP. IEEE International Conference on - December, 2009.

[40] JAYAPRAKASAM, KUMAR, A. \& SHARMA, V. Cooperative Robust Sequential Detection Algorithms for Spectrum Sensing in Cognitive Radio. Ultra Modern Telecommunications \& Workshops, 2009. ICUMT '09. International Conference on. - October, 2009.

[41] STEENKISTE, P.; SICKER, D.; MINDEN, G. \& RAYCHAUDHURI, D. Future Directions in Cognitive Radio Network Research. NSF Workshop March, 2009.

[42] PENNA, F.; PASTRONE, C.; SPIRITO, M.A. \& GARELLO, R. Energy Detection Spectrum Sensing with Discontinuous Primary User Signal. Communications, 2009. ICC '09. IEEE International Conference on - June, 2009.

[43] RENK, T.; KLOECK, C. \& JONDRAL, F.K. A Cognitive Approach to the Detection of Spectrum Holes in Wireless Networks. Consumer Communications and Networking Conference, 2007. CCNC 2007. 4th IEEE January, 2007. 
[44] BING, Z. \& LILI, G. Research of Spectrum Detection Technology in Cognitive Radio. Networks Security, Wireless Communications and Trusted Computing, 2009. NSWCTC '09. International Conference on - April, 2009.

[45] QUAN, Z.; CUI, S.; SAYED, A.H. \& POOR, H.V. Optimal Multiband Joint Detection for Spectrum Sensing in Cognitive Radio Networks. Signal Processing, IEEE Transactions on - March, 2009.

[46] CHEN, Z.; GUO, N. \& QIU, R.C. Demonstration of Real-Time Spectrum Sensing for Cognitive Radio. IEEE Communications Letters, Vol. 14, No. 10. - October, 2010.

[47] YUCEK, T. \& ARSLAN, H. A Survey of Spectrum Sensing Algorithms for Cognitive Radio Applications. Communications Surveys \& Tutorials, IEEE - April, 2009.

[48] CANAVITSAS, A.; FERREIRA, J.E. Switching Antenna Array to Improve Cognitive Radio Performance. SDR' 11 - Winn Comm Wireless Innovation Conference and Product Exposition - 29 November - 2 December, 2011 - Washington.

[49] CANAVITSAS, A.; SILVA MELLO, L.A.R.; GRIVET, M. Spectrum Occupation Modeling on the $450 \mathrm{MHz}$ Band for Cognitive Radios Application. 7th European Conference on Antennas and Propagation 2013 EUCAP 2013 - Gothemburg, Sweden - 08 - 12 April 2013.

[50] CANAVITSAS, A.; SILVA MELLO, L.A.R.; GRIVET, M. White Space Prediction Technique for Cognitive Radio Applications. $15^{a}$ edição da International Microwaveand Optoeletronics Conference (IMOC 2013), Sociedade Brasileira de Micro-ondas e Optoeletrônica \& Microwave Theory and Techniques Society - Institute of Electricaland Electronic Engineers (IEEE MTT-S) - 4 a 7 de agosto. 
Anexos

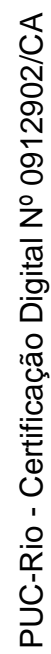




\section{ANEXO 1}

\section{Diagrama de Estados Completo}
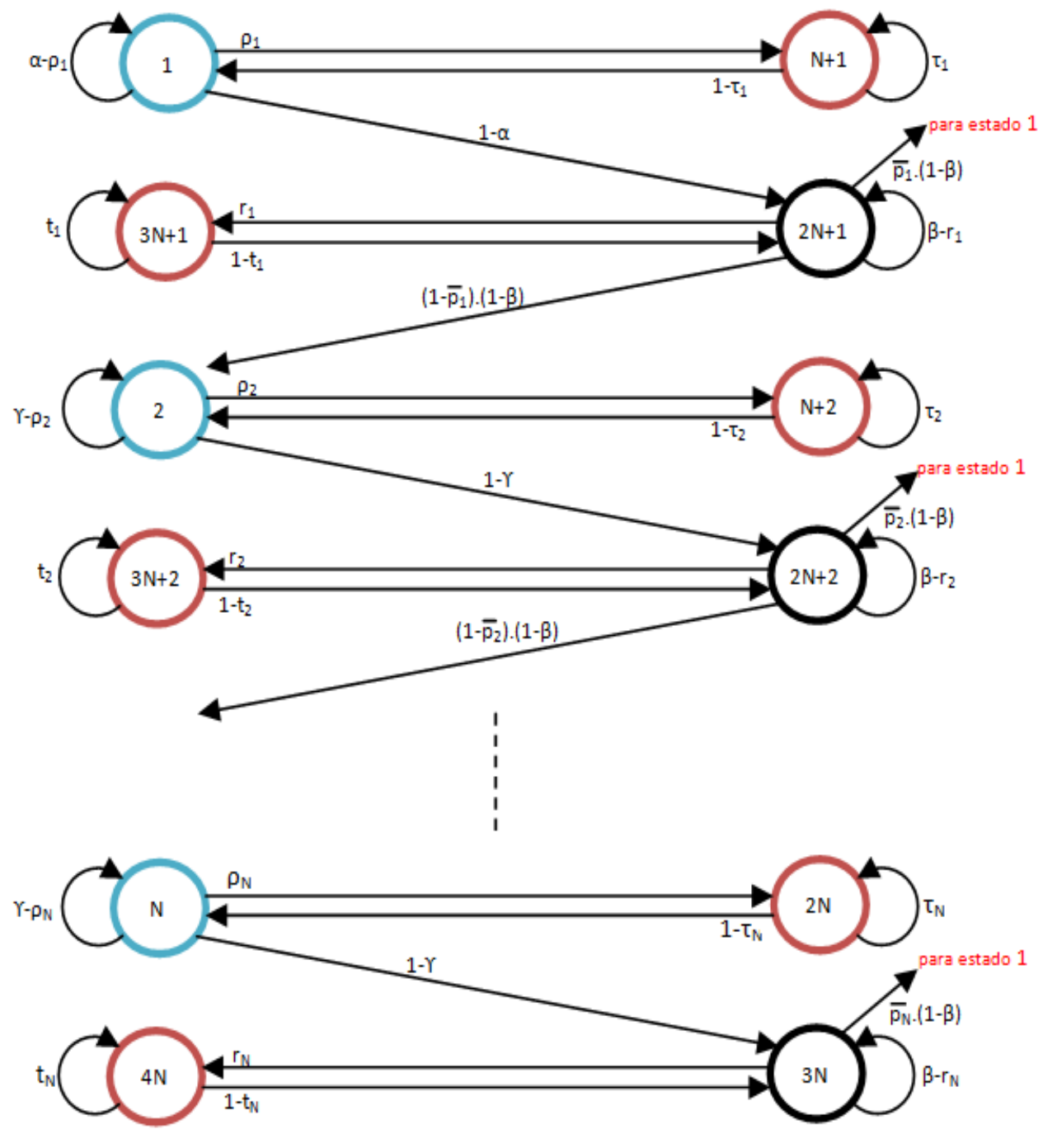

Os estados a esquerda, isto é, de 1 a $\mathrm{N}$ e de $3 \mathrm{~N}-1$ a $4 \mathrm{~N}$ emitem 0 , enquanto que os estados da direita, de N+1 a 3N, emitem 1. Estados S w WS-n são azuis, , estados de erro são vermelhos, estados BS-n são pretos. 


\section{ANEXO 2 \\ ESTATÍSTICAS DAS MEDIÇÕES EM CAMPO}

Em toda a análise estatística adequadamente realizada, a avaliação empírica do comportamento médio de alguma grandeza associada a um fenômeno deve ser feita com base em uma coleção, considerada grande, de valores observados ou empiricamente medidos.

Em face de restrições temporais e financeiras, as campanhas de medidas efetuadas para esta tese permitiram a coleta de apenas uma única sequencia amostral de dados, que embora útil, é insuficiente em princípio para qualquer análise estatística do fenômeno em questão.

Põe-se então o problema assim descrito: como ter disponível várias realizações de um experimento quando na realidade, limitações práticas permitiram apenas poucas (às vezes uma única) realizações do experimento?

A resposta proposta para este problema pela comunidade de pesquisadores nesta área consiste, de forma simplista, em estimar a distribuição estatística dos dados a partir das sequências de dados disponíveis, e gerar sinteticamente novos dados a partir desta distribuição empiricamente estimada. Este procedimento é conhecido na literatura técnica como bootstraping [1].

Na situação em discussão nesta tese, a campanha de medidas permitiu coletar dados de atividade de um canal utilizado por um usuário primário, onde:

- foram identificados e medidos os trechos de ocupação e de silêncio;

- em cada um dos trechos de ocupação, foram identificados e medidos as quantidades e os trechos de atividade e pausa;

- foram estimadas as distribuições estatísticas empíricas dos parâmetros correspondentes, a saber:

o quantidade de blocos de atividade-pausa no trecho de ocupação;

o duração do silêncio;

o durações dos i-ésimos blocos de atividade e pausa;

Com base nestas caracterizações estatísticas, a técnica de bootstraping permite gerar sinteticamente um número arbitrário de sequências de dados estatisticamente equivalentes e assim permitir levantar estatísticas de comportamento médio. 
Foi implementado um programa em MATLAB que, a partir da única sequência medida em campanha da atividade do canal, determine todas as estatísticas acima mencionadas. As Figuras a seguir ilustram as distribuições medidas que foram usadas para a caracterização da ocupação do canal.

A Figura 1 ilustra a estimação da função de distribuição acumulada (do inglês - CDF) da duração do período de silêncio (azul) e a distribuição exponencial a ela ajustante (vermelho). Na legenda, o texto "H0 rejeitado" indica que o teste de aderência Kolmogorov-Smirnov rejeita a possibilidade de identidades destas duas distribuições.

A Figura 2 apresenta o histograma de frequências observadas do tamanho do período ocupação em termos de pares atividade-pausa.

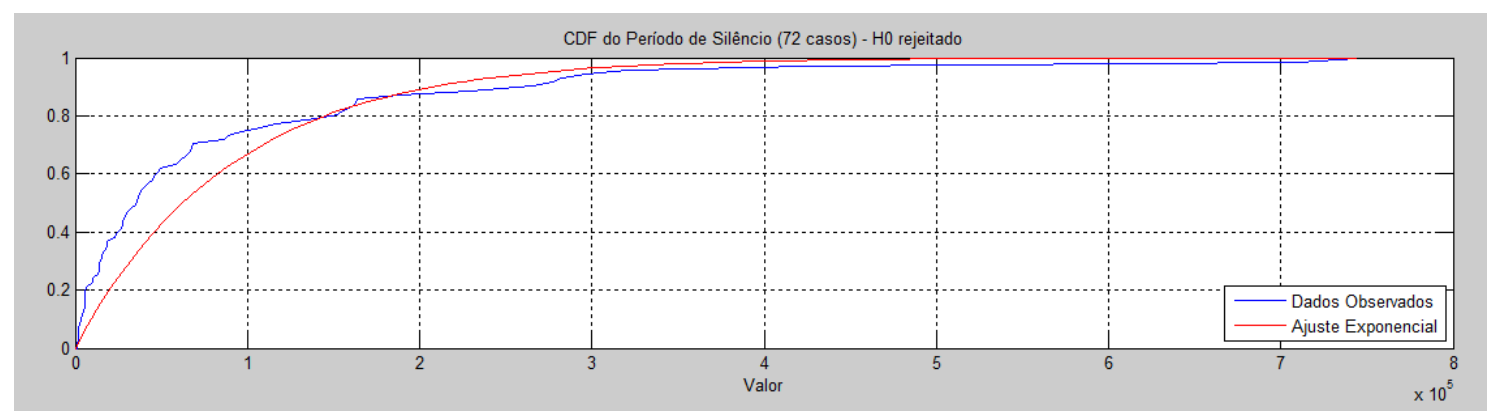

Figura 1 - CDF da duração dos períodos de silêncio

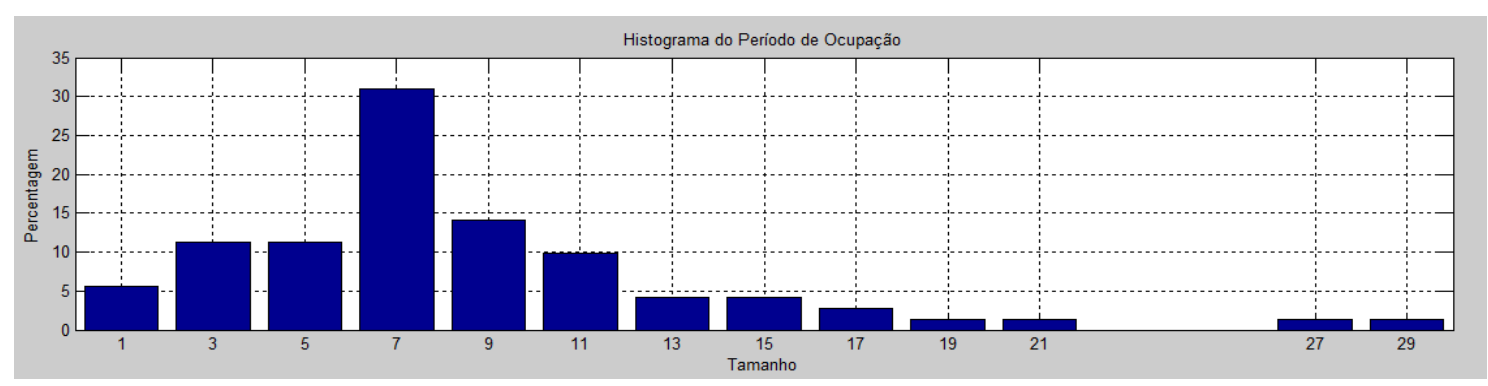

Figura 2 - Histograma de ocupação em termos de pares atividade-pausa.

A semelhança da Figura 1, a Figura 3 ilustra a estimação da função de distribuição acumulada para diversos black spaces e white spaces, seu ajustamento para a distribuição exponencial e o resultado do teste de aderência Kolmogorov-Smirnov. 

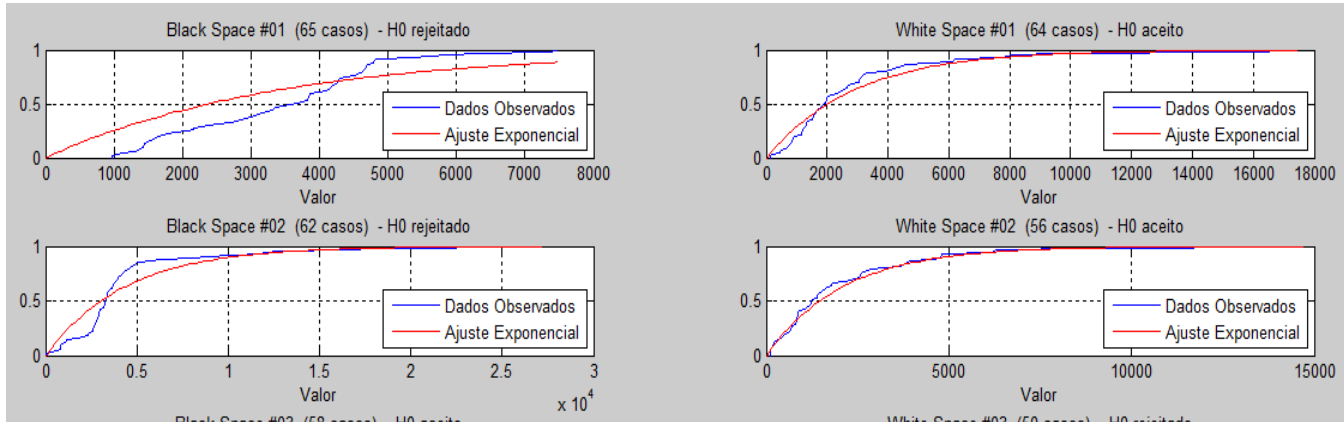

Black Space \#03 (58 casos) - H0 aceito
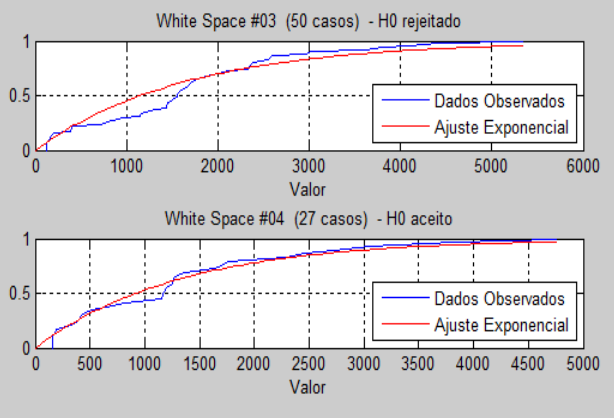

Figura 3 - Estimação da função distribuição acumulada para diversos BS eWS

Embora as figuras acima ilustrem a preocupação do autor de investigar a aderência exponencial às distribuições empiricamente levantadas, o processo de geração das realizações de ocupação do canal foi feito com base nas distribuições empíricas de fato observadas.

[1] Politis, D. N., “Computer Intensive Methods in Statistical Analysis”, IEEE Signal Processing Magazine, Janeiro 1998. 
ANEXO 3

\section{RESULTADOS DAS SIMULAÇÕES}
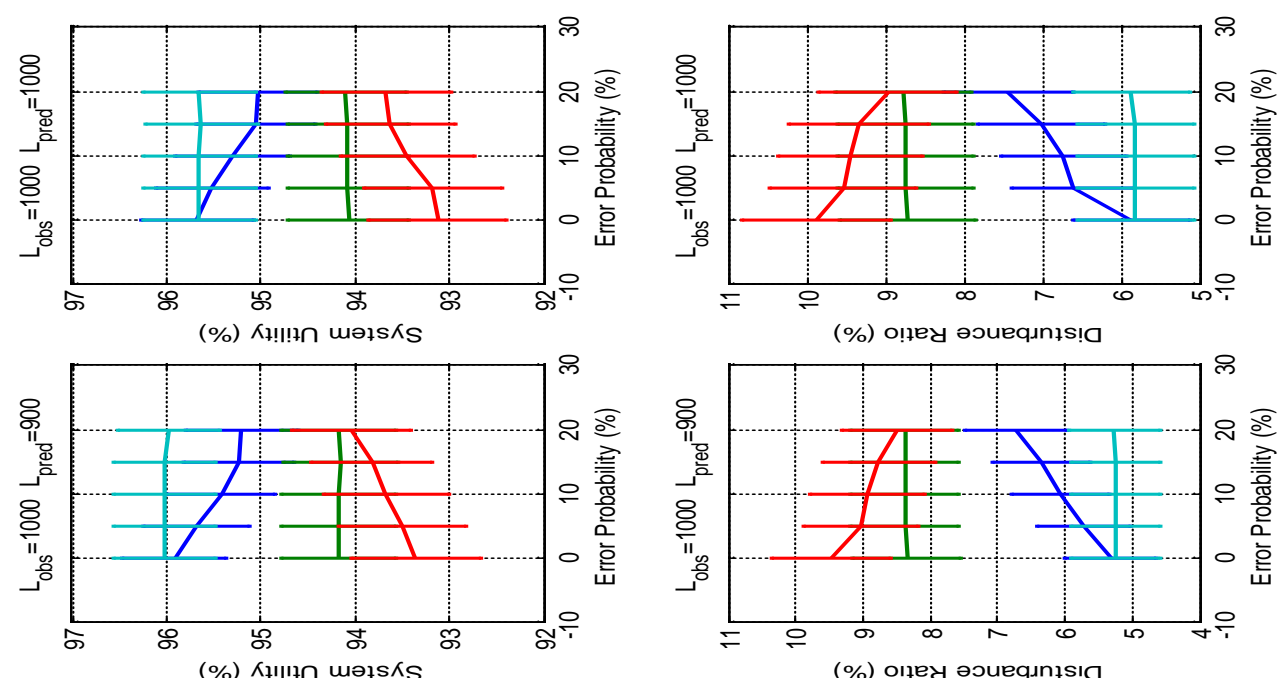

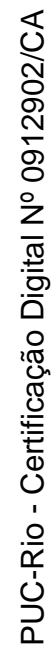
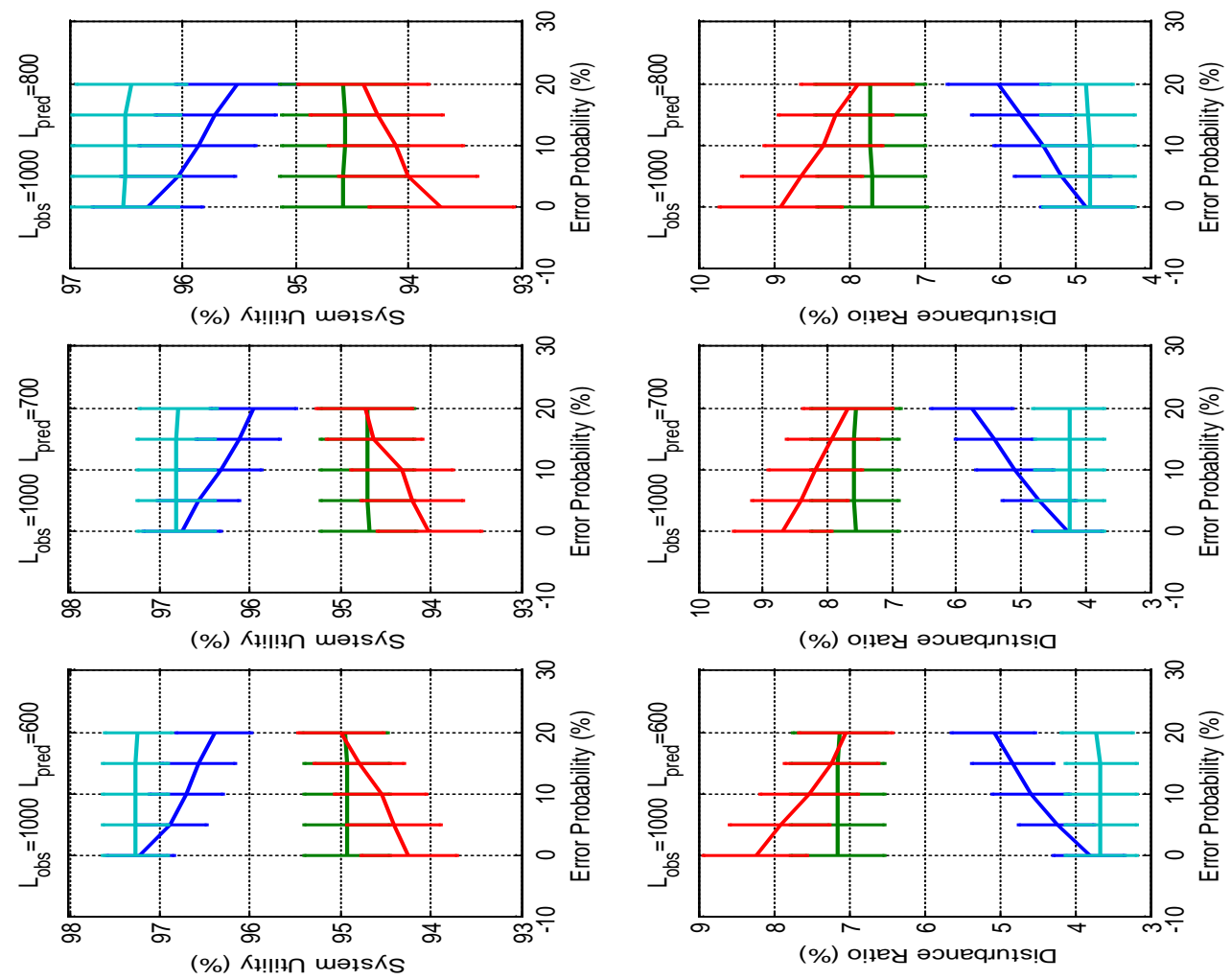

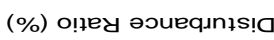

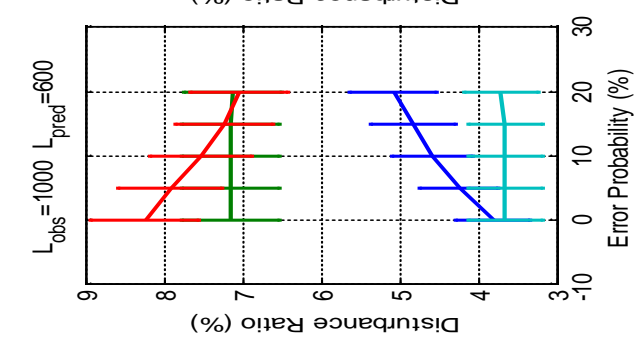

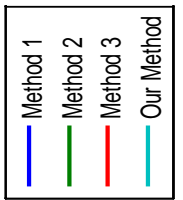

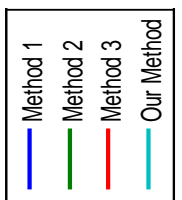




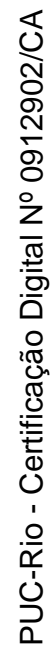
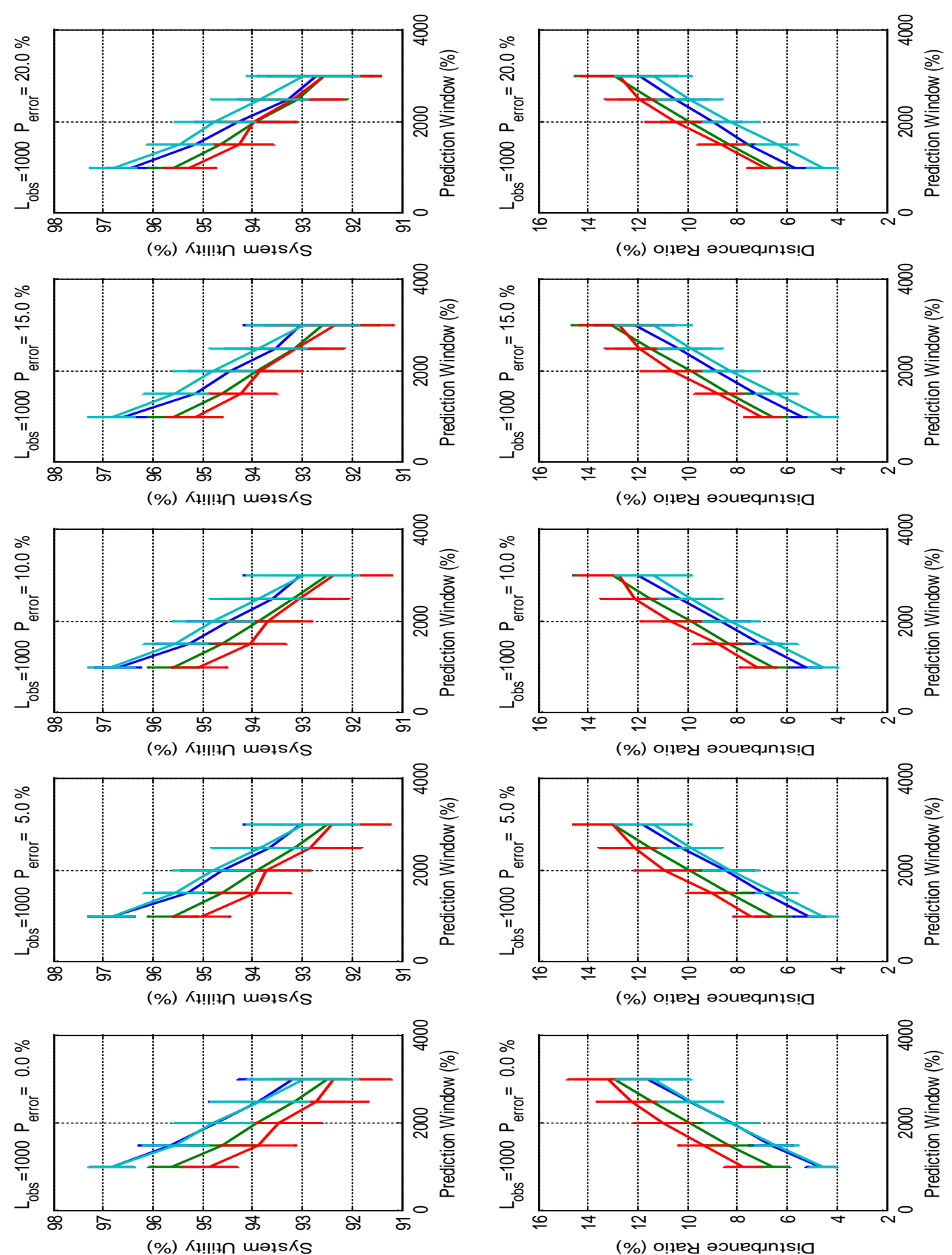

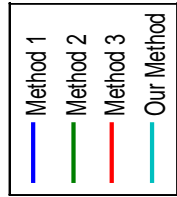

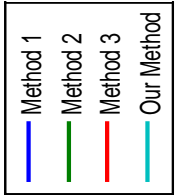

